UNIVERSIDAD NACIONAL DE LA PLATA

FACULTAD DE BELLAS ARTES

MAESTRÍA EN PSICOLOGÍA DE LA MÚSICA

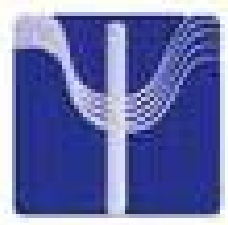

\title{
LA COMPRENSIÓN DE LA
}

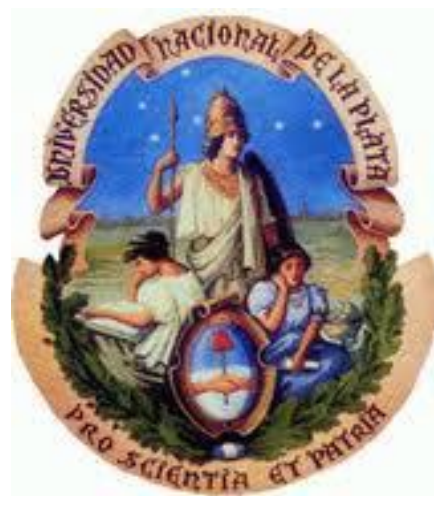
\author{
ESTRUCTURA MUSICAL
}

LA REPRESENTACIÓN UTILIZADA EN NIÑOS

ENTRE 10 Y 11 AÑOS

\section{GABRIELA ALICIA ORTEGA}

Tesis presentada para obtener el grado de

Magíster en Psicología de la Música

Directora de la Tesis: Dra. SILVIA RAQUEL MALBRÁN

Jurado

Dra. María del Carmen Malbrán (UBA)

Dra. Diana Fernández Calvo (UCA)

Dra. Susana Espinosa (UNLa)

Julio de 2014 


\title{
AGRADECIMIENTOS
}

A Dios por bendecir mi vida con oportunidades y personas que me han ayudado en el camino.

A la Dra. Silvia Malbrán por su excelencia que trasciende lo académico. Su guía, afecto y generosidad ayudaron a dar forma a las ideas y estímulo al esfuerzo.

A los expertos convocados:

\section{Eduardo Varela}

Dra. Susana Ozán

A la Directora de la Escuela 11 de Septiembre Sra. Graciela Lucero y las maestras de quinto año, por su permanente colaboración en el proceso del trabajo experimental.

A los amigos y colegas, por acompañarme y compartir con entusiasmo cada paso en el transcurso de este trabajo:

\author{
Mirita Cocinero \\ María Inés Graffigna \\ Adriana Fernández \\ Mónica Lucero \\ Adrián Rússovich \\ Luci Ferrarini \\ Carina Silva
}

A mis hijos, Florencia y Joel, por su comprensión y apoyo.

A mi madre.....por estar siempre. 


\section{ÍNDICE GENERAL}

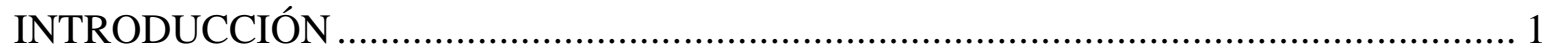

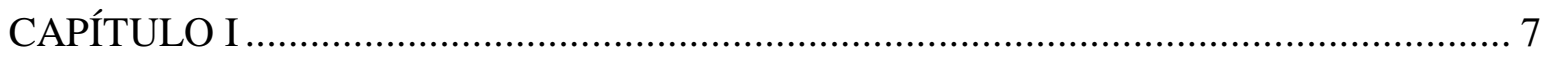

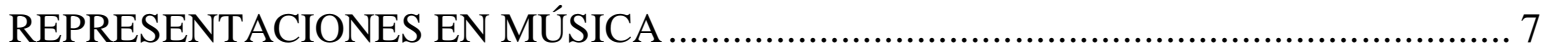

I.1. PROCESAMIENTO DE LA INFORMACIÓN MUSICAL ……………………....... 7

I.2. MODALIDADES DE REPRESENTACIÓN MUSICAL ……................................. 9

I.3. ORGANIZACIÓN DE LAS REPRESENTACIONES EN LA MEMORIA............. 13

I.4. EL ROL DEL CUERPO EN LA CONSTRUCCIÓN DE REPRESENTACIONES 20

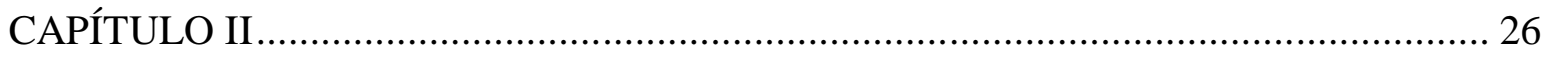

LA MÚSICA COMO OBJETO DE REPRESENTACIÓN ................................................... 26

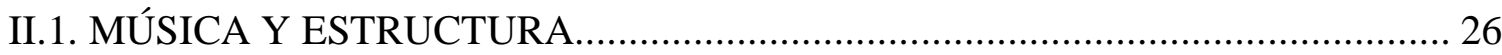

II.2. ESTRUCTURA DE AGRUPAMIENTO Y PERCEPCIÓN ………………............ 30

II.3. NIVELES DE REPRESENTACIÓN EN MÚSICA................................................. 35

II.3.1. MODELO DE REDESCRIPCIÓN REPRESENTACIONAL. KARMILOFF-

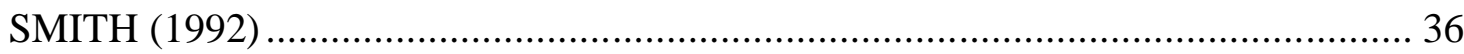

II.3.2. MODELO REPRESENTACIONAL DE JEROME BRUNER (1995)............. 40

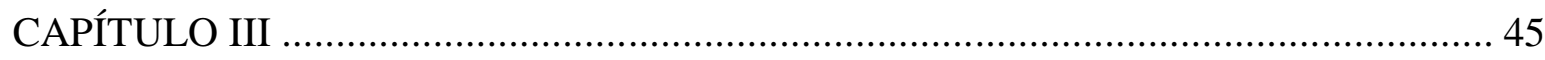

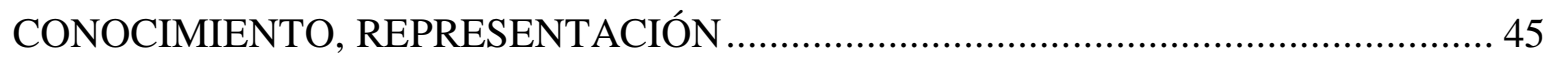

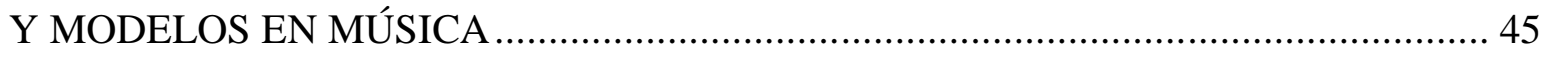

III.1. ADQUISICIÓN Y DESARROLLO DE COMPETENCIAS MUSICALES ......... 45

III.2. PROCESAMIENTO DE LA INFORMACIÓN................................................ 53

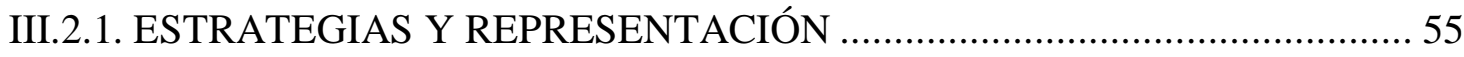

III.2.2. ACTIVACIÓN CEREBRAL Y MÚSICA. CORRELATO NEURAL............. 58

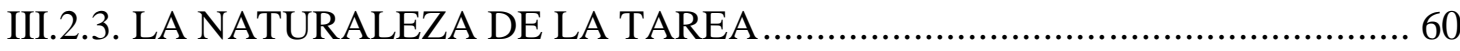

III.2.3.1. CONOCIMIENTO PROCEDIMENTAL Y DECLARATIVO...................... 61

III.2.3.2. CONOCIMIENTO PROPOSICIONAL Y EN IMÁGENES .......................... 63

III.2.3.3. CONOCIMIENTO EXPLÍCITO E IMPLÍCITO......................................... 65

III.2.3.3.1. PROCESOS CONTROLADOS Y AUTOMÁTICOS ................................ 67 


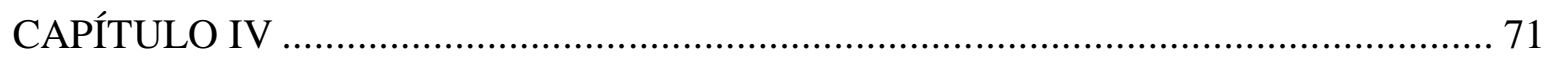

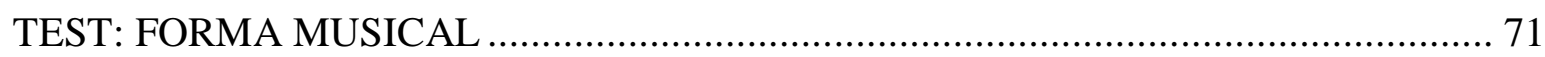

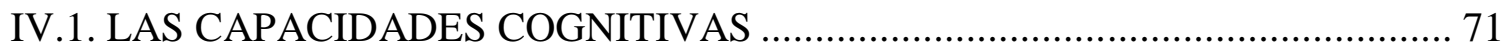

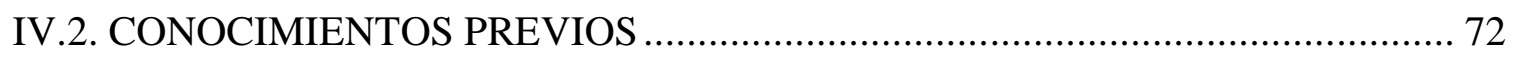

IV.3. NATURALEZA DE LAS TAREAS PROPUESTAS ....................................... 73

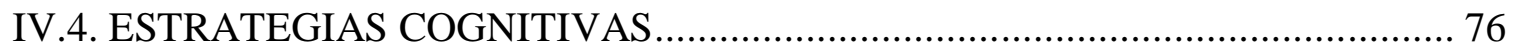

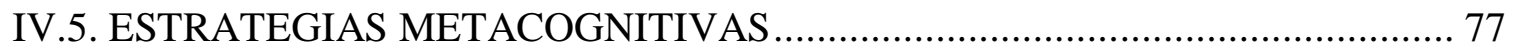

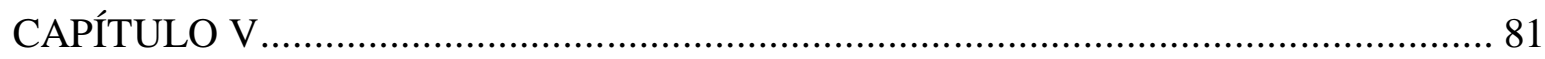

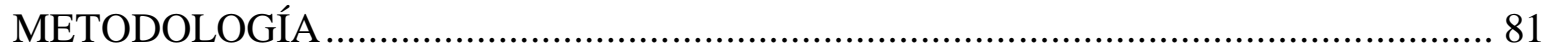

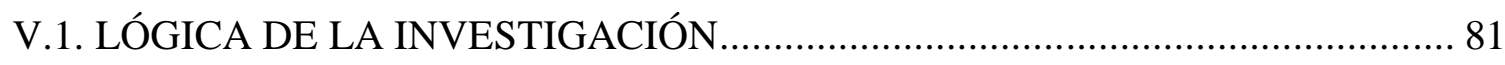

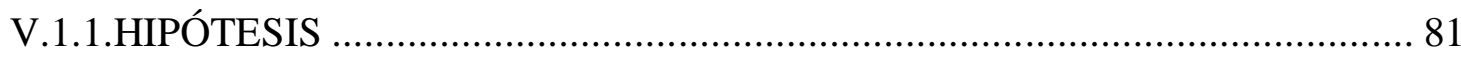

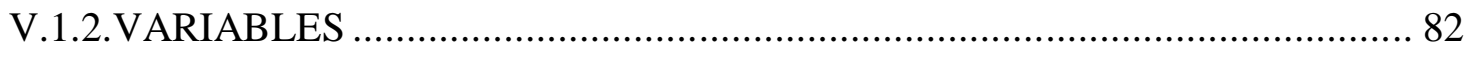

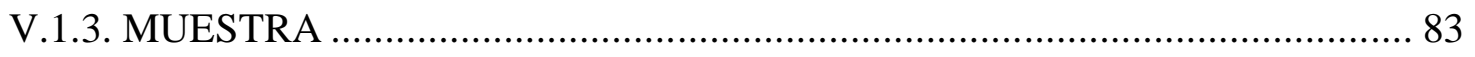

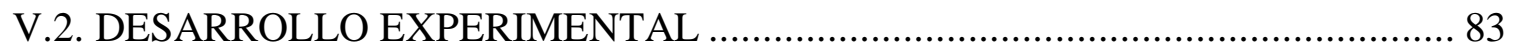

V.2.1.DESCRIPCIÓN DEL TEST FORMA MUSICAL ………………………......... 84

V.2.1.1. CONSIDERACIONES RESPECTO A LAS PARTES DEL TEST ............... 84

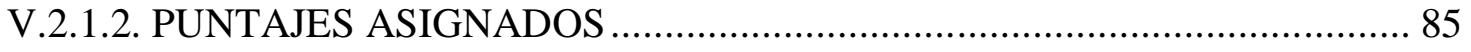

V.2.1.3. CRITERIOS DE SELECCIÓN Y REALIZACIÓN DE LOS EJEMPLOS... 87

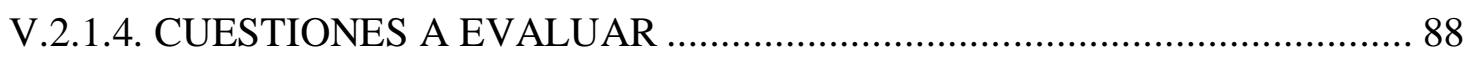

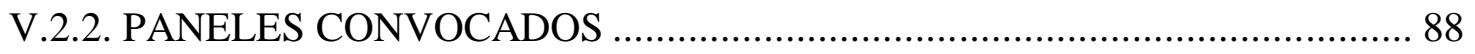

V.2.3. DISEÑO DE LA PRUEBA EXPERIMENTAL ………………..................... 89

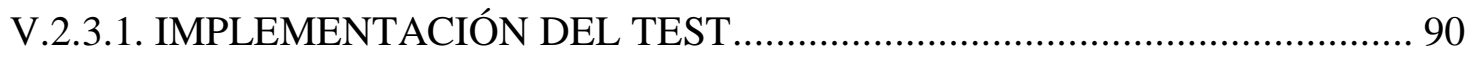

V.2.3.2. SESIONES CON EL GRUPO EXPERIMENTAL ....................................... 91

V.2.3.2.1. PRIMERA SESIÓN: 29 de Octubre de 2013 .............................................. 93

V.2.3.2.2. SEGUNDA SESIÓN: 31 de Octubre de 2013 ............................................. 94

V.2.3.2.3. TERCERA SESIÓN: 5 de Noviembre de 2013......................................... 96 


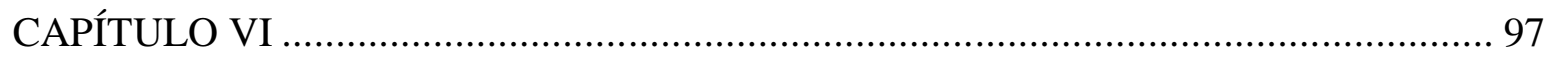

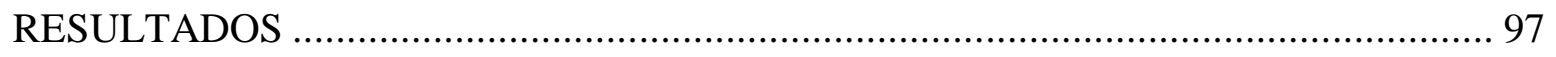

VI.1. ANÁLISIS DE LA VARIABLE A …………….......................................... 98

VI.1.1. COMPARACIÓN DE SUB-VARIABLES DE A.......................................98

VI.1.2. DESARROLLO DE LAS SUB-VARIABLES DE A................................... 101

VI.1.3. DESARROLLO DE LA VARIABLE A .................................................... 103

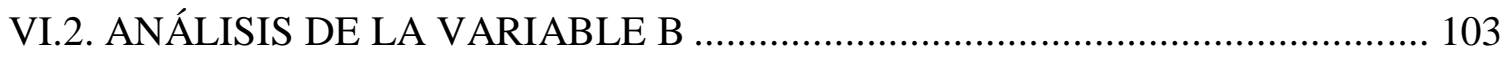

VI.2.1. COMPARACIÓN DE LAS SUB-VARIABLES DE B ................................ 104

VI.2.2. DESARROLLO DE LA VARIABLE B ………………………….......... 106

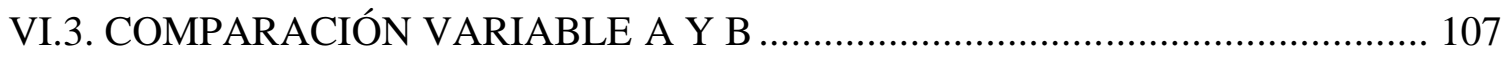

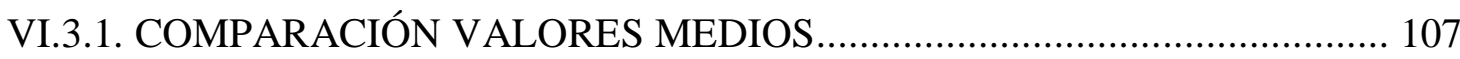

V.3.2. COMPARACIÓN DE DESARROLLO ENTRE VARIABLES A Y AB ...... 109

VI.3.3. DESEMPEÑOS ALCANZADOS POR LOS GRUPOS EXPERIMENTAL,

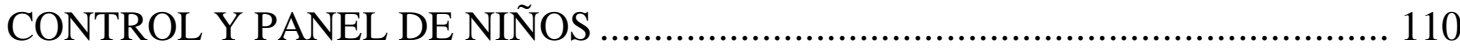

VI.3.4. COMPARACIÓN DE DESEMPEÑOS EN DISTINTOS ASPECTOS DEL

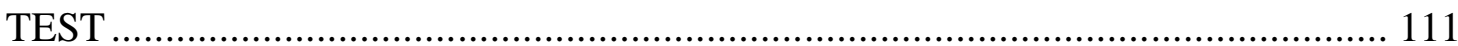

VI.3.5. COMPARACIÓN DE MUESTRAS PAREADASs .................................... 114

VI.3.6. ANÁLISIS DE DESEMPEÑOS RESPECTO A CADA EJEMPLO MUSICAL 116

VI.4. DESARROLLO GENERAL DE CADA GRUPO........................................ 120

VI.4.1. ANÁLISIS DE LOS GRUPOS SEGÚN RANGOS DE PUNTAJES ........... 121

VI.4.2. ANÁLISIS DE LOS GRUPOS SEGÚN NIVEL DE DESARROLLO.......... 123

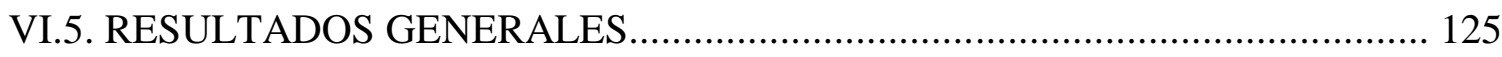

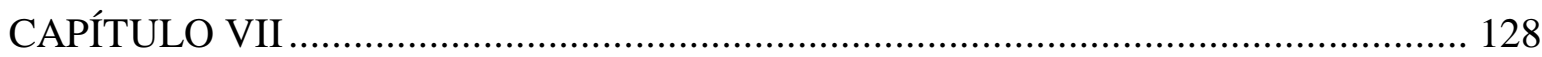

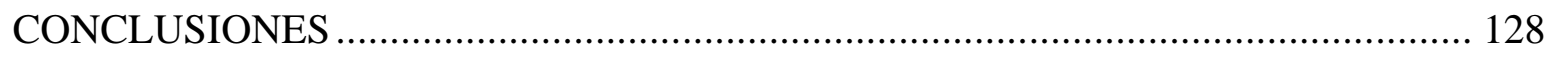

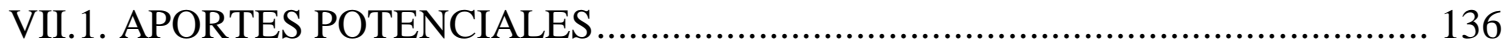

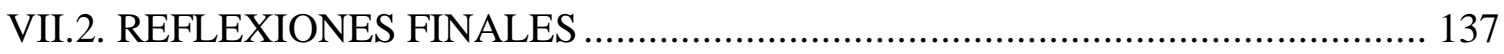

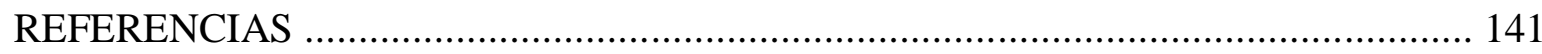

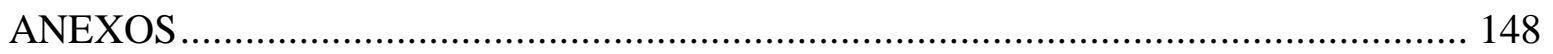

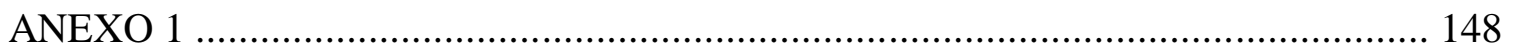




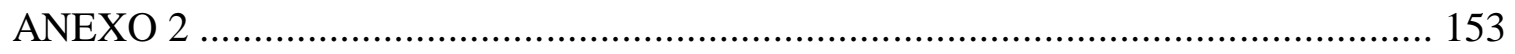

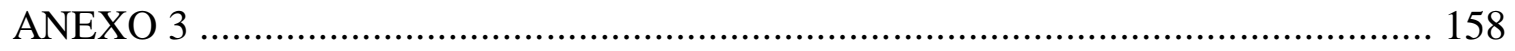

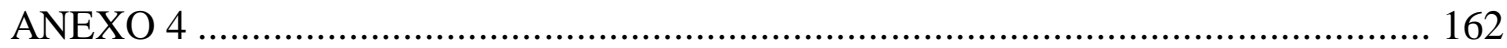

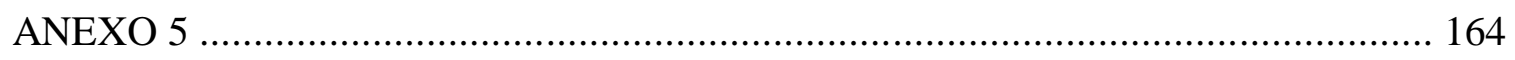

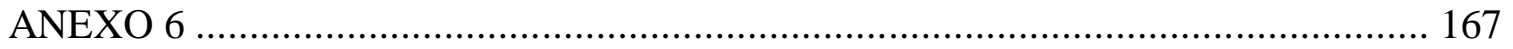

ANEXO AUDIO EN CD ADJUNTO

ANEXO 1 - TEST FORMA MUSICAL

ANEXO 2 - PRIMERA SESIÓN EXPERIMENTAL

ANEXO 3 - SEGUNDA SESIÓN EXPERIMENTAL

ANEXO 4 - TERCERA SESIÓN EXPERIMENTAL

ANEXO 5 - SESIONES GRUPO CONTROL 


\section{INTRODUCCIÓN}

Comprender los procesos por los cuales una persona otorga sentido a lo que escucha es adentrarse en complejos sistemas donde la mente, el cuerpo y el entorno se vinculan en un continuo con diferentes modalidades y magnitudes.

La audición musical permite construir significados a partir de la intervención de procesos cognitivos como: percepción, atención, memorización, representación, conceptualización y simbolización. Estos procesos se generan en el entramado de la mente y el cuerpo a través de las experiencias construidas culturalmente.

Sobre este complejo proceso nos detendremos en las diferentes modalidades, formatos y niveles de representación que la experiencia musical suscita en el sujeto, como un modo de indagar a través de ellas la comprensión musical.

En el presente trabajo nos situamos en el análisis de la comprensión musical en términos de las modalidades de representación que pueden construir, desde la audición, niños de 10 y 11 años, sin formación musical previa, respecto al atributo musical de la forma y su vinculación a gráficos con representaciones abstractas tales como formas geométricas y letras o números.

Un problema con múltiples aristas, aunque acotado, requiere un abordaje desde múltiples miradas. Priorizando el objeto de estudio y no una línea de investigación en particular, realizamos este trabajo sobre los aportes provenientes de la Psicología Cognitiva 
Clásica, los de la Cognición Corporizada y recientes hallazgos en el ámbito de las Neurociencias Cognitivas. ${ }^{1}$

La aclaración precedente surge a partir de la postura de ciertos autores en considerar la Línea en Cognición Corporizada no sólo como superadora de la Línea clásica sino que subestiman ciertas terminologías de esta. Tal es el caso del concepto de "Representación" al cual se lo califica de "ingenuo" y "reductivista".

Para la Psicología Cognitiva Clásica la mente funciona fundamentalmente como un ordenador: posee un proceso de input por el que registra, a través de los sentidos, la información del exterior. A continuación, de acuerdo con las características de la información, la misma, asume en la mente determinado formato y es "traducida" a símbolos generando una representación. El proceso cognitivo implica que estos símbolos se transformen produciendo un output que es la respuesta del sujeto al estímulo recibido. Esta perspectiva postula que la actividad cognitiva se concentra en un sistema centralizado del que depende todo el proceso: la mente. Para esta noción, el cuerpo aparece separado y ajeno a la mente y no interviene (o lo hace muy discretamente) en las tareas cognitivas.

Existen varias líneas de investigación en Cognición Corporizada. En general postulan la importancia del cuerpo en la cognición, la que depende de experiencias originadas en un cuerpo, indisociado de la mente, poseedor de diversas actitudes sensoriomotrices, las cuales se encuentran ancladas, simultáneamente, en un amplio contexto biológico, psicológico y cultural (López Cano, 2005).

Si bien es cierto que el rol del cuerpo en la cognición es fundamental, la descripción y análisis que la Psicología Cognitiva Clásica realiza sobre los procesos que intervienen en la cognición resulta a todas luces, desde nuestra perspectiva, indispensable.

\footnotetext{
1 "El problema radica en que se sigue pensando en función de disciplinas y no de problemas. Debemos desechar nuestros hábitos de pensamiento corporativo y buscar cuál es el ángulo del problema que nos compete para ofrecer soluciones." (Álvarez González, 2009:76)
} 
El conocimiento es más que lo que la mente percibe, y lo que el cuerpo experimenta. Se construye a través de la interacción de la mente, el cuerpo y la cultura. En esa interacción existe la música. Acercarnos a su comprensión es indagar los procesos que le dan existencia.

Conociendo ambas posturas, este trabajo las asume como complementarias en pos de acercarse al objeto de estudio. Consideramos que cada línea aporta y ayuda a entender los procesos implicados en la comprensión musical, tomando como nexo de unión, en ciertos puntos, algunos de los aportes de las investigaciones en Neurociencias Cognitivas, cuyos hallazgos confirman especulaciones de ambas teorías.

El interés en la temática de la tesis surge del ámbito pedagógico musical y allí es donde desea volcar los aportes que puedan obtenerse. Algunas de los inconvenientes recurrentes en asignaturas que realizan análisis musical dentro de las prácticas de clase son:

- $\quad$ La modalidad con que se realizan las segmentaciones de la música al aplicar el análisis tradicional en semifrases, frases, períodos, etc las que resultan muchas veces forzadas, siguiendo la partitura más que las posibilidades reales de audición,

- Los criterios con los cuales se seleccionan los ejemplos prestando insuficiente atención a la extensión y complejidad de los mismos, los que resultan difíciles de retener.

- $\quad$ El análisis insuficiente (en casos inexistente) de las saliencias perceptivas a partir de la audición de la obra motivo de estudio, respecto al contenido que se desea analizar. La partitura es un dato que no siempre revela cuál es el componente de la obra que resulta ponderado en la ejecución.

- La consideración minuciosa de los conocimientos y experiencias previas del alumno, de acuerdo a la dificultad planteada en la 
audición. Esto se evidencia en una falta de secuenciación de los materiales de audición.

- La atención multidimensional al interjuego entre las estrategias cognitivas requeridas para la audición, las características estructurales de la música y las competencias de las que disponen los alumnos.

El interés de la autora sobre esta temática comienza a partir de la observación de los desempeños de niños en relación a la percepción musical y los diferentes grados de comprensión manifestados. La realización de determinadas tareas de ejecución (corporal, vocal o instrumental), de gestualidad como "dibujar" determinado atributo o de desplazamientos en el espacio siguiendo la temporalidad de la música y su correlato formal, no siempre pueden traducirse inicialmente de manera exitosa en verbalizaciones, gráficos o notación de lo representado corporalmente.

Los diferentes desempeños manifiestan distintas modalidades de comprensión y distintos niveles en el acercamiento hacia un conocimiento cada vez más explícito, desarrollado y profundo. La investigación en estas temáticas aporta conocimiento a la Pedagogía Musical respecto de las estrategias a utilizar de acuerdo con el nivel de representación en que se encuentra el sujeto, la secuencia pedagógica a implementar, los criterios de selección de los ejemplos y la variedad de formatos representacionales como estímulo afectivo, sensorial y cognitivo en la construcción del conocimiento.

Este trabajo se propone indagar:

- la naturaleza de estas representaciones internas,

- el proceso que las genera,

- la relación entre las diferentes modalidades de representación externa que la música adopte, (auditiva, visual, kinestésica) y 
- la respuesta que el sujeto produzca a partir de la interacción de las modalidades representacionales.

La audición musical requiere del receptor operaciones mentales de alta complejidad caracterizadas por procesos de ida y vuelta entre información sonora ya escuchada y nuevos datos entrantes, acciones que demandan la comprensión, retención y anticipación de lo por venir. Estos procesos que ocurren en tiempo real se desenvuelven velozmente y desencadenan en el auditor comportamientos de participación tanto visibles como encubiertos y emociones basadas en el grado de familiaridad o novedad de acuerdo con sus experiencias previas. Las representaciones mentales que tienen lugar resultan difíciles de advertir en su verdadera envergadura y no fácilmente accesibles al examen y análisis riguroso.

Un elemento clave para aislar rasgos tanto comunes como diferenciales en comportamientos representacionales de los niños, es atender al lugar que ocupan los modos de "externalización" de dichos pensamientos internos. En tal sentido, la descripción verbal, la transcripción gráfica o la traducción corporal pueden verse afectadas por la asociación entre los modos externos de representación y su grado de conciliación con las imágenes internas.

Este estudio intenta analizar los resultados de representación gráfica, a partir de la audición, de una muestra de niños entre 10 y 11 años, sin experiencia musical escolar, comparando las respuestas de un grupo experimental que ha recibido un entrenamiento básico sobre las reglas o convenciones utilizadas para traducir estímulos musicales y el grupo control sin tales experiencias.

Las tareas de procesamiento, codificación, recuperación y ejecución de la respuesta requeridas para la resolución del test, imponen el uso de diferentes estrategias cognitivas vinculadas con la atención, la memoria, la representación y la simbolización. La eficiencia en el uso de las mismas, asume características fuertemente idiosincráticas vinculadas con la cantidad y calidad de experiencias previas del sujeto, y el uso operativo de estrategias de 
recuperación, codificación y transferencia de las mismas a nuevas situaciones de aprendizaje.

La mediación pedagógica aporta su impronta a este proceso de construcción de conocimiento, la que es dependiente de las características cognitivas estructurales y funcionales- ambientales de cada sujeto.

Son supuestos de este trabajo que:

- la música como experiencia humana suscita diferentes modos de representación.

- las representaciones son formas de conocimiento que conjugan mente y cuerpo, los mundos objetivo, subjetivo e intersubjetivo como así también los comportamientos explícitos e implícitos. Todos ellos, componentes complejos e interrelacionados que conforman un continuo que otorga significación y sentido a la experiencia musical.

- Las particularidades de cada individuo respecto a experiencias, contexto, oportunidades y motivación son factores intervinientes en los diferentes formatos que puede asumir la representación simbólica.

- La intervención pedagógica musical intenta obtener la traducción de las representaciones "espontáneas" o "naturales" en representaciones fundadas en la sintaxis musical. 


\section{CAPÍTULO I}

\section{REPRESENTACIONES EN MÚSICA}

\section{I.1. PROCESAMIENTO DE LA INFORMACIÓN MUSICAL}

La complejidad que presenta una obra musical, dada la cantidad y calidad de datos acústicos que ocurren de manera sucesiva y simultánea, impone a nuestra percepción un recorte de la información recibida. La mente humana presenta limitaciones para prestar atención a tan alto margen de información. La percepción selecciona ciertos datos e ignora otros. Bregman $(1990)^{2}$ denomina esta actividad asociada a la audición "segregación de eventos sonoros". Utilizando el término "eventos" en oposición a "objetos discretos", ya que las investigaciones demuestran que el sistema auditivo realiza un procesamiento de los datos acústicos que los organiza en unidades de sentido. La atención actúa así, como un mecanismo de control activo, que "filtra" información, eligiendo la más relevante. Bregman denomina "estela audible" a este punto de escucha que selecciona la percepción, en la cual el oyente focaliza su atención siguiéndola mientras persiste en el tiempo.

Dado que la música es un arte temporal, los datos acústicos presentes en la obra musical, transcurren en el tiempo, son datos dinámicos, no estáticos como las formas y colores de una pintura en los que podemos detener la observación. Para poder analizar los atributos musicales de una obra debemos recordarlos. "Sólo puede observarse la huella del sonido en tanto persiste en la memoria” (Furnó, 2005: 84). La cantidad de datos acústicos

\footnotetext{
${ }^{2}$ Citado por Furnó , 2003
} 
discretos que podemos memorizar es limitada, por ello, la memoria optimiza su funcionamiento agrupando o segmentando información. "El agrupamiento de componentes musicales funciona como un eficiente recurso de almacenamiento de información, al retener paquetes de acontecimientos sonoros en lugar de eventos discretos" (Malbrán, 2005: $58)$.

Dichos recursos mentales son formas de ahorro cognitivo que agilizan el procesamiento de información y economizan esfuerzo. Los mecanismos de agrupamiento y segmentación de estímulos musicales se fundamentan en la Teoría de la Gestalt, cuyos principios de proximidad, buena continuidad, cierre, similitud, regularidad y destino común, permiten explicar las razones por las cuales ciertos datos son agrupados con los siguientes o separados para conformar un nuevo paquete de información (Malbrán, 2005).

A partir de los datos disponibles la mente jerarquiza unos por sobre otros, particularmente aquellos que a la percepción resultan pregnantes. Esta ponderación de ciertos atributos en la música se denomina "saliencia perceptiva”.

En la audición musical, los datos ingresan al Sistema de memoria sensorial ecoica, especializada en la retención de las propiedades temporales de la información y precategorial ya que no analiza ni abstrae los datos receptados (de Vega, 1998). Estos son posteriormente enviados a la Memoria a corto plazo (MCP) que repite, almacena, agrupa y codifica la información para compararla o referirla con la información recuperada de la Memoria a Largo Plazo (MLP). Se produce luego una recodificación de los datos de la MCP gracias a la mediación de los conocimientos ya existentes provenientes de la MLP. Es decir, construimos nuevos conocimientos estableciendo una red de relaciones con los ya existentes. Las investigaciones describen la memoria conformando "esquemas" que ante el nuevo estímulo pueden ser activados si reconocen una correspondencia con aquel o descartados si pertenecen a esquemas no conocidos.

El proceso descripto permite acceder a una representación mental resultado de la experiencia con características invariantes de eventos y funciones perceptuales a través de 
las cuales se logra un anclaje referencial para la asimilación de estructuras de eventos perceptiblemente similares (Malbrán, 2005).

Las representaciones de la información musical que se van construyendo, son influidas por la característica temporal de la música escuchada, por ello Bamberger (1991) ${ }^{3}$ habla de la reversibilidad de la música representada e irreversibilidad de la música real.

A través de los procesos cognitivos comprometidos en el tratamiento de la información musical, se ponen en juego formas de interrelación entre las características estructurales de la obra y los mecanismos cognitivos que se ponen en marcha para tal fin, lo que deviene en particulares modos de percepción y posterior representación de la información.

\section{I.2. MODALIDADES DE REPRESENTACIÓN MUSICAL}

Según Mayor (1995:13) "el conocimiento del mundo que posee un sujeto está representado en la memoria a través de diferentes sistemas, códigos o formatos de representación y es adquirido, manipulado y utilizado para diferentes fines por el sistema cognitivo que incluye, además del subsistema de la memoria, otros subsistemas que procesan, transforman, combinan y construyen esas representaciones del conocimiento"

Uno de los temas centrales de la Psicología Cognitiva es determinar qué formato (o formatos) reviste la información receptada como materia prima de la actividad mental en su interrelación con en el tipo de procesamiento.

"Las formas de representación son los dispositivos que los seres humanos utilizan para exteriorizar las concepciones internas. Son los vehículos por los cuales las

\footnotetext{
${ }^{3}$ Citado por Furnó, 2005:32.
} 
concepciones (que son visuales, auditivas, kinestésicas, olfatorias, gustativas y táctiles) reciben carácter público. Este carácter público puede adoptar la forma de palabras, cuadros, obras musicales, matemática, danza, etc.” (Eisner, 1987:65)

Eisner asimismo argumenta que una forma de representación puede ser visual, auditiva, táctil, kinestésica, gustativa u olfatoria. La forma de representación es el medio expresivo que se utiliza para transmitir información utilizando uno o más sistemas sensoriales. La música, entonces, al ser un medio determinado y definido culturalmente, implica para él, un nivel mayor de abstracción y significa que pueden llegar a usarse diversas formas de representación en su procesamiento.

En este proyecto la representación infantil, indaga si el conocimiento almacenado en la memoria como imagen encubierta, puede resultar susceptible de traducción en formatos visibles bajo la forma de actos y grafismos.

Con frecuencia se ha tratado de organizar el conocimiento representacional, como alternativas contrapuestas. De acuerdo al tipo de información que ingresa al sistema cognitivo es el tipo de formato y de procesamiento que se realizará. De acuerdo a Mayor (1995) las propuestas clásicas de la Psicología Cognitiva son:

- $\quad$ Proposicional y en imágenes (o analógico)

- $\quad$ Procedimental y declarativo

- $\quad$ Explícito e implícito (o tácito).

- $\quad$ Serial o paralelo

- $\quad$ Específico y abstracto

- $\quad$ Distribuido o localizado

- Basado en esquemas y en modelos mentales 
Las representaciones pueden, presentar niveles dispares de abstracción y organización, desde unidades pequeñas y elementales ligadas a la entrada perceptiva, hasta otras organizadas como totalidades y con un alto nivel de elaboración. Por lo tanto, de acuerdo al estímulo entrante o información y el nivel representacional del sujeto, será el formato que revista dicha representación, su nivel de procesamiento, y la recurrencia a la MLP de información o experiencias previas cuyas características puedan sumarse a la información entrante (reagrupando los ítems de MCP en unidades más complejas y optimizando así su capacidad).

La investigación en Psicología de la Música muestra que el procesamiento y la elaboración cognitiva de la información musical, ponen en marcha ciertos modos de interrelación entre las características estructurales de la obra y mecanismos cognitivos que facilitan la comprensión y retención de la información entrante. Por ende, las características del estímulo desencadenan procesos cognitivos funcionales a la representación en la mente. Una cuestión crucial, es el tránsito de dichas representaciones encubiertas a comportamientos manifiestos tanto verbales, corporales como gráficos.

"Según Swanwick (1991) en el más bajo nivel de recepción la música puede provocar la evocación de imágenes, situaciones y sensaciones varias. Para acceder a niveles superiores, en los que las relaciones sonoras puras adquieren preponderancia, es necesario desarrollar mecanismos que ayuden a encontrar sentido y a configurar en la mente el discurso" (Furnó, 2005:32).

Dumarier (1990) diferencia la percepción-aprehensión (tratamiento sensorial de la información) de la percepción-comprensión (tratamiento verbal de la información), permitiendo otro tipo de almacenamiento y organización y posibilitando así percepciones más profundas y focalizadas.

"El intento de explicar relaciones sonoras implica la traducción de una forma representacional (acústica) a otra de tipo verbal (proposicional). Das, Kar y Parrilla (1998) afirman que el esfuerzo de la memoria a corto plazo difiere si la información retenida está representada verbalmente o no. Cuando no lo está, como posiblemente sucede con el 
sonido, se hace necesario interpolar la operación de encontrar los rótulos faltantes para que esos datos acústicos puedan ser traducidos en un formato verbal" (Furnó, 2005:34).

Las investigaciones (Lerdahl y Jackendoff, 1983) muestran que, un oyente sin entrenamiento, pero musicalmente enculturado, puede advertir componentes constructivos de la obra musical, aunque es posible que presente dificultades en verbalizarlo. Probablemente porque el conocimiento por enculturación no es suficiente para explicitar las representaciones internas que la música suscita.

Las diversas modalidades de representación adquieren en la mente un formato a través del cual esta información se procesa cognitivamente. Por las características del discurso musical es probable que se presente en un formato abstracto y temporal con lo cual requiera su traducción a otros formatos representacionales que permitan su comprensión y que ayuden a dar cuenta de ella. En este sentido la modalidad comunicacional que acompañe al discurso musical (gestual, gráfica, verbal, etc) aportará un formato representacional particular, lo cual puede colaborar tanto a la comprensión musical del perceptor como a la comunicabilidad de la forma representacional adoptada.

Por ello los modos externos de representación de la música asumen diferentes formatos. La situación específica de audición musical considerada como proceso, involucra no sólo los datos del contexto, auditivos y visuales, sino los que emergen del continuo mente-cuerpo-entorno como las emociones, el movimiento manifiesto o encubierto, las expectativas, y recuerdos (López Cano, 2007). Esta interrelación entre representación externa e interna del sujeto produce una respuesta cuyas características representacionales están vinculadas a la naturaleza de la tarea y a la confluencia de los elementos intervinientes en las otras representaciones.

De este modo la información se condensa en particulares formatos multimodales que suponen una construcción por parte del oyente en interrelación entre estos y sus características particulares en cuanto a experiencias y conocimientos previos.

A raíz de lo expuesto surgen los siguientes interrogantes: 
LA COMPRENSIÓN DE LA ESTRUCTURA MUSICAL.

LA REPRESENTACIÓN UTILIZADA EN NIÑOS ENTRE 10 Y 11 AÑOS.

- ¿cuáles formas particulares de conocimiento compromete la música?,

- ¿qué tipo de formato adquieren en nuestra mente?,

- ¿en qué medida el sujeto es consciente de lo que sabe acerca de lo que ha escuchado, cantado o ejecutado?

- ¿Cómo transforma el perceptor su representación interna para poder explicitarla y comunicarla?

La complejidad de la temática impone la necesidad de un análisis detallado de los diferentes elementos que intervienen en esta dinámica: la música como objeto de la representación y el sujeto que crea la representación.

\section{I.3. ORGANIZACIÓN DE LAS REPRESENTACIONES EN LA MEMORIA}

La naturaleza de las representaciones mentales y los posibles formatos que la definen, algunas de las cuestiones de interés de la Psicología Cognitiva se centran en aspectos más complejos de las representaciones, como son las estructuras en las que se organizan dentro de nuestra memoria.

Como se ha visto (pp.8) por Estructuras de la Memoria, nos referimos a tres dispositivos básicos (Modelo general de la memoria propuesto por Atkinson y Shiffrin 1968): la memoria sensorial, la memoria a corto plazo (MCP) y la memoria a largo plazo (MLP). "Cada una de estas estructuras tienen propiedades funcionales específicas, relativas al tipo de información que almacenan, la capacidad de almacenamiento, la persistencia temporal de la información y el formato simbólico de la información” (de Vega, 1984:60). 
Los Procesos de la Memoria son aspectos dinámicos que se presentan en forma sucesiva a través de las operaciones de: codificación, almacenamiento, retención y recuperación. En estos procesos intervienen las distintas Estructuras de la Memoria. (de Vega 1984, Sternberg, 1987)

Según de Vega (1984) los procesos de codificación son imprescindibles para transformar los estímulos sensoriales en pautas de información posibles de organizarse y almacenarse en la memoria.

"Un modo de organizar las representaciones es a través del pensamiento categorial. Los sistemas de categorías proveen información ordenada reduciendo el esfuerzo cognitivo" (Malbrán, 2005:16). Esta organización permite a su vez una recuperación eficiente de la información, como la asimilación y ordenamiento de nuevos conocimientos. (Melen, 2000) ${ }^{4}$

Los diferentes Niveles de Procesamiento de la Memoria reconocen la existencia de multiplicidad de categorías las cuales tendrían una organización funcional de tipo jerárquico. "Los niveles inferiores o más "superficiales" corresponderían al procesamiento de rasgos físicos del estímulo, mientras que los niveles más "profundos" se encargarían de extraer propiedades más abstractas" (de Vega, 1984:178)

Diferentes músicos e investigadores (Salzer, 1962; Schenker, 1935/79; Lerdahl y Jackendoff, 1983) han considerado el análisis musical en términos de una estructura jerárquica con diferentes niveles desde los más superficiales a los más profundos, estableciéndose un paralelo entre la estructura de la música y la estructura de procesamiento de la información (niveles de procesamiento de la memoria).

La memoria para la música involucra una codificación jerárquica. Esto se evidencia en la dificultad de comenzar una ejecución en cualquier punto arbitrario, fuera de un inicio

\footnotetext{
${ }^{4}$ Malbrán, 2005
} 
de frase o punto estructuralmente importante. De ser así, mentalmente se debe recorrer la frase hasta ese punto.

Un término utilizado por la Psicología referido al procesamiento de información en la memoria es el de "esquema". "Los psicólogos etiquetan los esquemas con diversos términos: esquema (Anderson, 1976), red (Goldstein y Papert, 1977; Minsky, 1975), prototipo (Posner, 1969), gramática (Mandler y Jonson, 1977; Millar y Chomsky, 1963), además de jerarquía, matriz y varios más." ${ }^{5}$

La noción de esquema fue originariamente propuesta por Piaget (1926) para quien conocer es asimilar la nueva realidad a los viejos esquemas o crear nuevos esquemas que se acomodan a la nueva información. Según Piaget el ser humano dispone de un amplio abanico de esquemas que van desde los perceptivos, hasta los afectivos, cognitivos y motrices. Los denomina esquemas operatorios por entenderlos como acciones susceptibles de realizarse sobre los objetos, bien físicamente o de forma interiorizada para lograr el ajuste o equilibrio del sujeto con el medio, Considera asimismo que se construyen espontáneamente.

Para la Psicología Cognitiva un esquema es una estructura de datos, una estructura de información residente en nuestra memoria que nos permite comprender ciertos eventos, objetos, episodios, etc.

Los esquemas pueden caracterizarse como estructuras mentales que i) organizan y relacionan cierto conjunto de información sobre el mundo que ii) contienen información relacionada y iii) se activan en momentos específicos guiando nuestro comportamiento. Su nivel de complejidad y abstracción es mucho mayor que en el caso de las categorías, ya que

\footnotetext{
${ }^{5}$ En Goñi Grandmontagne, 1995: 42.
} 
en un esquema podemos poner en juego muchas de esas categorías y relaciones (causales, temporales, etc.) entre categorías.

Para explicar los procesos de categorización en los sistemas de memoria se han propuesto distintas teorías de la formación de "concepto" (Piaget, 1961; Ausubel, 1976; Vigotsky, 1934-1995).

"Los conceptos son representaciones almacenadas en la memoria, que posibilitan tratar cognoscitivamente a distintos ejemplares como miembros de una misma clase de objetos, acciones y situaciones" (Goñi, 1995:41). Sin embargo no todos los miembros de una misma categoría son igualmente representativos, o coincidentes en sus rasgos definitorios, algunos miembros se consideran más típicos que otros. Una categoría se describiría mejor, más que a partir de una lista de rasgos que comparten todos sus miembros, a partir de ejemplares prototípicos (Goñi, 1995; Levitin, 2006)

La noción de prototipo fue propuesta por Rosch (1975) y la describe como un ejemplar con características típicas en su categoría. La tipicidad es un rasgo de la representación de los conceptos, que puede afectar a los procesos de memoria, en concreto, a la rapidez, la precisión del reconocimiento y el recuerdo.

Las categorías no están representadas mentalmente en términos de propiedades definitorias, es decir la representación conceptual de una categoría no se logra a través del reconocimiento de un listado de propiedades, sino de un prototipo. La comprensión de un concepto se alcanza a través de ejemplares prototípicos y no por la frecuentación del universo de categorías que pueden estar relacionados con dicho concepto. Premisa que es fundamental en educación ya que como vimos las categorías se estructuran jerárquicamente y por lo tanto la organización del conocimiento de esta manera ayuda a estructurarlo. Este mecanismo agiliza y efectiviza el trabajo de la memoria, tanto en el almacenamiento como en su recuperación.

Respecto al contenido de lo memorizado, Levitin (2006) menciona dos teorías: la teoría de archivo y la constructivista. La teoría de archivo sostiene que la memoria puede almacenar especificaciones, y detalles. Tal capacidad ha quedado demostrada 
experimentalmente cuando al solicitar a los sujetos que canten sus canciones favoritas, tienden a cantar en los tonos absolutos o muy cerca de ellos, en el tempo de la versión recordada e inclusive con particularidades en la ejecución como la imitación de afecciones vocales del cantante original (Levitin, 2006). La teoría constructivista propone que la memoria guarda abstracciones. Por ejemplo al reconocer una melodía aunque esté presentada con otra instrumentación a la original, diferente tempo, tonalidad e inclusive con algunos cambios de altura.

El autor amplía el concepto al expresar que "la teoría del prototipo tiene una conexión cercana a la teoría constructivista de la memoria, en que los detalles de los casos individuales son descartados, y se guarda lo esencial o la generalización abstracta" (Levitin, 2006:159)

A pesar de lo valiosa que fue la Teoría del Prototipo para confirmar los datos experimentales sobre la conformación de categorías, surgieron algunos cuestionamientos referidos a las posibilidades de categorías muy amplias o miembros de categorías muy diferentes entre sí. "La información de contexto es parte de nuestro conocimiento sobre las categorías y los miembros de la categoría, y la teoría del prototipo no explica esto" (Levitin, 2006:160).

Smith y $\operatorname{Medin}^{6}$ propusieron la teoría ejemplar como una alternativa a la Teoría del Prototipo. Según dicha teoría, se retienen los detalles y el contexto en el sistema de memoria conceptual.

Las teorías constructivistas y las de archivo, como la ejemplar, explican una de las facetas de las capacidades presentes en la memoria. Investigaciones neurocientíficas (Zatorre, 2005) describen diferentes especializaciones de la corteza auditiva que se activan paralelamente ante el estímulo musical; ciertas áreas codifican información específica (como el timbre) y otras áreas registran abstracciones (los lóbulos temporales dorsales

\footnotetext{
${ }^{6}$ En Levitin, 2006
} 
parecen activarse prestando atención al tamaño de intervalos y distancia entre tonos, lo que permite reconocer la melodía transpuesta).

La naturaleza paralela del cerebro hace posible que se puedan memorizar abstracciones y especificaciones, ambas de carácter categorial, para lo cual requiere información de contexto.

Hallazgos en experimentos con neuroimagen (Janata, 1997)) ${ }^{7}$ muestran que la actividad eléctrica del cerebro es la misma al escuchar o al pensar en música. "Esto sugirió que la gente usa las mismas regiones cerebrales para recordar como para percibir" (Levitin, 2006:154). Este indicio daría cuenta de la información de contexto que se anexa a un recuerdo y provee fundamento para considerar significativo el ambiente afectivo de aprendizaje y la riqueza de estímulos que provea.

La convergencia de la teoría ejemplar y la teoría de la memoria han nutrido a un grupo de teorías relativamente nuevo, colectivamente llamado "modelos de memoria de múltiples vías". "En esta clase de modelos, cada experiencia que tenemos es preservada con alta fidelidad en nuestro sistema de memoria de largo plazo. Las distorsiones de la memoria y las confabulaciones ocurren cuando, en el proceso de recordar algo, o tenemos la interferencia de otra información que está compitiendo por nuestra atención - con pequeños detalles diferentes - o algunos de los detalles de la memoria original se han degradado debido a procesos neurobiológicos que ocurren normalmente" (Levitin, 2006:162-163).

Los modelos de memoria de múltiples vías son eficaces para explicar el recuerdo de eventos casi olvidados, debido a que preservan el contexto (y basta con recordar un elemento que se recupere el resto de los recuerdos asociados), pero también, la exactitud de la memoria para los atributos musicales.

De acuerdo con los modelos de memoria de múltiples vías, cada experiencia está potencialmente codificada en la memoria. "No en un lugar particular del cerebro, porque el

\footnotetext{
${ }^{7}$ En Levitin, 2006
} 
cerebro no es como un depósito; más bien, los recuerdos están codificados en grupos de neuronas que, cuando están en los valores adecuados y se configuran de un modo particular, ocasiona que un recuerdo sea traído a la memoria y vuelva a ser ejecutado en el teatro de nuestras mentes" (Levitin, 2006:165).

Existen evidencias experimentales (modelo de procesamiento paralelo de Douglas Hintzman $)^{8}$, que demuestran la posibilidad neuronal de los modelos de memoria de múltiples vías.

Conocer la manera en que los sistemas de memoria están capacitados para codificar información relevante o estructural para crear abstracciones o detalles y especificidades para identificar individualidades, como así también características del contexto, sugiere potenciales guías para estudiar los procesos que subyacen a la comprensión musical.

Los datos anexos, generalmente íntimamente ligados a la experiencia musical previa, se guardaron en la memoria junto con la música y en la música, aportando evidencia de la importancia de los comportamientos cognitivos, corporales y emocionales en los procesos tanto de percepción, como de comprensión musical.

La audición musical implica no solo la recepción de la señal física, sino los procesos imaginativos que la vinculan al movimiento, a las imágenes y a las emociones. Recordar música, es de alguna manera, volver a vivirla.

${ }^{8}$ En Levitin, 2006. 


\section{I.4. EL ROL DEL CUERPO EN LA CONSTRUCCIÓN DE REPRESENTACIONES}

La ciencia cognitiva clásica, luego de una larga tradición de debates filosóficos en torno al problema mente-cuerpo, parte de una postura que escinde, en cierto modo, a la mente del cuerpo, considerando la mente el centro de "cómputos" y al cuerpo como el soporte físico capaz de llevar a cabo las órdenes del cerebro. Desde esta perspectiva la cognición es mental y el procesamiento de la información se realiza en el cerebro a través de representaciones simbólicas bajo la forma de algoritmos con datos perceptivos que el cuerpo toma del exterior; de esta manera el cuerpo es solo un medio y quien construye los significados es la mente. Se establece así la metáfora del ordenador. La mente se constituye en el software y el cuerpo en el hardware, la mente operacionaliza y procesa la información, el cuerpo incorpora información y ejecuta las órdenes (Pérez, 2005).

El post-cognitivismo planteó la necesidad de otorgarle al cuerpo un rol más activo en la construcción de conocimiento; se comienza a pensar en una cognición interactiva, enactiva, corporizada y situada (Gomila y Calvo 2008) ${ }^{9}$ De esta manera el cuerpo no es solo un medio para incorporar información, es un componente vital en la construcción de significados. La audición musical, desde esta perspectiva, asume al movimiento y las respuestas corporales y emocionales como formas implicadas en la comprensión musical. Resulta ineludible para la pedagogía musical revalorizar la acción, el movimiento y las experiencias subjetivas ligadas a él, al transitar los procesos que parten del sonido para construir conceptos y símbolos, sin desdeñar por ello los avances sobre la representación emergentes del cognitivismo clásico.

La ejecución musical, la audición y reflexión musical ponen en juego diferentes comportamientos, parte de ellos con importante compromiso corporal. Cómo activan el

\footnotetext{
${ }^{9}$ En Jaquier y Pereira Ghiena (2010)
} 
pensamiento, cómo son ejecutados, imaginados o recordados y cómo se relacionan con la propia estructura de la música, son algunos de los temas que las diferentes líneas de investigación sobre cognición están estudiando. Resultan por lo tanto de interés para el presente estudio las investigaciones en este modelo, ya que aportan nuevos enfoques acerca de la importancia del cuerpo en la construcción del conocimiento musical y su representación.

Los teóricos de la hipótesis corporizada conciben los procesos cognitivos y motores como fundamentalmente inseparables, mutuamente informados y estructurados de tal manera que en ellos se basan nuestros sistemas conceptuales (Reybrouck, 2005)

Los movimientos implicados en la experiencia y comprensión musical no son siempre manifiestos como aquellos encargados de la producción de sonido o los gestos expresivos revelados en la interpretación, esto es, existen también movimientos encubiertos: propioceptivos, recordados o imaginados (Peñalba, 2008). Ambos tipos de movimientos están presentes en el oyente, para quien la escucha es también un acto interpretativo y los movimientos que la experiencia musical le suscita, influyen en la manera de entender la música y crear significados. Así, el movimiento ligado a la acción corporal manifiesta o imaginada, está involucrado en la construcción de representaciones internas.

La percepción es un registro activo de datos externos bajo el formato de significación enactiva basada en la historia corporizada del sujeto. Según esta postura el mundo y la mente emergen juntos durante el mismo proceso cognitivo (Varela, Rosch y Thompson 1992: 202-206) ${ }^{10}$ y el compromiso del cuerpo en la música está siempre presente aun cuando no haya un movimiento manifiesto, sino recuperado o recordado, actividad mental que ha dado en llamarse simulación ideomotora (Reybrouck, 2005).

La simulación ideomotora cumple un rol importante en el aprendizaje motor y en la escucha enactiva. Existe una estrecha relación entre imaginería motora y ejecución motora,

\footnotetext{
${ }^{10}$ En López Cano, 2004
} 
con evidencia empírica que muestra que ambos procesos comprometen estructuras neuromotoras muy similares (Crammond, 1997) ${ }^{11}$. Es posible concebir la música en términos motores sin estar efectivamente realizando movimientos, (supuesto basado en los avances de las neuronas espejo) con lo cual existiría un acoplamiento entre percepción y acción, en el sentido que la imaginería motora se implica en la percepción. Los conceptos precedentes vinculan categorías estáticas de la percepción y categorías funcionales e integran atributos perceptivos y tipos de acción. En este sentido el rol del cuerpo en sus interfaces sensoriales y motoras concebirían la cognición musical en términos corporizados y experienciales (Reybrouck, 2005).

La música como experiencia sónica en movimiento destaca su posibilidad de impactar en nuestro cuerpo, por lo tanto posee significación a través de la acción corporal (Leman 2008). La importancia de considerar la música en estos términos radica en que a su vez esa modalidad corporal en la que es expresada la música, puede ser traducida en otras modalidades. En tal sentido la comprensión de la música es de naturaleza transmodal, siendo el resultado de la concurrencia de estímulos y procesos que involucran diferentes modalidades perceptuales (Shifres, 2006).

Se ha visto que las diferentes modalidades sensoriales en que se presenta la información musical (auditivas, visuales, espaciales, táctiles y motoras) se integran en una única representación, mediante la acción de neuronas multi-sensoriales distribuidas en diversas áreas cerebrales (Stein y Meredith $(1993)^{12}$. Al combinarse los diferentes formatos en que cada modalidad sensorial codifica la información proveniente del entorno y del propio cuerpo en interacción con él, logran no sólo una integración multimodal, sino más bien, una amplia transformación que va más allá de las partes componentes.

La música ha suscitado tradicionalmente una serie de representaciones externas relacionadas al gesto, el movimiento y la danza. El avance tecnológico permite convivir

\footnotetext{
${ }^{11}$ En Reybrouck, 2005

${ }^{12}$ En Malbrán, 2010.
} 
con representaciones mediante imágenes multimediales que forman parte de la performance musical. Las investigaciones muestran que esta "redundancia intersensorial", es decir, la información propuesta en dos o más modalidades (por ejemplo visual, auditiva, temporal y espacial), potencializa la comprensión del estímulo, con notables diferencias a que si el estímulo se presentara por una sola vía (Bahrick 2004) ${ }^{13}$

Las formas de representación externas inciden en la comprensión del contenido representado; el formato representacional que acompaña a la música, (grafías analógicas, gestos, movimientos) puede resultar un facilitador del proceso de comprensión.

En este sentido resultan interesantes los aportes de las investigaciones en cognición corporizada ya que muestran la importancia que el cuerpo tiene en la construcción del conocimiento. Esta construcción del conocimiento comienza con la interacción con los estímulos del medio, utilizando como herramienta el cuerpo. La adquisición mediante el cuerpo de la representación de las características del estímulo serían estrategias facilitadoras del proceso de representación.

La Teoría de la Metáfora (Lakoff y Johnson 1980) sostiene que parte del pensamiento humano, muestra una forma de entender el mundo, de naturaleza metafórica que implica proyectar patrones de un dominio cognitivo concreto a otro de mayor abstracción. En el caso del pensamiento concreto implica utilizar esquemas básicos que, derivan de la propia experiencia inmediata con el entorno El ser humano utiliza estos esquemas básicos, esquemas imagen, para dar sentido a experiencias en dominios más abstractos mediante proyecciones metafóricas.

Las diferentes líneas teóricas en cognición corporizada encuentran correspondencia en los avances de las Neurociencias y particularmente con la identificación del comportamiento de las neuronas espejo. Tales avances muestran que es posible realizar mentalmente los pasos implicados en la realización de una acción y obtener similares comportamientos mentales a que si la acción se hubiera efectivamente realizado. Es decir

\footnotetext{
${ }^{13}$ En Malbrán y García Malbrán (2010)
} 
que se activan las mismas neuronas que si se estuviera realizando la acción pero en este caso no se mueven los músculos efectores (Rizzolatti y Sinigaglia, 2006) ${ }^{14}$.

Según López Cano (2011), la enacción no se interesa tanto por la manera de representar el conocimiento sino por los procesos que guían las acciones del perceptor en las que el punto de referencia no es la situación en sí sino la propia estructura sensoriomotriz.

Este trabajo, a partir de la masa crítica acumulada, propone que el sujeto frente a la experiencia musical, vivida o recordada, crea representaciones que son algo más que un cómputo mental posterior a la experiencia realizada a través del cuerpo. Se trata de formas de conocimiento que amalgaman lo mental y lo corporal, lo objetivo, subjetivo e intersubjetivo, lo explícito y lo implícito, lo consciente y lo inconsciente, lo auditivo y lo multisensorial. Todos ellos, componentes complejos e interrelacionados en un continuo, que dan existencia y sentido a la experiencia musical.

Esta propuesta intenta conjugar la visión clásica con la visión corporizada de la Psicología Cognitiva, encuentra sustento en los aportes provenientes de la Neurociencia. El descubrimiento de las neuronas espejo por ejemplo, materializa la incumbencia de lo corporal en lo mental, pero lo mental sigue presente. La hipótesis acerca de que acción y percepción comparten códigos neuronales comunes está obteniendo creciente soporte empírico desde la neurociencia cognitiva (Jackson y Decety, 2004; Hommel y otros, $2001)^{15}$. Otro hallazgo que permite pensar la representación de la experiencia en términos más abarcadores proviene a través de los Modelos de Memoria de Múltiples Vías (Hintzman, 1986; Goldinger, 1998) y sus correlatos neurales, explicando la riqueza de la experiencia humana al incorporar la información sobre el evento a la del entorno, con lo cual percepción, cognición, motricidad y afecto se unen en una representación de lo

\footnotetext{
${ }^{14}$ En Levitin, 2006

${ }^{15}$ En Leman, 2008
} 
experimentado. La realidad física es la integración de idénticos circuitos neuronales en la ejecución y en la recuperación.

La música como experiencia humana cotidiana, social y comunicacional, suscita representaciones. Los componentes de dichas representaciones conforman un continuo en el que se relacionan i) el grado de emoción manifestado, ii) las acciones corporales realizadas, y iii) los significados otorgados. Esta dinámica permite pensar en diferentes niveles de representación.

En relación a la Pedagogía Musical, la visión de la representación como un continuo sugiere el análisis del grado de relación entre la experiencia, los diversos enfoques analizados, y los conceptos teóricos musicales. Su interés en este sentido, es tomar en consideración las diversas modalidades representacionales presentes en la experiencia musical durante el proceso de enseñanza aprendizaje, para que el sujeto sea capaz de arribar a una representación teórica. 


\section{CAPÍTULO II}

\section{LA MÚSICA COMO OBJETO DE REPRESENTACIÓN}

Nuevos enfoques teóricos afirman que el procesamiento de la información se realiza a partir de las características de superficie de los discursos musicales, es decir de los rasgos que resultan más pregnantes a la percepción; en consecuencia la atención variará de acuerdo a la importancia estructural del evento en el que el oyente enfoque su escucha (Martínez, 2006). Por ello "las decisiones implícitas y/o explícitas que el oyente tome al escuchar serán el producto de la interacción entre la estructura cognitiva de la audición atenta y las características organizativas de la estructura de la obra musical" (Martinez, 2006:90).

La representación que se logra construir depende de los rasgos del estímulo en los que se focaliza la atención. Dado que no se puede prestar atención a todo al mismo tiempo, la mente realiza recortes de información para poder procesar el discurso, por ende sólo se alcanza la representación de algunos componentes que intervienen en la trama. "Así como la percepción es selectiva para hacer foco, también debe ser selectivo el contenido que una forma de representación contenga" (Eisner, 1987:67)

\section{II.1. MÚSICA Y ESTRUCTURA}

En la simultaneidad y sucesión temporal de elementos sonoros que conforman una obra musical coexiste una red de relaciones, en las que un evento sonoro puede contener a 
otros o ser contenido por eventos más inclusivos, estableciéndose de este modo una estructura jerárquica.

Existe acuerdo en considerar la música como una estructura con niveles jerárquicos. Esta cualidad aparece planteada en distintas Teorías Musicales (Salzer, 1962; Schenker, 1935/79; Lerdahl y Jackendoff, 1983)

Las estructuras jerárquicas que aparecen en los modelos de organización de procesos cognitivos como los modelos de organización de la representación de la información, encuentran un paralelo en la Teoría Musical que ha desarrollado modelos que describen la estructura de la obra musical en términos de una organización también jerárquica. De esta manera existe una relación estructural análoga entre los modelos teóricos musicales y la naturaleza de su experiencia (Martínez, 2006).

Para Lerdahl y Jackendoff las construcciones y relaciones que describe la Teoría de la Música residen en la mente. "Según nuestro enfoque, la tarea clave de la Teoría de la Música debería ser explicar esta organización producto de la mente" (Lerdahl y Jackendoff, 1983-2003:2) Esta posibilidad se debe a la capacidad humana de poseer por enculturación, las reglas de construcción del lenguaje musical, lo que los autores denominan "intuiciones musicales del oyente experimentado". "Existiría una correspondencia entre la estructura de la música tonal y la estructura del funcionamiento mental musical y las reglas de la gramática tonal constituirían un caso particular de leyes cognitivas más generales" (Imberty, 1990:9)

Diferentes investigaciones han sometido a control experimental la realidad psicológica de ciertos aspectos de estos constructos teóricos (Sloboda [1985]- 1996; Krumhansl 1990; Dowling y Harwood 1986; Mc Adams y Bigand 1994; Aiello y Sloboda 1994; Deustch 1999; Howell, Cross y West 1991; Deliege y Sloboda 1997)

Lerdahl y Jackendoff (1983-2003:10) describen de la siguiente manera los componentes de la intuición musical de naturaleza jerárquica, que desarrollan en su Teoría Generativa de la Música. 
- La estructura de agrupamiento expresa la segmentación jerárquica de la pieza en motivos, frases y períodos.

- La estructura métrica da expresión a la intuición de que los distintos eventos de una pieza están relacionados con una alternancia regular de tiempos fuertes y débiles en distintos niveles jerárquicos

- La reducción interválica-temporal asigna a los tonos de una pieza una jerarquía de importancia estructural con respecto a su posición en la estructura de agrupación y métrica

- La reducción de prolongación asigna a los tonos una jerarquía que expresa la tensión y la relajación armónica y melódica, su continuidad y progresión.

En una estructura jerárquica todos los elementos o áreas de la misma jerarquía son subordinados en una dirección o dominantes en otra. Los elementos que se presentan en un mismo nivel son correlativos con otros niveles de mayor o menor inclusividad, conformando así una estructura jerárquica. A su vez, un nivel determinado puede calificarse como de pequeña escala o de gran escala, dependiendo del tamaño de sus elementos o áreas constitutivas (Lerdahl y Jackendoff 1983-2003:14).

La complejidad de la trama musical en términos de desarrollo de la obra, con las distintas posibilidades de abstracción entre niveles jerárquicos, es funcional a la complejidad de procesos cognitivos puestos en marcha para su análisis.

Una estructura jerárquica y sonora que se desenvuelve en el tiempo y que porta una significación para quienes la comparten, ha llevado a plantear en numerosas ocasiones la analogía entre música y lenguaje.

Emmanuel Bigand (1991) explorando esta analogía y tratando de avanzar hacia la conceptualización de los procesos implicados en la comprensión musical, establece coincidencias y especificidades en ambos lenguajes. Según el autor ambos lenguajes permiten a través de una cantidad finita de reglas conformar una cantidad infinita de 
producciones, una "gramática generativa transformacional" aprendida por enculturación (Chomsky, 1969; Lerdahl y Jackendoff 1983-2003). La capacidad transformacional de la gramática genera en el lenguaje una estructura de superficie donde discurren todas las palabras del mensaje unidas a través de una sintaxis determinada y una estructura profunda donde reside el significado (semántica) del discurso hablado.

De la misma manera, el lenguaje musical presenta niveles jerárquicos. El teórico de la armonía, compositor y analista Schenker (1935/79) fue quien primero planteó el análisis musical en estos términos proponiendo tres niveles:

- la "base generadora de superficie" que despliega los detalles del discurso y a partir de la cual se comienza el procesamiento de la información, (y a través de procesos reduccionales puede abstraer la idea generadora contenida en la estructura generadora profunda)

\section{- "la base generadora mediana"}

- "la estructura generadora inicial" que contiene en última instancia el acorde de tónica que despliega a través de procesos prolongacionales la obra completa hasta llegar a los detalles de superficie.

Bigand (1991) expresa que la comprensión musical, al igual que en el lenguaje, implica establecer cognitivamente una red de relaciones entre los niveles de la estructura que conforman el discurso. "El concepto de obra musical solo tendría realidad psicológica después de un cierto número de audiciones durante las cuales nuestra memoria establecería las conexiones asociativas entre las diferentes secciones que la forman, basándose únicamente en sus relaciones de contigüidad temporal” (Bigand, 1991:74).

El contenido de la representación que el sujeto construye es afín a las características estructurales de la música, objeto de la representación y a los procesos cognitivos que le dan origen.

Debido a la naturaleza de la tarea requerida a los sujetos durante el test, examinaremos las características de la percepción de la estructura de agrupamiento y 
posteriormente los niveles de representación que puede suscitar de acuerdo al conocimiento del sujeto y las modalidades de representación externa que acompañen el estímulo.

\section{II.2. ESTRUCTURA DE AGRUPAMIENTO Y PERCEPCIÓN}

Durante la audición, la percepción se focaliza en los elementos más pregnantes: las saliencias perceptivas (Malbrán, 2007). Según Dowling (1994) la melodía es el elemento musical perceptualmente más saliente.

La experiencia sostenida con melodías de la propia cultura conforman en el auditor una variedad de esquemas que conserva en su MLP, a los que referencia la nueva información melódica, lo que permite predecir su desenvolvimiento. En estos esquemas se aloja información sobre las relaciones jerárquicas entre las funciones armónicas que conforman la melodía: "jerarquía tonal" y las relaciones de alturas que la configuran: “jerarquía de eventos” (Malbrán, 2007).

Los patrones de tensión - relajación musical generados por las relaciones armónicas desencadenan en el oyente imágenes categoriales que conforman la jerarquía tonal (Krumhansl, 1990, Narmour, 1990b) ${ }^{16}$. Las funciones armónicas otorgan a las alturas diferentes jerarquías de acuerdo a la función armónica a la que pertenecen en el contexto de la obra. Esa situación pone en juego relaciones de estabilidad/ inestabilidad que requieren ser resuelta melódica y armónicamente. La teoría del Anclaje melódico estudió este comportamiento (Bharucha 1984-1996).

Con esta información alojada en la MLP, el oyente transita por el devenir temporal de la música, estableciendo relaciones que emrgen de las características del material musical entrante, lo cual requiere la participación de la MCP. A partir de este procesamiento de percepción, retención, comparación y codificación, el oyente realiza

\footnotetext{
${ }^{16}$ En Malbrán, 2007
} 
segmentaciones de la superficie musical conformando "grupos". "La estructura de agrupamiento es el elemento más elemental de la comprensión musical" (Lerdahl y Jackendoff 1983-2003:14).

La segmentación y agrupamiento de información es un proceso cognitivo común a otras áreas de conocimiento. Permite agilizar y reducir el esfuerzo de la memoria al agrupar elementos con características comunes y segmentar el flujo de información para ordenarlo y darle sentido. "El agrupamiento es un heurístico clave en la configuración del fraseo. Su análisis constituye una valiosa ayuda para la comprensión de los componentes macro y micro-estructurales de una obra" (Malbrán, 2007:83).

"El componente de agrupamiento consiste en dos grupos de reglas. Las reglas de formación correcta establecen la estructura formal de los esquemas de agrupamiento y su relación con la cadena de eventos tonales que forman la pieza. Las reglas de preferencia de agrupamiento establecen cuáles de las estructuras formalmente posibles que pueden asignarse a una pieza se corresponden con las intuición real del oyente" (Lerdahl y Jackendoff 1983-2003:42).

Lerdahl y Jackendoff propusieron en su modelo una serie de reglas para la conformación de grupos que se basan en los Principios de la Gestalt: proximidad, buena continuidad, cierre, similaridad, regularidad y destino común.

A partir de las características de la superficie musical (timbre, altura, intensidad, duración, pausas, etc.), y siguiendo los principios de la Gestalt, la percepción, al detectar un cambio en cualquiera de estos parámetros, realizará un corte en la secuencia creando un nuevo grupo.

Irene Deliege $(1987)^{17}$, observó en su estudio que la saliencia tímbrica posee la mayor claridad perceptiva y que parece más fácil reconocer los cambios de registro y de densidad instrumental. Por ello estableció dos clases de factores:

\footnotetext{
${ }^{17}$ En Malbrán, 2007
} 
- Los que corresponden a diferencias acústicas: timbre, intensidad, registro y densidad.

- $\quad$ Los que corresponden a diferencias de altura y duración.

En relación a la secuencia de adquisición de los elementos perceptivos Pflederer Zimmerman (1990) ${ }^{18}$, propone que el orden de desarrollo de los conceptos musicales es: intensidad, timbre, tempo, duración, altura y armonía. Juan Roederer (1997) propone a la intensidad en primer término y su correlato perceptivo la sonoridad, luego la altura y después el timbre (Furnó, 2003).

"La longitud, punto de comienzo y cierre de cada grupo, depende de la configuración rítmico-melódica, de las cesuras y/o pausas articulatorias, de la resolución y confirmación de la tensión melódico-armónica y de la ubicación métrica” (Malbrán, 2007:84). Al establecer perceptualmente la longitud de un grupo, la mente configura esta "medida" como patrón de longitud en la elección de los siguientes grupos, confirmando o rechazando esta hipótesis inicial, por lo cual se requiere una primera audición antes de proceder a la segmentación (Malbrán, 2007).

"Los agrupamientos periódicos como seriales están limitados por el presente psicológico" (Parncutt, 1994) ${ }^{19}$. El presente psicológico es un intervalo de tiempo, particular y variable, un espacio de atención, donde es posible el desarrollo de la percepción acotada a ese presente y procesada como una unidad (Malbrán, 2005).

Según Malbrán (2005-2008) en el presente psicológico inciden factores tales como:

$\checkmark \quad$ Magnitud de los intervalos temporales entre perceptos sucesivos.

\section{$\checkmark \quad$ Longitud de la presentación.}

\footnotetext{
${ }^{18}$ En Furnó, 2003

${ }^{19}$ Cit por Malbrán, 2005:35.
} 
LA COMPRENSIÓN DE LA ESTRUCTURA MUSICAL.

LA REPRESENTACIÓN UTILIZADA EN NIÑOS ENTRE 10 Y 11 AÑOS.

$\checkmark \quad$ Duración de la memoria a corto plazo.

$\checkmark \quad$ Número de sonidos sucesivos que pueden ser percibidos como una unidad con un máximo de veinticinco (Fraise, 1982).

$\checkmark \quad$ Extensión, generalmente, no más de cinco segundos y de acuerdo a la tarea y el contexto puede extenderse a 10-12 segundos (Dowling y Harwood, 1986).

$\checkmark \quad$ Número de ítems o elementos $7( \pm) 2$ para alojar en la memoria inmediata (Miller, 1991).

Dado que la capacidad atencional se circunscribe al presente psicológico, los ejemplos musicales para el análisis auditivo deben ser elegidos tomando en cuenta estas restricciones. El análisis de fragmentos más extensos requerirá segmentar la obra para su tratamiento en espacios temporales susceptibles de poder ser procesados cognitivamente.

Las características musicales del ejemplo a analizar, en términos de saliencias perceptivas y presente psicológico determinan el nivel de agrupamiento.

Las audiciones sucesivas permiten establecer relaciones entre distintos niveles de agrupamiento. La audición a pequeña escala dentro de un nivel jerárquico percibe determinada longitud de grupo y en base a esto segmenta-agrupa. Cuando esa pequeña escala de audición se integra a la audición de un fragmento más extenso, los agrupamientos percibidos inicialmente, se reagrupan conformando grupos de mayor extensión en un nivel supra-ordinado o grupos de menor extensión en un nivel sub-ordinado.

La trama jerárquica musical (la estructura formal específicamente) se comprende en sucesivas audiciones, partiendo del análisis del nivel de agrupamiento básico, el que requiere la intervención de la MCP para el recuerdo de los agrupamientos y su posterior nominación a partir de la comparación. Si estos datos pueden ser representados en la mente, entonces pueden relacionarse con los otros niveles de agrupamiento, logrando una representación de la trama completa de la forma musical. 


\section{LA COMPRENSIÓN DE LA ESTRUCTURA MUSICAL. \\ LA REPRESENTACIÓN UTILIZADA EN NIÑOS ENTRE 10 Y 11 AÑOS.}

Este procesamiento es posible a través del pensamiento categorial que organiza la información en niveles subordinado, básico y supraordinado. (de Vega, 1994). La categorización se forma en torno a ejemplos prototípicos (Quinn y Eimas, 1986) ${ }^{20}$.

La configuración de prototipos provenientes de la música de la práctica usual se relaciona con sus características estructurales donde las melodías se desenvuelven en patrones de regularidad temporal, esquemas cadenciales que permiten prever las resoluciones armónicas y cuadratura formal (entre otras).

Según Rodríguez (2007), los oyentes perciben relaciones de variación entre los grupos sólo cuando son capaces de percibir similitudes entre ellos.

La percepción de similitud entre grupos es influida por la extensión del grupo, probablemente por dificultades en la resolución de la MCP, es decir, la cantidad de información que debe ser procesada. Es factible que grupos grandes contengan otros grupos a su vez y ante estructuras de agrupamientos largas, el cerebro adopte mecanismos reduccionales del tipo de la reducción temporal (Rodríguez, 2007).

Cuando se comparan grupos pequeños o motivos, la identidad de estructuras de agrupamiento parece ser una condición previa al establecimiento de similitud, la evidencia sugiere incluso, que un mínimo cambio en dicha estructura es suficiente para provocar cambios en el establecimiento de similitudes.

El Modelo de Reglas Preferenciales de Similitud (Rodríguez, 2007) propone que los oyentes experimentados en el idioma tonal establecen similitud entre materiales musicales que comparten una misma estructura básica, la cual puede presentar variaciones rítmicométricas, en el contorno melódico o por la incorporación de arpegios. "La similitud de las estructuras de agrupamiento pequeñas y el establecimiento de reglas de similitud coocurren" (Rodríguez, 2007:2).

\footnotetext{
${ }^{20}$ En Malbrán, 2008
} 
Según Furnó (2005:90) “es posible que la comparación entre fragmentos musicales para determinar su semejanza o igualdad, tenga lugar en la memoria operativa a partir del procesamiento de información acústica retenida".

La caracterización que Malbrán (2008:67) realiza para la Estructura métrica es aplicable a la Estructura de Agrupamiento:

$\checkmark \quad$ Jerárquica. Por las relaciones de dependencia e inclusividad entre niveles de agrupamientos.

$\checkmark \quad$ Periódica. Porque los espacios temporales, determinados por la extensión de los grupos tienden a ser regulares, conformando un equilibrio formal.

$\checkmark \quad$ Recursiva. Porque los distintos niveles de agrupamientos pueden contener a otros o ser contenidos determinando una estructura de múltiples niveles.

\section{II.3. NIVELES DE REPRESENTACIÓN EN MÚSICA}

Algunos modelos de representación (Bruner, 1995, Karmiloff-Smith 1992) establecen un gradiente en la representación de un conocimiento cuya existencia en el sistema comienza desde lo enactivo, inconsciente, implícito, hasta llegar a consolidarse como un conocimiento simbólico, consciente, explícito.

Los antecedentes precedentes sugieren que el conocimiento sobre determinado componente de un dominio específico, recorrerá un itinerario que le permitirá conformarse en diferentes formatos representacionales hasta adquirir la categoría de conocimiento susceptible de explicitarse verbalmente, traducirse simbólicamente o ejecutarse.

"En cuanto al oyente, el grado de maduración de su sistema nervioso, que varía con la edad en los niños, los factores biológicos, la experiencia musical adquirida en un medio 
determinado, la educación musical recibida, hacen que la decodificación de toda la información contenida en el mensaje no sea la misma para todos los individuos" (Zenatti, 1991: 63).

Son preguntas de interés: ¿en qué medida el sujeto es consciente de lo que sabe acerca de lo que ha escuchado, cantado o ejecutado? ¿Cómo transforma su representación interna para poder explicitarla? ¿En qué momento esto es posible?

A continuación se analizará sucintamente el Modelo de Redescripción Representacional de Karmiloff- Smith, y el Modelo Representacional de Jerome Bruner (1995) cuyas propuestas aportan a la comprensión de estos procesos.

\section{II.3.1. MODELO DE REDESCRIPCIÓN REPRESENTACIONAL. KARMILOFF- SMITH (1992)}

El Modelo de Redescripción Representacional (MRR) explica la representación como un "proceso mediante el cual la información que se encuentra implícita en la mente llega a convertirse en conocimiento explícito, primero dentro de un dominio y posteriormente, a veces a lo largo de diferentes dominios" (1992: 37). La mente así explora la información almacenada y redescribe esas representaciones en diferentes formatos.

Según la autora un dominio es el conjunto de representaciones que sostiene un área específica de conocimiento: el lenguaje, la matemática, la música. A su vez dentro de ellos se encuentran microdominios: por ejemplo la adquisición de los pronombres dentro del lenguaje o el reconocimiento de las alturas en la música. Un módulo, en cambio, es una unidad de procesamiento de la información que encapsula tanto ese conocimiento como las computaciones que se hacen con él. En tal sentido Karmiloff sostiene que el desarrollo es un fenómeno de dominio específico más que modular (en el sentido Fodoriano). Es decir que el almacenamiento y procesamiento de información puede ser específico de un 
dominio dado sin ser al mismo tiempo encapsulado, preestablecido u obligatorio. La autora habla de un proceso de modularización gradual más que de módulos predeterminados. Desde una perspectiva del desarrollo, argumenta que si bien existen sesgos atencionales y predisposiciones específicas (innatas) que guían la entrada de información hacia ciertos dominios para su procesamiento, esos dominios se desarrollarán en la medida que exista un intercambio con el ambiente el que a su vez moldeará ese módulo. Por ende la autora adopta así una postura epigenética.

La redescripción representacional (R.R.) es de dominio general, no en el sentido que implique cambios en todos los dominios, sino, que dentro de cada dominio el proceso es el mismo que ocurre en forma recurrente a lo largo del desarrollo. Esta recurrencia implica tres fases:

Fase 1: El niño se centra en la información proveniente del medio externo creando "adiciones representacionales". Estas representaciones no se relacionan ni alteran las representaciones ya existentes, por lo cual esta fase no involucra cambio representacional. La fase culmina con la "maestría conductual", es decir, cuando el niño adquiere la capacidad de ejecutar de manera correcta las conductas de cualquier microdominio donde se haya alcanzado este nivel.

Fase 2: El niño ya no se centra en los datos externos, predomina el estado actual de representaciones del conocimiento que tiene en un microdominio dado.

Fase 3: el niño puede lograr un cambio representacional a partir de la "nueva" comparación entre las representaciones internas con los datos externos, alcanzándo un equilibrio entre la búsqueda de control interno y externo.

La idea de fases supone un desarrollo en el nivel de representación sobre un dominio (o microdominio dado), es decir, alude a múltiples niveles en los que un mismo conocimiento puede representarse. ¿Cómo se manifiesta o materializa este cambio?. El modelo RR postula la existencia de diferentes formatos a través de cuatro niveles en los que el conocimiento puede representarse y re-representarse. 
Nivel Implícito: Según Karmiloff Smith en este nivel, las representaciones se encuentran en forma de procedimientos de análisis y respuesta a estímulos del ambiente externo. Hay una serie de restricciones que operan sobre las adiciones representacionales que se forman en este nivel

- $\quad$ La información se codifica de forma procedimental.

- Las codificaciones procedimentales están secuencialmente especificadas.

- Las representaciones nuevas se almacenan de forma independiente, por lo cual no se producen vínculos representacionales inter o intra dominios.

Nivel Explícito 1: Las representaciones de este nivel son el resultado de las redescripciones de las representaciones codificadas procedimentalmente en el nivel 1 en un nuevo formato comprimido. La representación redescrita, es por una parte más sencilla y de propósito menos específico, pero al mismo tiempo cognitivamente es más flexible, lo que le permite comprender analogías.

Las representaciones originales de nivel 1 (implícitas) pueden seguir intactas en la mente del niño, quien puede recurrir a ellas para determinadas tareas cognitivas que requieran velocidad y automaticidad. Las representaciones redescritas se utilizan para otros fines que requieren conocimiento explícito. A partir de aquí el conocimiento puede manipularse y ponerse en relación con otras representaciones redescritas con lo cual supera las restricciones impuestas en el nivel 1 (implícito).

Aunque las representaciones alcanzadas en el nivel explícito 1 hayan superado el nivel procedimental, no pueden explicitarse verbalmente ni pueden ser objeto de reflexión consciente. En este sentido este modelo propone superar la dicotomía: conocimiento procedimental- implícito y conocimiento declarativo- explícito. Por lo tanto, el tercer nivel Explícito 2 supone que las representaciones se hacen accesibles a la consciencia pero aun no pueden verbalizarse, lo cual será posible en el nivel Explícito 3. 


\section{LA COMPRENSIÓN DE LA ESTRUCTURA MUSICAL. \\ LA REPRESENTACIÓN UTILIZADA EN NIÑOS ENTRE 10 Y 11 AÑOS.}

Esta serie de redescripciones indicaría que en la mente coexisten múltiples representaciones del mismo conocimiento con diferente grado de detalle y profundidad. Por lo tanto, en muchos casos no se trataría de ausencia de conocimiento, sino que de acuerdo al Modelo RR el conocimiento representado internamente en formato I o Explícito 1, no permite aun el acceso consciente ni la expresión verbal, pero a través de redescripciones de ese mismo conocimiento se podrá alcanzar diferentes niveles de desarrollo. Según Karmiloff- Smith "el proceso consiste en recodificar información almacenada en un formato o código representacional pasándola a otro distinto. Una representación espacial puede recodificarse por ejemplo, en formato lingüístico, o una representación propioceptiva, en formato espacial. Cada representación o re-representación) constituye una versión más condensada o comprimida del nivel anterior" (1992: 43).

Las investigaciones muestran que poseemos una serie de reglas sintácticas adquiridas por enculturación (Sloboda, (1985)-1996; Imberty, 1990; Cross y West, 1991; Lerdahl y Jackendoff, 1983), las cuales nos permiten abordar el discurso musical., desde el canto de una melodía o la ejecución instrumental hasta un simple acompañamiento con palmas o "tocar de oído". Pero, en términos del modelo RR, no es suficiente este tipo de conocimiento (enculturado) para hacer explícitos diferentes aspectos del lenguaje musical. Resulta necesario re-representar el conocimiento accediendo a diferentes niveles de desarrollo para lo cual se produce un cambio de formato entre uno y otro nivel.

En relación con la adquisición del lenguaje en el niño, según Karmiloff-Smith las representaciones lingüísticas que se construyen durante la infancia sirven a los niños para comprender y producir con su lengua materna. Estas representaciones se almacenan como información en la mente pero aun no constituye información para la mente; para que se vuelvan flexibles, manipulables y accesibles a la reflexión metalinguística, es necesario que el conocimiento implícito (inconsciente) se re-represente.

Un proceso similar observamos en el lenguaje musical: el niño convive con un acervo musical que le permitirá construir las representaciones que guiarán sus manifestaciones musicales, pero que requerirán múltiples re-representaciones hasta transformarse en conocimiento explícito. 
¿Cómo explicamos nuestra comprensión de la música? ¿Cómo ponemos en palabras un determinado aspecto del discurrir musical y que la música dice en un formato acústico diferente? Si observamos los cambios producidos en un conocimiento desde el primer nivel hasta lograr formas de representación más abstractas o complejas de manera que se pueda explicitar el conocimiento que se tiene de ella y hacer así comunicable la experiencia, es probable pensar que esas re-representaciones se faciliten con la mediación pedagógica, mediante estrategias de representación musical que expliciten verbal o gráficamente las reglas y convenciones habituales en la tradición musical de Occidente. Olson (1998) expresa "la conciencia de la estructura lingüística es producto del sistema de escritura" ${ }^{21}$ En este sentido los procesos de alfabetización y enseñanza en general ayudan a hacer explícitos a través de distintos sistemas lo que se conoce y práctica de manera implícita.

\section{II.3.2. MODELO REPRESENTACIONAL DE JEROME BRUNER (1995)}

Para Bruner (2005) es imposible comprender los procesos cognitivos de la mente, si se omiten los complejos procesos simbólicos del desarrollo cultural, esto es lo mental y cultural se co-implican y fusionan.

Desde la perspectiva de Bruner, la representación consiste en una construcción mental guiada por el principio de "selectividad" intencional que

a) actúa como un "médium" a través del cual nos relacionamos con el mundo o con determinados rasgos de nuestra experiencia

b) opera "sintéticamente" mediante reglas establecidas

${ }^{21}$ Citado por Burcet , 2010:59 
c) se manifiesta fundamentalmente a través de tres modalidades posibles: la representación "enactiva" -por medio de la acción motora-, la representación "icónica" (a través de dibujos, imágenes o demás formas perceptivas) y la representación "simbólica" (mediante determinadas formas sígnicas o lingüísticas)

Según Curto (2005:192) las modalidades comprometidas en el proceso de desarrollo mental no suponen una simple secuenciación por etapas, sino una evolución dialéctica guiada por el creciente dominio en el manejo de estas tres formas de representación y por el incremento de la capacidad de traducirse entre si.

La representación enactiva se caracteriza por el dominio y competencia práctica de una determinada actuación, por tanto consiste en una forma de representación mental asociada particularmente a las estructuras de la acción.

Se ha visto que la adquisición de las habilidades motoras genera una serie de hábitos organizados secuencial e irreversiblemente, cuyos esquemas mentalmente representados mantienen unidos entre sí los diferentes componentes motores en que se subdivide la acción (Curto, 2005).

Bruner (1984-1998) plantea que estas habilidades dispondrían de una suerte de sintaxis cuya estructura sería análoga a la encontrada en el lenguaje, además estarían dotadas de una capacidad combinatoria a mitad de camino entre lo innato y lo adquirido, a partir de la cual se podrían crear nuevas estructuras. Esta capacidad combinatoria va relacionándose de forma progresiva con la adquisición, por parte del niño, de las estructuras sintácticas, semánticas y pragmáticas del lenguaje, lo cual facilita el acceso a las acciones simbólicas.

La representación icónica como manera de comprender la información recurre a esquemas visuales, a dibujos o en general a imágenes. que generan una representación análoga a aquello que representan, a la experiencia vivida. 
Según Clarke (1997) las representaciones que se construyen del entorno son en parte icónicas, es decir que lo que guardamos de la experiencia es una copia analógica (no simbólica) de la información sensorial. Esto implica que se puede utilizar una forma analógica para comprender otra, por ejemplo la información de las formas sensoriomotoras para comprender el despliegue de las formas musicales.

La representación simbólica supone la capacidad de utilizar el lenguaje "y en la medida que este va adquiriéndose, tanto las representaciones enactivas como icónicas, se verán con el tiempo, alteradas y afectadas por él" (Curto, 2005:192).

Una custión clave para Bruner (1984) es que la acción simbólica (culturalmente determinada) está mediatizada por la adquisición del lenguaje y por las habilidades cognitivas a él vinculadas y en este sentido acción, pensamiento y lenguaje conforman una unidad indisoluble. Respecto a la adquisición de la competencia lingüística, Bruner (1984) propone que además del "Dispositivo de Adquisición del lenguaje" propuesto por Noam Chomsky (de carácter innato) existiría un "Sistema de Apoyo de la Adquisición del Lenguaje" de carácter interactivo e intersubjetivo.

Bruner (1984) concluye que en la adquisición de la capacidad del lenguaje, como medio de acceso a la cultura, se desarrollan funciones psicológicas superiores asociadas: percepción, memoria, pensamiento, emoción, imaginación y/o voluntad. De esta manera estas funciones cognitivas están culturalmente construidas y socio-históricamente determinadas. En la internalización de este proceso, se modela la conducta social de los individuos.

Podríamos establecer una analogía entre lenguaje y lenguaje musical en tres sentidos.

1. Comunicarnos musicalmente es posible porque poseemos una capacidad innata para ello. (Imberty, 1990; Cross, 2007).

2. Adquirimos dicha posibilidad culturalmente. Teorías musicales como la de Lerdahl y Jackendoff proponen que la comprensión de las estructuras 
musicales es posible gracias a la enculturación del oyente, por formar parte de un entorno musical

3. Desarrollamos capacidades que las investigaciones en Neurociencias Cognitivas han mostrado que generan una reorganización de los circuitos neuronales y mejoran las integraciones multimodales (Bigand, 2011). Esto es así gracias a la plasticidad cerebral, es decir la posibilidad del cerebro de modificar su estructura frente a la experiencia (Zatorre, 2005; Schön, 2012).

La práctica musical es considerada un neuro-estimulador ya que la riqueza de su experiencia requiere un ajuste permanente entre las áreas neurológicas encargadas de la percepción y encargadas de los aspectos motrices de la ejecución, las que se activan mutuamente (Bigand y Lallite, 2007; Bigand, 2011). Los hallazgos científicos muestran que la práctica musical no sólo incide sobre las habilidades perceptivas y motrices, sino que afecta al desarrollo de las funciones cognitivas generales, incrementando la atención, la memoria, las habilidades verbales y la inteligencia general (Trainor, 2003)

Aronoff (1998) propuso un Modelo de Aprendizaje Musical basado en los tres niveles de representación del Modelo de Bruner. Supone una secuenciación pedagógica del contenido que comienza con lo motriz, luego las respuestas corporales (incluido el canto) son relacionadas a representaciones icónicas (de carácter metafórico y analógico) y finalmente trasladadas a la representación simbólica, al signo. Convencional, en esencia. puede traducirse en notación tradicional o en nuevas propuestas de escritura.

El Modelo de Bruner postula que alcanzar la representación simbólica implica la adquisición del lenguaje y la lectoescritura, que según el autor es la principal habilidad simbólica después del habla. Al adquirir el lenguaje se obtiene también la capacidad de conceptualizar, porque en el proceso social de su aprendizaje también se aprende a interpretarlo: la palabra porta un significado compartido.

En la música, en cambio, se requiere traducir las percepciones de las relaciones sonoras a palabras, colocarles un rótulo, para poder conceptualizar los contenidos 
musicales. "Las unidades perceptivas aisladas necesitan de la palabra para alcanzar significación, estabilidad, dominio y disponibilidad" (Furnó, 2005:34)

Disponer del lenguaje musical por enculturación no implica poseer conceptos musicales. Según Furnó (2003) sin el correlato verbal no se completa el circuito relativo a la formación del concepto musical. La palabra en este sentido cumpliría un rol fundamental y la mediación pedagógica sería el nexo entre la experiencia musical y la adquisición del concepto.

Alcanzar la modalidad de representación simbólica en música estaría ligado a la adquisición de la lectoescritura: traducir la información musical a símbolo, previa adquisición del concepto. Esto requiere de la experimentación en las modalidades representacionales previas: la enactiva y la icónica.

Las grafías analógicas son utilizadas como estrategias pedagógicas de facilitación del acceso a la notación simbólica en las que se trata de trasladar perceptos sonoros a imágenes que progresivamente proceden de lo concreto a lo abstracto, de lo figurativo a lo simbólico. En este sentido los gráficos analógicos propuestos por el test intentan ayudar a relacionar la forma musical con una imagen, la que a su vez se constituye en un medio para hacer explícito el contenido implícito y así poder comunicarlo. 


\section{CAPÍTULO III}

\section{CONOCIMIENTO, REPRESENTACIÓN}

\section{Y MODELOS EN MÚSICA}

\section{III.1. ADQUISICIÓN Y DESARROLLO DE COMPETENCIAS MUSICALES}

La tarea solicitada a los sujetos a través del test indaga la capacidad para reconocer la forma musical desde la audición. Hay acuerdo general en el medio científico en que las capacidades rítmicas, melódicas y armónicas se co-implican en la comprensión del discurso.

\footnotetext{
Reconocer la forma de la música de la práctica usual requiere

$\checkmark \quad$ trackear las regularidades temporales propias de la música pulsada,

$\checkmark \quad$ advertir sus encuentros de fase,

$\checkmark \quad$ reconocer configuraciones rítmico-melódicas,

$\checkmark \quad$ registrar cadencias tonales,

$\checkmark \quad$ establecer agrupamientos y segmentaciones discursivas
} 
Los trabajos de investigación aplicada relacionados con el desarrollo de competencias musicales han aportado evidencias en torno a diferentes factores de incidencia tales como la enculturación, la edad, el desarrollo cognitivo y la educación.

La capacidad musical plantea el problema de la relación entre la herencia y el medio, lo innato y lo adquirido, los genes y la cultura. Existe consenso en considerar las posibles interrelaciones entre ambos elementos. Se subraya la importancia de la interacción de las influencias del medio cultural, de los factores psico-acústicos y psico-fisiológicos, de las capacidades y personalidades individuales.

Estudios realizados sobre la influencia del entorno familiar en el desarrollo musical de niños, (Zenatti, 1976a, 1981) muestran que las variables socio-culturales inciden, en menor medida, en el desarrollo de habilidades perceptivas y resultan mucho más importante en el caso de la asimilación de las características de la lengua musical que los niños escuchan con mayor frecuencia. Estos estudios evidencian que la variable "riqueza musical del medio familiar" es la que aporta resultados estadísticos más significativos. A partir de los 6-7 años la influencia socio-cultural es más evidente en pruebas armónicas y melódicas y en menor medida en pruebas rítmicas.

La experiencia rítmica es otro aspecto de las repercusiones afectivas del grupo sobre el individuo, ya sea a través de la audición o sobre la práctica musical grupal. Muchos autores han insistido en el componente kinestésico del ritmo (Fraise, 1974; Parncutt, 1994; Reybrouck, 2005, Malbrán, 2008). Cuando se percibe la periodicidad del ritmo, ésta produce el efecto de inducir movimientos (ya sea manifiestos o encubiertos) A esta sincronización perceptivo motora corresponde una participación compleja de centros nerviosos superiores. Los comportamientos perceptivos son de orden cortical, pero la kinestesia excita especialmente el diencéfalo, es decir nuestro cerebro afectivo (Fraise, 1974: 114-115) 22 .

${ }^{22}$ Cit por Zenatti, 1991 


\section{LA COMPRENSIÓN DE LA ESTRUCTURA MUSICAL.}

LA REPRESENTACIÓN UTILIZADA EN NIÑOS ENTRE 10 Y 11 AÑOS.

Las diversas manifestaciones musicales de Occidente, desde las nanas y rondas infantiles, la música folklórica y popular, como la del vasto repertorio académico, presentan en su constitución patrones periódicos y regulares. Estos rasgos comunes han impuesto, por el uso, cánones gramaticales y sintácticos que son parte del conocimiento implícito del oyente (Malbrán y García Malbrán, 2010).

"Investigaciones transculturales sobre los universales en música (Drake y Bertrand, 2001), han mostrado un patrimonio común de respuestas: la tendencia a la regularidad, el equilibrio de la cuadratura formal y la presencia de la cadencia tonal. Estos sistemas de reglas acuñados intuitivamente, se han internalizado como modos de escucha de personas sin formación musical previa" (Malbrán y García Malbrán, 2010: 128).

Según Clarke y Krumhansl (1990) la percepción del tiempo trasciende el tema de la duración para incluir otros parámetros como la saliencia de los sucesos a la percepción y la expectativa de los sujetos. ${ }^{23}$

Las investigaciones muestran que a partir de la identificación de saliencias perceptivas dentro de la regularidad del discurso, el oyente extrae un primer nivel de pulso que corresponde al de distribución moderada del tiempo. A partir de este nivel de pulso (tactus) que actúa como anclaje cognitivo atencional, puede atender y relacionar a otros niveles de pulso que conforman la estructura métrico-jerárquica de la música.

La extracción de regularidades a partir del discurrir temporal de la música, es una construcción mental y un proceso fundamental para la comprensión musical (Malbrán, 2008; Parncutt, 1994; Ledahl y Jackendoff, 1983).

Advertir desde la audición diferentes niveles de pulso, a partir del más saliente, y relacionarlo con otros dentro de la estructura métrica, involucra adentrarse a niveles más profundos del lenguaje musical, lo cual implica la realización de abstracciones e

\footnotetext{
${ }^{23}$ Cit por Malbrán, 2008:23
} 
inferencias. Estos procesos están disponibles a partir de la segunda infancia (Malbrán, 2008).

La destreza cognitiva descripta requiere un proceso que involucra no solo el conocimiento por enculturación, sino cierto grado de práctica senso-motriz y el desarrollo del pensamiento.

"La adquisición de estrategias métricas totalmente desarrolladas, en la cual el ritmo superficial de una secuencia es percibido y representado en relación a una dimensión invariante (la métrica subyacente) bien puede ser susceptible de una precisa interpretación según la lógica de las operaciones concretas" (Hargreaves, 1998:114)

Según el modelo piagetiano, durante la etapa operacional concreta (7 a 10 años) los niños desarrollan la conservación, la reversibilidad y la habilidad para realizar inferencias transitivas resuelven problemas de duración y sucesión, los que una vez adquiridos les permiten la estructuración lógica de relaciones temporales.

La teoría sensorio-motora sostiene que la experiencia del ritmo asume dos representaciones complementarias: i) una representación sensorial de las propiedades rítmicas del movimiento de una fuente externa y ii) una representación motora del sistema músculo-esquelético del ejecutante. Si las propiedades témporo-dinámicas de la fuente y las del sistema músculo-esquelético tienen correspondencia, la imagen motora va a tender a sincronizar con la fuente (Tood, O’Boyle y Lee, 1999) ${ }^{24}$.

Un Programa de Investigación llevado a cabo en la UNLP muestra que la sincronía rítmica con el tactus es el cimiento a partir del cual se puede construir el desarrollo rítmico (Malbrán, 2008).

Se consideran efectos asociados a la adquisición de la sincronía rítmica, la influencia de la edad y el grado de experiencia musical, la estructura métrica y tempo de la obra, la correspondencia y el sostén, ajuste y regularidad con el tactus (Malbrán, 2008). El

\footnotetext{
${ }^{24}$ En Malbrán, 2008
} 
estudio de esta investigadora muestra que los niños más pequeños manifiestan discontinuidades en la sucesión de golpes y que esa discontinuidad tiende a desaparece a partir de los 8 años. Esto le permite determinar diferentes grados de desarrollo rítmico en el niño y propone un Modelo de tres fases en el desarrollo rítmico: difusa, fluctuante y precisa. De acuerdo al nivel alcanzado es el tipo de ajuste a demandar al niño: global, puntual no sonoro y puntual (Malbrán, 1991).

Según Pflederer Zimermann (1990) durante el desarrollo del estadio operacional concreto el niño progresa hacia la reflexión, la especulación y los conceptos de conservación y reversibilidad. Estas competencias le permiten abstraer las invariantes de la estructura métrica más allá de los cambios rítmicos; se inicia así el distanciamiento progresivo de los rasgos más llamativos de la superficie musical lo que facilita el manejo estructural de la información (Pflederer-Zimermann, 1990) ${ }^{25}$.

La inferencia a partir de la audición de patrones de pulso y de configuraciones rítmicas, implica un nivel de representación diferente al de la ejecución. Posiblemente el formato kinésico en el que se encuentra la experiencia del movimiento adquirido durante la ejecución, sea traducido a otros formatos durante el análisis auditivo, para lograr un conocimiento declarativo.

Desde una perspectiva evolutiva, algunos aspectos de la Teoría de Jean Piaget se han estudiado en un contexto musical, partiendo del concepto de auto-regulación (Pflederer Zimmerman, 1964, 1983; Serafine, 1980; Shuter-Dyson y Gabriel, 1981). Esto implica que los esquemas de conocimiento son asimilados al organismo a partir de elementos presentes en el medio, mediante procesos de acomodación y reorganización. Los nuevos esquemas adquiridos sirven como marco de regularidades rítmico-melódica-tonales a partir de los cuales se juzgan los nuevos estímulos.

"Para Krumhansl y Castellano (1983) los esquemas musicales son estructuras cognitivas basadas en el conocimiento abstracto que el oyente tiene de las estructuras

\footnotetext{
${ }^{25}$ En Gainza, 1990
} 
musicales; esto se adquiere observando y extrayendo regularidades de las diferentes obras. Estos esquemas existen en una interacción dinámica con la información sensorial y perceptual ingresante" (Hargreaves, 1998: 92).

Las investigaciones sobre la percepción melódica la describen como la adquisición y desarrollo de esquemas de contorno (Dowling, 1984; Davison, 1983). "Los patrones de intervalos de las escalas tonales dentro de la música de una cultura, son aprendidos e incorporados al patrimonio de alturas de los auditores, analizando procedimientos y representaciones del contorno como el principio organizador más importante para las alturas de melodías" (Dowling y Harwood, 1986) ${ }^{26}$

"Como índice global de la percepción melódica, el contorno conjuga el registro general de las alturas, la distribución de ámbitos de intervalos y la proporción de intervalos ascendentes con relación a los descendentes" (Malbrán, 2007:100).

"El contorno melódico es un rasgo de la música que para el auditor se destaca distintivamente en la primera audición" (Dowling, 1994: 5). Los estudios muestran cómo la percepción melódica comienza a partir del reconocimiento del contorno, como un trazado general de la melodía y esta capacidad se desarrolla con la edad y la experiencia, hasta poder reconocer los intervalos exactos que la conforman. En la memorización de canciones nuevas predomina el recuerdo del contorno, sin embargo en canciones familiares prevalece el recuerdo de los intervalos determinados (Dowling, 1994).

Con respecto al desarrollo de la percepción melódica los estudios muestran que en el reconocimiento de melodías conocidas en comparación con versiones cambiadas tonales $y$ atonales pero que en todos los casos mantienen el contorno, los niños de 5-6 años juzgan como iguales todas las versiones, es decir se guían especialmente por el contorno, los niños de 7-8 años tienden a identificar principalmente las melodías tonales originales y cambiadas, es decir siguen juzgando como iguales las que mantienen el contorno pero

\footnotetext{
${ }^{26}$ Cit por Dowling, 1994:8
} 
pueden reconocer cambios de tonalidad. Los niños de 9-10 años reconocieron las versiones originales y cambiadas tanto tonales como atonales (Dowling, 1994).

El desarrollo de la percepción melódica tiene un correlato en los estudios sobre desarrollo del canto, lo que sugiere la interrelación entre las capacidades perceptivas y sensorio-motrices, en este caso relacionada con el comportamiento vocal. Graham Welch (1986-1993) ha propuesto un Modelo de Fases en el desarrollo del canto que comienza con un acercamiento al canto de tipo más holístico donde predomina la exploración de los registros vocales y la utilización de patrones descendentes. En la siguiente etapa hay una creciente conciencia del control del sonido y el perfil melódico cantado comienza a seguir los contornos generales de la melodía. En la etapa posterior se observa una conformación melódica a través de intervalos más exactos, aunque pueden ocurrir cambios en la tonalidad por fragmentos de la canción. En la última etapa el sujeto puede mantenerse en la afinación correcta y permanecer en la tonalidad.

En 1967 Zenatti se planteó en qué medida podía explicar la Teoría de Piaget, el desarrollo de una inteligencia musical. La autora concluyó en que "la génesis de la inteligencia musical se da como una construcción progresiva, en la que cada nivel aporta una nueva coordinación de elementos musicales. Esta coordinación se basa en la interacción de la actividad perceptiva y la sensorio-motriz" (Zenatti, 1967:220). Esta coordinación se manifiesta en tres estadios caracterizados por una complejidad creciente de las estructuras perceptivas, donde la actividad operativa se va desligando poco a poco de los datos perceptivos. Según Zenatti (1991) la aculturación tonal comienza a manifestarse hacia los 7-8 años (que corresponde en su estudio al segundo estadio).

Desde la perspectiva del desarrollo Shuter-Dyson y Gabriel (1981) ${ }^{27}$ enuncian que entre los 9 y 10 años mejora la percepción rítmica y la memoria melódica, se perciben melodías a dos voces y se reconoce el sentido de cadencia. Para estos autores, entre los 10

\footnotetext{
${ }^{27}$ Cit por Hargreaves, 1998
} 
y 11 años se comienza a establecer el sentido armónico y cierta apreciación de puntos refinados en la música.

Frente a la postura de desarrollo musical aparecen propuestas que explican la percepción y comprensión de la música a partir de sistemas modulares (Fodor, 1983). Según Fodor existirían mecanismos modulares distintos y específicos para el tratamiento de las alturas (melodía) y para el tratamiento de la organización temporal (ritmo). "Pero en niveles superiores del tratamiento de la información musical y de su memorización se debe admitir que hay dependencia de los dos módulos...a menos que deba suponerse que la tonalidad en general pueda definirse como un sistema modular" (Imberty, 1990:8).

Imberty (1990) a partir de la síntesis de los puntos de vista de Piaget, Chomsky y Fodor, propone un Modelo de Gramática Evolutiva de las Estructuras Melódicas en el Niño. En este modelo establece reglas que describen ciertos procedimientos observados en producciones melódicas espontáneas de niños entre 3 y 10 años. En ellas enuncia "obligatorios fijos" que describen procesos generales y estables, y partes "no obligatorias" que describen procesos de evolución estructural previsibles en el curso del desarrollo psicológico de los niños.

Respecto al desarrollo de la competencia melódica Imberty describe "esquemas simples" que muestran entre los 3-6 años la capacidad de realizar fragmentos melódicos de manera espontánea en forma yuxtapuesta, sin conexión. En esta etapa, la secuencia melódica solo presenta una concepción global sin identificar comienzos o finales estructurados. Después de los 6 años y hasta los 8-9 años aparecen los "esquemas de relaciones” que suponen la capacidad de organizar de manera lógica la sucesión de eventos en un tiempo determinado. Estos esquemas tienen correspondencia con el estadio de las operaciones concretas de Piaget concomitantemente con las representaciones del tiempo y el espacio. Entre los 8 y 10 años las estructuras melódicas se articulan en segmentos dependientes unos de otros, produciendo una percepción de orden integral, así aparece lo que Imberty denomina “esquemas articulados". 


\section{LA COMPRENSIÓN DE LA ESTRUCTURA MUSICAL.}

LA REPRESENTACIÓN UTILIZADA EN NIÑOS ENTRE 10 Y 11 AÑOS.

En relación al desarrollo de la competencia tonal Imberty (1990) considera que antes de los 6 años, el niño no es sensible a ninguna referencia armónica. A partir de esta edad comienza a identificar la culminación de la frase musical cuando concluye sobre un apoyo rítmico fuerte. La organización estructural comienza por la referencia a elementos dinámicos y rítmicos más que a elementos armónicos. Hacia los 8 años comprende las cadencias (conclusivas o suspensivas) como cierre de la frase musical aunque las armonías no son reconocidas en el plano funcional. Recién a los 10 años los niños pueden comprender la función armónica de la tónica y la dominante y reconocer que una frase que termina sobre la dominante no es una secuencia terminada. Esto le permite al autor delinear el concepto de reversibilidad tonal. A partir de este momento y dada la creciente capacidad de abstracción, les resulta viable operar mentalmente con el tiempo musical, basándose en la construcción de esquemas lógicos que Imberty denomina "tiempo abstracto". "Son estos esquemas que se construyen en el que puede denominarse presente psicológico de la percepción en cuyo interior el tiempo se inmoviliza, se mueve en un espacio mental en el cual las operaciones complejas y abstractas pueden estar efectuadas independientemente de la duración" (Imberty, 1990) ${ }^{28}$.

\section{III.2. PROCESAMIENTO DE LA INFORMACIÓN}

Los modelos clásicos de procesamiento de la información no se preocupan mayormente por los cambios evolutivos, más bien, su objetivo es describir y explicar el funcionamiento del sistema cognitivo humano en un momento determinado y ante una tarea concreta. Sin embargo, después de los primeros modelos (Attkinson y Shifrin, 1971) surgieron investigaciones que se propusieron aplicar las concepciones teóricas del procesamiento de la información al estudio evolutivo del ser humano, describiendo cómo un sistema

\footnotetext{
${ }^{28}$ Cit por Furnó y Malbrán, 2005:19
} 
procesador de información puede cambiar a lo largo del tiempo para dar cuenta de los patrones de comportamiento observado.

Dichas investigaciones explican los cambios fundamentalmente como un proceso de auto-modificación del propio sistema. De esta manera el foco de atención de los modelos de procesamiento de la información se sitúa en los factores internos al propio sistema como disparadores del cambio, más que en los externos o ambientales. El ambiente importa como fuente de estímulo (de información) con la que trabaja nuestro sistema cognitivo, más que como factor causal del cambio evolutivo.

Los diferentes modelos pertenecientes a esta línea de investigación tienen en común un rasgo característico: son mecanismos que permiten al niño reducir el alcance de las limitaciones inherentes al sistema cognitivo.

Estos mecanismos se pueden clasificar según Flavell, Miller y Miller (1993) en dos grandes grupos:

- Cambios estructurales $u$ orgánicos: implican un cambio en parámetros del sistema, de manera que las limitaciones en el procesamiento de la información resultan menores.

- Cambios funcionales: en este caso el sistema sería estructuralmente idéntico y lo que cambiaría sería la eficiencia con la que el niño de una y otra edad puede emplear los recursos de los que dispone.

En 1968 los investigadores Atkinson y Shiffrin introdujeron la distinción, en cuanto a la memoria, entre procesos estructurales y procesos de control. La primera categoría se refiere a aquellos aspectos de la memoria que son independientes de la experiencia y que imponen límites a la capacidad y a la eficiencia de funcionamiento del sistema. Según estos autores es probable que las diferencias individuales en los aspectos estructurales se deban a características anatómicas y fisiológicas de los individuos, determinadas en gran medida en forma innata. Los procesos de control aluden a aquellos aspectos del sistema que resultan del adiestramiento y la experiencia individual y que, probablemente, se hallan bajo control 
voluntario, como el empleo de reglas mnemotécnicas, las estrategias de búsqueda y la repetición. Sin embargo, aun cambios estructurales como la amplitud en la capacidad de memoria o la velocidad de procesamiento puede estar influidos por cambios funcionales. Gran parte de la investigación dedicada al desarrollo y sus mecanismos explicativos desde la perspectiva del procesamiento de la información está centrada en examinar los cambios funcionales en el sistema cognitivo asociados con la edad.

Algunos de los mecanismos que intervienen para lograr una mayor eficiencia en el sistema procesador de información son:

- $\quad$ las estrategias utilizadas

- la velocidad en el procesamiento de la información (puede relacionarse con las estrategias y con la base de datos y su organización en la memoria)

- $\quad$ la base de datos

- $\quad$ la naturaleza de la tarea

- $\quad$ las capacidades metacognitivas.

Se considera que estas serían las capacidades influyentes en las diferencias individuales de capacidad en la resolución de problemas.

\section{III.2.1. ESTRATEGIAS Y REPRESENTACIÓN}

Las estrategias son operaciones cognitivas tendientes a resolver un determinado problema y que debido a la experiencia que el individuo obtiene en la interacción con ese tipo de problema, se supone, adquiere estrategias cada vez más eficientes. La intención de 
resolver el problema es siempre conciente, pero el tipo de estrategia o cambio de estrategia a utilizar no lo es siempre.

Investigaciones en Psicología Cognitiva (Sternberg, 1987) adjudican importancia a las estrategias utilizadas por el sujeto a la hora de obtener mayor eficiencia en el sistema procesador de información. Las diferencias individuales en la resolución de tareas, traducido en la elección de estrategias, pueden deberse a diferencias de "estilos cognitivos" $\left(\right.$ Messik, 1976) ${ }^{29}$.

La elección de una estrategia (conciente o inconciente) incluye las operaciones mentales para comparar formatos representacionales entre el estímulo y los alojados en la memoria (Cooper, 1980) ${ }^{30}$.

Las investigaciones (Hunt y McLeod 1980) ${ }^{31}$ muestran que la elección del tipo de estrategias a utilizar por una persona para la representación puede estar relacionada con su capacidad relativa en este tipo de tareas (puede llegar a ser automática). Según Cooper $(1980)^{32}$ pueden considerarse estrategias naturales. Los estudios previos muestran que se alcanza una considerable flexibilidad y modificabilidad en la selección de estrategias, de la mano de la instrucción.

En este sentido los "estudios sobre el adiestramiento de estrategias" (Brown y Campione, 1978; Buterfield, 1981) ${ }^{33}$ a través de un procedimiento que incluya test, adiestramiento, retest, constituye una herramienta que nos permitiría evaluar los procesos que intervienen en la tarea estudiada.

\footnotetext{
${ }^{29}$ Citado por Sternberg (1987)

${ }^{30}$ Citado por Sternberg (1987)

${ }^{31}$ Citado por Sternberg (1987)

${ }^{32}$ En Sternberg (1987)

${ }^{33}$ En Sternberg (1987)
} 
Por lo expuesto sería plausible adjudicar a la mediación pedagógica un rol de herramienta versátil para acceder a instancias de representación musical, a través de la enseñanza de estrategias que posibiliten la aplicación de reglas y convenciones habituales en la tradición musical de Occidente. Esta posibilidad se ve reafirmada en la explicación que ofrece de Vega (1984:115) sobre la recodificación que realiza la MCP, ya que para que esta ocurra eficazmente se requiere la mediación de reglas y conocimientos acumulados en la MLP. Las representaciones internas dispondrían así de recursos para expresar y hacer manifiesto el conocimiento musical que puede concretarse en diferentes formatos representacionales.

En tal sentido el presente estudio, indagará las modalidades que asumen las representaciones infantiles en la modalidad gráfica cuando son mediadas por experiencias corporales de organización en el espacio y en el tiempo.

Atendiendo a los objetivos trazados para el Anteproyecto y su sustanciación en la aplicación del test se observa que las experiencias necesitan ser:

- iniciadas en el espacio vertical

- traducidas a iniciativas de acción corporal (canto, movimiento)

- traducidas al espacio horizontal propio del grafismo escrito de los atributos musicales.

De este modo, las prácticas corporales resultan mediadoras para mantener el plano de representación vertical del espacio real y luego traducirlas al espacio horizontal de la gráfica. Este proceso formó parte de las ejercitaciones en el grupo experimental

La indagación incluye interrogantes relativos a la representación gráfica de los estímulos musicales, en términos tales como:

- ¿Puede advertirse el rol de los aprendizajes previos de las convenciones acerca de cómo se grafican determinados atributos de la música? 
- ¿Cambian los resultados en grupos naturales de igual edad, cuando uno de ellos participa de prácticas específicas y otro sin ellas a la hora de representar gráficamente cada atributo musical?

- ¿Difiere la calidad representacional de la respuesta gráfica según el atributo en cuestión?

- ¿Varían los resultados entre representación corporal y gráfica?

\section{III.2.2. ACTIVACIÓN CEREBRAL Y MÚSICA. CORRELATO NEURAL}

Se ha visto que desde la simple escucha y goce de la música (conocimiento por enculturación), hasta los diferentes niveles de ejecución instrumental, la danza, el canto, la lectoescritura musical, el análisis y la conceptualización de los diferentes parámetros de la estructura musical, proveen al sujeto de experiencias que adquieren en su mente un formato representacional con diferente grado de complejidad.

Las propuestas teóricas referidas a las capacidades involucradas en la percepción y ejecución musical ofrecidas por la Psicología de la Música encuentran su correlato en los recientes hallazgos de las investigaciones en Neurociencia Cognitiva los que revelan, (mediante la lectura de neuroimágenes), que los circuitos neuronales comprometidos en una actividad determinada se modifican en cada sujeto de acuerdo a su conocimiento y/o experiencia previa, como al uso que hace de diferentes estrategias lo que se ve reflejado en las diferentes áreas del cerebro que utiliza. Los hallazgos sugieren la posibilidad de que las partes del cerebro que se usan para cualquier tarea musical particular dependen de la naturaleza de la tarea, del nivel de experiencia individual en diferentes tipos de habilidades y de las estrategias que se empleen (Levitin, 2008; Schön, 2012) 
Las características de la representación alcanzada dependen de la interacción entre las particularidades de la música y de las experiencias y conocimientos previos del sujeto, por eso podemos hablar de diferentes formatos y modos de representación. De acuerdo a las investigaciones en Neurociencia, estos formatos y modos representacionales tienen su correlato en los distintos circuitos neuronales implicados en tareas de percepción y ejecución musical, lo que sugiere que hay una relación entre representación alcanzada, conocimiento/experiencia y magnitud del área cerebral empleada.

En cuanto a las áreas comprometidas en la percepción, el patrón de activación hemisférica da cuenta de que, mientras el hemisferio izquierdo se especializa en la percepción temporal y el ritmo, el derecho lo hace en la percepción del tono y el timbre. Dentro de cada hemisferio, los lóbulos temporales están implicados predominantemente en la percepción musical y los frontales en la expresión y la producción musical. No obstante, se ha observado que el entrenamiento influye sobre la manera como se responde a la música, y juega un rol crucial en la participación diferencial de los hemisferios durante diversas tareas musicales (Altenmüller, 2002).

Como lo proponen Lalitte y Bigand (2007), la música modifica la organización cerebral de quienes la escuchan o la practican con intensidad y tal modificación puede incluso tener efectos positivos para la adquisición de múltiples actitudes cognitivas de carácter fundamental.

De acuerdo con estudios electroencefalográficos realizados en el campo de la percepción musical, se ha podido evidenciar que los músicos presentan numerosas diferencias cognitivas en comparación con sujetos sin formación musical, principalmente en áreas tales como: la discriminación de frases musicales, identificación de contornos melódicos e intervalos y la detección de cambios en el patrón de sonidos musicales (Gómez y Gutiérrez, 2010).

Durante el procesamiento de melodías la activación cerebral depende del grado de experticia musical. Mientras que en no músicos se activa predominantemente la corteza fronto-temporal derecha, en músicos se presenta activación adicional de áreas auditivas del 
hemisferio izquierdo (Altenmüller, 1986) ${ }^{34}$. Estas variaciones en los patrones de activación auditiva se asocian a diferentes estrategias cognitivas y representaciones musicales empleadas por personas con o sin entrenamiento musical.

En el caso de los no músicos, las melodías son analizadas de una manera global basada en contornos, la cual constituye una estrategia que depende principalmente de redes neuronales del hemisferio derecho (Heinze., 1994) ${ }^{35}$. En contraste, los sujetos con formación musical pueden emplear estrategias verbales ya que están en condiciones de explicitar nominando lo que escuchan. De esta manera, sujetos con entrenamiento están en condiciones de analizar melodías de una manera secuencial, basada en intervalos lo que obedece al funcionamiento de redes neuronales del hemisferio izquierdo (Altenmüller, 2002).

En relación a la influencia de la experticia musical sobre la percepción de frases musicales, se ha detectado un correlato neuronal para la percepción de la segmentación musical en sujetos con formación musical. De acuerdo con algunos estudios de potenciales evocados y campos magnéticos asociados a eventos, los sujetos músicos parecen procesar las frases musicales de una manera estructurada muy similar a la empleada en la percepción del lenguaje. Por su parte, los no músicos detectan principalmente las discontinuidades de las melodías (Friederici, Knösche, Nan, 2006) ${ }^{36}$.

\section{III.2.3. LA NATURALEZA DE LA TAREA}

\footnotetext{
${ }^{34}$ En Altenmüller., 2002

${ }^{35}$ En Altenmüller., 2002

${ }^{36}$ En Gómez, D. y Gutierrez, M., 2010
} 
La naturaleza de la tarea puede influir en el nivel de resolución de los sujetos (Hargreaves, 1998). Cada contenido musical puede abordarse desde la ejecución, audición, composición y reflexión analítica. A su vez cada una de estas tareas puede proponerse en diferentes niveles de complejidad, de acuerdo a las experiencias previas del sujeto. En este sentido cada tipo de tarea supone un tipo de conocimiento, y asume un tipo de formato representacional particular.

Los términos representación y conocimiento comparten gran parte de su significado, el de "representación" alude al formato concreto en que se almacena el conocimiento. Si bien, para algunos autores el conocimiento hace referencia a la capacidad del sujeto de ser conciente de él y verbalizarlo, en este trabajo se utilizará indistintamente representación y conocimiento como información recepcionada, procesada y almacenada por el sistema cognitivo con la posibilidad de recuperarla y utilizarla.

\section{III.2.3.1. CONOCIMIENTO PROCEDIMENTAL Y DECLARATIVO}

La diferencia entre ambos tipos de representaciones se centra en el "saber cómo" y el "saber qué". Mientras las representaciones declarativas almacenan conocimientos descriptivos del mundo, las procedimentales almacenan conocimientos respecto a secuencias de acciones y habilidades para actuar sobre el mundo.

El conocimiento procedimental, es de difícil acceso a la conciencia y a ser explicitado por medio del lenguaje. Típicamente su aprendizaje es lento y se produce a partir del refuerzo de cadenas asociativas a partir del ensayo repetitivo, ensayos que producen mejoras progresivas. El conocimiento procedimental, por otra parte, tiende a estar ligado a contextos de aprendizaje; una vez adquirido es difícil de desglosar en sus componentes o de transferir a situaciones muy diferentes a aquellas en las que fue adquirido. Es un conocimiento difícilmente explicitable, verbalizable. 
El conocimiento declarativo es, en principio, susceptible de ser representado en forma de proposiciones verbales o de imágenes mentales accesibles a la conciencia. Es un conocimiento descriptivo y factual que se refiere a objetos, personas y eventos. El conocimiento declarativo a diferencia del procedimental, puede adquirirse (almacenarlo y reproducirlo) a partir de ser expuestos a él (en algunos casos) en un único ensayo y es comunicable verbalmente con facilidad.

La ejecución musical es típicamente un conocimiento de tipo procedimental. Su aprendizaje es lento y requiere numerosas repeticiones para lograr la destreza que otorgue fluidez a la interpretación. Sea cual fuere el nivel de ejecución, la práctica musical en sus múltiples manifestaciones es el sustento experiencial al que se remiten los conocimientos declarativos. Siendo la música un lenguaje, su práctica es previa al conocimiento declarativo de su desarrollo.

Según Furnó (2005:31) "El aprendizaje musical sustentado en la audición parecería consolidarse en la memoria explícita y correspondería a la modalidad declarativa"

"No debiéramos equivocarnos pensando que impartir conocimiento declarativo ayuda mucho a la gente a entender la música (salvo en niveles más elevados de estudio). Durante las etapas iniciales del aprendizaje el énfasis debiera estar puesto en la construcción de esquemas que más tarde puedan ser puestos bajo control declarativo. Los estudiantes no pueden utilizar elaboradas estructuras declarativas hasta que no han obtenido los esquemas básicos con los cuales operar con el material sensorial" Dowling (1998:39)

En términos cognitivos podríamos argumentar en este sentido que la música presenta en sí misma un formato abstracto y temporal. Lograr comprensión, y conceptualización sobre ella requiere traducir a otros formatos que hagan más comunicable la experiencia (conocimiento declarativo). Esto resulta posible recuperando el conocimiento producido a través de las acciones kinéticas y corporales construidas a partir del aprendizaje procedimental, es decir, otros tipos de formatos. Es posible pensar entonces, que diferentes tipos de formatos son sucesivos en el orden de adquisición en el sistema, lo cual es de vital importancia para la elaboración de las secuenciaciones pedagógicas. Hay 
acuerdo general en que gran parte de los conocimientos que logran construirse en el historial de aprendizajes comenzaron con la experimentación de tipo corporal-sensorial (de ahí que construimos "esquemas imagen" en términos de la cognición corporeizada o "esquemas preoperatorios" en términos de Piaget). Es este un circuito que no se puede obviar en el aprendizaje, por lo tanto en música, se debe propiciar la práctica musical (conocimiento procedimental) para luego remitir a ellas los conocimientos declarativos, a partir de los cuales se podrá acceder luego al concepto y de ahí al símbolo.

\section{III.2.3.2. CONOCIMIENTO PROPOSICIONAL Y EN IMÁGENES}

Una de las propuestas teóricas que sostiene la existencia de los formatos representacionales verbal e imaginativo es la Hipótesis Dual de Paivio (1971, 1977). Los concibe como estrechamente interconectados pero con propiedades estructurales y funcionales diferentes. Según este investigador la imaginación está especializada en el procesamiento de información concreta y preserva de modo analógico las propiedades espaciales y métricas del estímulo (tamaño, forma, localización, orientación, movimiento, etc.) De esta manera el sistema de imágenes guarda una similitud funcional y estructural con la percepción, traduciendo la información a formatos viso-espaciales.

El sistema verbal puede procesar tanto información concreta como abstracta, tiene un carácter descriptivo y una estructura sintáctica y semántica, pero según Paivio (1977) no retiene una réplica isomórfica del estímulo. El sistema verbal posee un formato proposicional, lo que implica que puede traducir el pensamiento a un lenguaje de la mente que se expresa en forma lingüística, porque lo que se piensa, se piensa en términos lingüísticos.

Dada las características del lenguaje musical: abstracto (en el sentido en que no es verbal o viso-espacial) y temporal, es posible pensar que la mente utiliza formatos en 
imágenes y proposicionales para explicar su experiencia con la música. De hecho, a lo largo de la historia, estos han sido los términos en los que se ha dado cuenta de diversos aspectos musicales. La melodía ascendente y descendente, el círculo de quintas, la distancia entre sonidos, volver al tema. De acuerdo con estos formatos representacionales, la experiencia perceptual, genera una traducción a formato viso-espacial (de carácter imaginativo) que puede, a su vez, ser traducido a palabras. Las propuestas provenientes de las líneas en Cognición Corporizada explican estos procesos en términos de mapeos transdominios, en donde un dominio más abstracto (como puede ser el de la música) es entendido en términos de otro dominio mediado por la experiencia corporal más concreta a través de procesos asociativos-imaginativos.

Podemos considerar a su vez, los formatos viso-espaciales y proposicionales que acompañan la presentación musical en término de imágenes, gráficos, presentaciones multimedias, narraciones y la partitura. Todas ellas se configuran en representaciones externas que inciden en la conformación de representaciones internas o mentales y por lo tanto colaboran en la comprensión.

Como las representaciones externas tienden a facilitar o hacer más comunicable la experiencia musical, la Teoría de la Música ha tomado estos formatos (viso-espaciales y proposicionales) configurándolos como representaciones teóricas (Shifres, 2004).

La representación mental tendría su correlato en representaciones teóricas, o dicho de otra manera, las representaciones teóricas de la música, son muchas veces, representaciones teóricas de representaciones mentales (Shifres, 2004). Al respecto, existen propuestas teóricas de la estructura musical preocupadas en validar la realidad psicológica de sus constructos teóricos (Lerdahl y Jackendoff, 1983; Salzman, 1962) aunque en algunas ocasiones entran en colisión las representaciones internas de la música con las representaciones teóricas.

Por ende los formatos en imágenes y proposicionales pueden formar parte de representaciones mentales, externas y teóricas de la música. La relación estructural entre ellas sería equivalente a una mayor comprensión del fenómeno musical. Entendiendo que, 
comprender, implicaría dar cuenta de esa estructura musical expresada en imágenes y/o en palabras.

\section{III.2.3.3. CONOCIMIENTO EXPLÍCITO E IMPLÍCITO}

A diferencia de las distinciones entre representaciones proposicionales y en forma de imágenes o las representaciones procedimentales y declarativas en las que la diferencia estriba en el formato y naturaleza misma de la representación, en la contraposición entre lo explícito y lo implícito, la diferencia no es el formato, sino el grado de accesibilidad a la conciencia que tiene la información representada. Según Mandler (1998), la diferencia tiene que ver con el tipo de procesamiento, por eso, podemos hablar de procesamiento explícito frente a procesamiento implícito. A su vez estos tipos de procesamiento se diferencian en el modo de aprendizaje y en la forma en que se recuperan de la memoria, por lo cual podemos hablar de memoria implícita y memoria explícita.

El procesamiento explícito codifica información sobre acontecimientos autobiográficos, así también sobre conocimientos de hechos, es decir conocimiento declarativo. Puede recordarse por un acto deliberado de evocación y a veces sólo basta un ensayo o experiencia para establecerse en la memoria. Entonces el procesamiento explícito trabaja sobre información con formato de tipo declarativo, es de fácil almacenamiento y recuperación de la memoria, a la que (por este motivo) denominamos explícita; la recuperación de la memoria en este tipo de procesamiento se relaciona con la frecuentación del contenido. Es decir, la recuperación se facilita cuando se trata de un contenido frecuentemente "visitado".

Recuperar información de la memoria impone un proceso creativo, ya que la “percepción sensorial en sí misma no es un registro fiel del mundo externo" (Kandel, 
Schwartz y Jessell, $1997^{137}$. En todo proceso perceptivo intervienen habitualmente dos planos fenoménicos complementarios: el de las señales físicas y el de las representaciones mentales asociadas (Basso, 2006). En la percepción auditiva, por ejemplo, se trata de atender a los modos particulares en que la información acústica es estructurada en la señal física, procesada en el sistema nervioso (desde el oído hasta la corteza cerebral) e interpretada contextualmente dando lugar a una representación mental única.

En la recuperación de información de la memoria explícita, el recuerdo no es absolutamente fiel, sino que es transformado a través de diversas estrategias cognitivas: comparación, inferencia, conjeturas, suposiciones; con el fin de darle sentido al recuerdo. Por lo tanto se produce un proceso de síntesis por ejemplo, cuando recordamos una melodía conocida y cambiamos, aunque en forma coherente, algunas alturas respecto al original, tratando de dar sentido a la melodía. Esto debido a que nuestra mente necesita proporcionar sentido a la información almacenada o recuperada de la memoria (ley de cierre de la Gestalt). La memoria actúa como las "capas de cebollas", se reconstruye en cada recuerdo, "recordamos lo último que recordamos", lo que decimos recordar, lo que reconstruimos, con el tiempo, puede ir variando, y la falta de frecuentación con ese dato a recordar puede provocar un "olvido", salvo que se encuentre muy estructurado en la memoria, lo cual está muy ligado al impacto afectivo del mismo.

En cuanto al procesamiento implícito, es de carácter automático o reflejo y se adquiere lentamente mediante la repetición a lo largo de muchos ensayos. Se manifiesta básicamente por el aumento de rendimiento y normalmente no puede expresarse en palabras. Este tipo de procesamiento opera sobre conocimiento de tipo procedimental, la forma en que se almacena y recupera no depende por completo de la conciencia, interviniendo la memoria implícita.

Ejecutar un pasaje instrumental veloz requiere haber estudiado y repetido muchas veces una determinada digitación hasta lograr una automatización que permita el

\footnotetext{
${ }^{37}$ Citado por Furnó (2005: 30)
} 
virtuosismo que el pasaje requiere. Es un ejemplo de conocimiento procedimental, que requiere un procesamiento implícito, almacenado y recuperado de la memoria implícita; una vez automatizado es difícil explicarlo verbalmente y desglosarlo en partes, de ahí la importancia de la memorización correcta de secuencias de este tipo. En cuanto a la recuperación de la memoria, se ha visto que basta recordar el inicio y se desprende el bloque completo de las secuencias de movimiento. Otro ejemplo de este tipo de procesamiento implícito, se pone de manifiesto al tratar de recordar el inicio de una canción. En este caso difícilmente se pueda recordar el texto solo sin la melodía, se necesita recordar la melodía, porque fue memorizada conjuntamente con el texto, se memoriza el procedimiento.

\section{III.2.3.3.1. PROCESOS CONTROLADOS Y AUTOMÁTICOS}

Esta distinción entre lo implícito y lo explícito es paralela a la que establecieron autores como Shiffrin y Schneider (1977) o Hasher y Zacks (1979) entre procesos automáticos y procesos controlados. Las diferencias entre ambos procesos (entendidos como extremos dentro de un continuo) serían las siguientes:

- Los procesos automáticos insumen cantidades mínimas de esfuerzo mental y su ejecución no interfiere con procesos adicionales que se realicen simultáneamente. Su funcionamiento requiere poco control conciente y la ejecución mejora poco con la práctica adicional (una vez automatizado). Los procesos automáticos varían relativamente poco una vez adquiridos son variables de incidencia en la inteligencia, la motivación y el nivel educativo alcanzado. Según Sloboda (1986) la adquisición de la habilidad en ejecución musical se caracteriza por ser automática, fluida, y rápida. Además la automatización de destrezas permite

prestar atención a otros elementos al mismo tiempo que se realiza, de manera que también se caracteriza por la simultaneidad. 
- Los procesos controlados requieren esfuerzos concientes en sus operaciones, necesitan una gran inversión de recursos cognitivos y por ello limitan nuestras posibilidades de ejecutar simultáneamente otros procesos. De este modo pueden producir interferencias o incluso sobrecargas del sistema lo que determina un desplome en el rendimiento de la tarea. El análisis auditivo de la música requiere fundamentalmente, la puesta en marcha de procesos controlados y el despliegue de estrategias atencionales, mnémicas, de categorización y conceptualización.

\section{III.2.4. DESARROLLO Y METACOGNICIÓN}

Un factor que es frecuentemente aludido para explicar las diferencias cognitivas entre niños de diferente edad es que los mayores tienen un mayor conocimiento y control sobre sus propios procesos cognitivos, lo que ayuda a que sean más eficientes. Es lo que conocemos con el nombre de metacognición.

Podemos diferenciar dos aspectos de la metacognición como (Nickerson, 1988; Baker y Brown, 1982) $)^{38}$

- $\quad$ actividad que llevamos a cabo para gestionar y regular nuestras propias operaciones cognitivas. Por ejemplo dedicar más tiempo y esfuerzo a los problemas más difíciles, planificar cómo va a ser la resolución, poner en marcha la estrategia más efectiva en el momento preciso, acudir a cursos de acción alternativos cuando llegamos a un callejón sin salida, entre otras.

- conocimiento sobre cómo funciona nuestro sistema cognitivo. Por ejemplo, saber si somos capaces de saber si vamos a solucionar un problema o no, si

\footnotetext{
${ }^{38}$ En Mayor et al, 1995
} 
cierta tarea requiere más esfuerzo que otra, o qué estrategias son más efectivas para determinadas tareas, entre otras.

El primer tipo de metacognición se refiere más a aspectos de tipo procedimental (a un "saber cómo"), muy dependiente del tipo de tarea y no necesariamente autoconciente, ya que en ocasiones la persona pone en marcha estas actividades de manera automática. El segundo tipo de metacognición corresponde a una información de tipo declarativa (a un "saber qué"), relativamente estable, habitualmente accesible a la consciencia (podemos reflexionar y discutir con otros sobre ella) y con la posibilidad de ser falible (es decir, podemos tener creencias erróneas sobre la cognición).

La metacognición de tipo procedimental se relaciona con el concepto de procesos ejecutivos. Es decir una serie de procesos que controlan la actividad del sujeto, garantizando que se lleven a cabo con eficacia. En general, los diferentes procesos de control ejecutivo propuestos pueden resumirse en tres tipos. Se trata de procesos de:

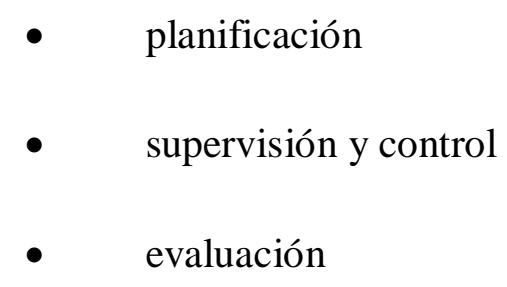

Con respecto al conocimiento metacognitivo de tipo declarativo, se diferencian tres tipos de conocimiento. El conocimiento de:

- atributos cognitivos de la propia persona

- aspectos de la tarea que son susceptibles de influir en su procesamiento.

- estrategias sobre cómo se realizan, qué tipo de tareas son aplicables y en cuáles más efectivas.

Para poder ejercitar control metacognitivo sobre un proceso los sujetos deberían saber qué hechos y conceptos son necesarios para la tarea, cuáles estrategias, heurísticos o 
procedimientos son apropiados y cómo aplicar la estrategia, procedimiento o heurístico elegido.

En este sentido las sesiones experimentales inter-test, a través de clases orientadas a trabajar específicamente las tareas y estrategias requeridas por el test, pueden colaborar en desarrollar procedimientos metacognitivos. Específicamente las evaluaciones al final de cada sesión (con el grupo experimental) y su devolución al principio de la siguiente, tuvieron como objetivo estimar los resultados obtenidos hasta el momento, promoviendo la autoevaluación y favoreciendo una actitud de control y ajuste sobre el propio desempeño.

Respecto de la falta de transferencia de estrategias en situaciones de aprendizaje, frente a una nueva propuesta, una hipótesis extendida, es que el sujeto no llega a comprender el significado de las actividades de instrucción, es decir que el origen de muchos de sus problemas son de naturaleza metacognitiva (Brown, 1978; Flavell, 1978) ${ }^{39}$.

En los estudios referidos a la adopción de estrategias, se incluye un nivel denominado adiestramiento de autocontrol. En él se instruye al niño en el empleo de una estrategia y además en cómo utilizar, supervisar, comprender y evaluar esa estrategia (Sternberg, 1987).

\footnotetext{
${ }^{39}$ En Sternberg, 1987
} 


\section{CAPÍTULO IV}

\section{TEST: FORMA MUSICAL}

A continuación se vinculan los temas desarrollados anteriormente en relación específica a la realización del test.

\section{IV.1. LAS CAPACIDADES COGNITIVAS}

Teniendo en cuenta que el test está dirigido a niños de 10 y 11 años sin formación musical previa se consideran variables de incidencia:

a. Capacidad atencional. La atención es selectiva, limitada y activa (de Vega, 1984). Se la vincula con elementos motivacionales extrínsecos e intrínsecos. Los estudios muestran que la persistencia en una determinada tarea se relaciona en mayor medida con la motivación intrínseca (Amabile, 1983) ${ }^{40}$. Por ello resulta necesario atender a la calidad y atractivo de los ejemplos musicales a utilizar

b. Capacidad de la memoria: Estudios sobre memoria musical (Dumarier, 1992) muestran que la capacidad de aprehensión auditiva es de tres elementos en niños de 8 años y de cuatro en niños de 10 años. Los datos pertenecen según la autora al nivel de memoria de estructuración que registra los eventos en el orden que van a ser codificados y permite recordar ese orden (aunque tiene una capacidad limitada). Previo a este nivel se observa un primer nivel de memoria periférica, que otros autores denominan sensorial ecoica (de Vega, 1982) y posterior a la memoria de estructuración, la memoria semántica

\footnotetext{
${ }^{40}$ En Romo, 1997
} 
que define la significación, permite la anticipación y otorga una estructuración al conjunto de la información. Según Dumarier la intervención de la memoria semántica durante la etapa de la memoria de estructuración, interrumpiría el proceso de memorización en etapas sucesivas, debiendo recomenzar la secuencia. La memoria semántica puede intervenir en cualquier momento para establecer relaciones con estructuras de conocimiento ya aprendidas, pero debe hacerlo cuando ya se memorizó la secuencia para luego organizar la sucesión de elementos en una connotación global.

c. Presente psicológico: Manejo del tiempo en un espacio mental (Imberty 1990) donde es posible representarse y organizar los eventos sonoros por la reversibilidad del pensamiento. Esto facilita la práctica de la audición de música en tiempo real con niños de esta edad. El número de elementos que puede alojar la memoria inmediata es de 7 ( \pm ) 2 (Miller, 1991). La cantidad de sonidos sucesivos que pueden percibirse como una unidad es de 25 (Fraise, 1982).

d. Pensamiento operacional concreto: Abstracción y reversibilidad que permite operar mentalmente con el tiempo musical. La presencia de la capacidad de conservación y reversibilidad permiten al niño abstraer regularidades, memorizar secuencias rítmicomelódicas, detectar finales de frase, pudiendo organizar secuencias lógicas en el tiempo. Se inicia así el distanciamiento progresivo de los rasgos más llamativos de la superficie musical lo que facilita el manejo estructural de la información.

\section{IV.2. CONOCIMIENTOS PREVIOS}

Los niños que participaron en la realización del test y de las sesiones experimentales manifestaron no poseer estudios musicales previos. 
Se consideran conocimientos previos, en este contexto particular, a los conocimientos musicales sistemáticos adquiridos en una institución educativa.

Esta característica común de la muestra, supone a la hora del análisis de los resultados, la toma en consideración del efecto de la enculturación, esto es, las experiencias que desde la temprana infancia van forjando en el sujeto una "gramática musical" construida por "esquemas de conocimiento" que le permiten reconocer de manera implícita aspectos métricos, rítmico-melódicos, formales y armónicos.

\section{IV.3. NATURALEZA DE LAS TAREAS PROPUESTAS}

Diversos autores (Willems, 1964; Reybrouck, 2005; Chion, 2008) distinguen entre oír y escuchar, el primero como proceso puramente fisiológico, el segundo como proceso en el que intervienen factores psicológicos tales como la atención y la motivación. Más allá de la implicación de la atención hay además una distinción adicional entre escucha acústica y auditiva. La escucha acústica está determinada por las cualidades acústicas de la música, la escucha auditiva es un proceso de creación de sentido que va más allá de la mera descripción acústica del sonido (Haendel, 1989). ${ }^{41}$

En la distinción que Dumarier (1999) realiza sobre percepción-aprehensión y percepción-comprensión, el factor que diferencia ambas propuestas es la naturaleza de la tarea implicada en cada una y por ende la modalidad del tratamiento de la información, lo cual conlleva un nivel de representación posible.

La audición musical que intenta comprender las relaciones sonoras, organizándolas y asignando significaciones, implica el uso de abstracciones (que el sujeto opere con

\footnotetext{
${ }^{41}$ En Reybrouck, 2005
} 
relaciones de sonidos) simbolizaciones (traduciendo a símbolos las relaciones sonoras) y para ello es preciso el desarrollo del pensamiento reflexivo.

"El pensamiento se define como la actividad de un sistema que opera sobre las representaciones internas de que dispone acerca de algún aspecto del mundo interior y/o exterior en el marco de una situación contextual, fruto de su interacción con el entorno, que contribuye a determinarla" (Mayor et al, 1995:42).

Varios autores reconocen rasgos particulares o fases en el pensamiento reflexivo (Mayor, 1985; Oléron, 1979; Mayer, 1977; Craik, 1943; Dewey, 1933) caracterizados por el uso y manipulación del conocimiento representacional el cual puede intervenir en la resolución de problemas, en la adquisición y transformación del conocimiento, lo cual constituye el meollo del aprendizaje.

El test propone una modalidad de tarea que induce al sujeto a llegar al símbolo a partir de la música. Se propone como un juego simbólico en el sentido que representa el vehículo para aprender reglas y convenciones mientras "se juega" (Bruner, 1984). En este sentido Gardner (1971) advirtió que los niños pueden mejorar significativamente la habilidad para ejecutar una tarea durante la misma sesión experimental (Hargreaves, 1998:96).

Las características de la tarea imponen al sujeto emplear sus experiencias musicales previas posiblemente relacionadas al movimiento, imágenes, afectos, como niveles implícitos de representación musical. A partir de estos relatos internos y ante la consigna de la tarea y la propuesta de un gráfico a seleccionar, es posible que el sujeto realice asociaciones que le permitan traducir el/los formatos en que inicialmente representó el estímulo musical a otros de tipo verbal y gráfico.

De esta manera el tratamiento de la información a través de las consignas solicitadas, requieren un procesamiento inter o multimodal. Para ello se ponen en marcha procesos imaginativos que vinculan la música con experiencias corporales, movimientos, imágenes, gráficos, etc. Estos procesos suponen transitar las modalidades enactivas, icónicas y simbólicas (Bruner, 1995). La tarea requiere, a partir de la atención selectiva 
procesos controlados que permitan llevar a cabo las segmentaciones del discurso para así comparar con los gráficos propuestos, presunciones implícitas y decisiones explícitas.

En el test, esta inducción conduce a respuestas de dos tipos: cerradas en la primera parte del test (ya que se les solicita que a partir de la identificación auditiva de la forma la relacionen con gráficos propuestos, abiertas en la segunda parte del test donde se les solicita que a partir de la identificación de la forma, la grafiquen sin gráficos de referencia.

La naturaleza de las tareas requeridas en el test a través de la secuenciación propuesta, requiere atención sostenida, procesos imaginativos de asociación entre la música, las representaciones internas y los gráficos propuestos, lo que impone el uso del pensamiento reflexivo, transformando las representaciones internas en producciones corporales, vocales y gráficas.

En este sentido la realización del test constituye un aprendizaje. Por sus características podría ser definido como aprendizaje por descubrimiento guiado y aprendizaje significativo (Ausubel, Novak y Hanesian, 1978) ${ }^{42}$. De acuerdo a la distinción que Marton (1975) realiza sobre enfoque superficial y profundo respecto al aprendizaje, la audición (en los términos establecidos) podría situarse en el enfoque profundo porque intenta comprender e interpretar la información musical y las abstracciones producto del análisis son relacionadas a símbolos. Dentro de este enfoque profundo de aprendizaje Van Rossum y Shenk (1984) ${ }^{43}$ ubican dos de sus concepciones respecto a tipos de aprendizajes y podríamos asociarlas a la audición musical. Estas se refieren también a la abstracción de significado, lo cual implica el descubrimiento de relaciones dentro de la trama musical y el aprendizaje entendido como procesos interpretativo, lo cual implica una comprensión y reinterpretación del conocimiento.

\footnotetext{
${ }^{42}$ En Mayor et al, 1995

${ }^{43}$ En Mayor et al, 1995
} 
El aprendizaje por descubrimiento guiado y aprendizaje significativo, a su vez, concede importancia al mediador (Feuerstein, Rand, Hoffman y Miller, 1980) ${ }^{44}$, encargado de seleccionar, enmarcar y filtrar los estímulos. El papel del mediador no es exclusivamente presencial, ya que el texto escrito puede desarrollar esas funciones (Mayor, 1995). En este sentido la secuencia de actividades propuestas por el test puede guiar el conocimiento previo del sujeto a través de los ejemplos musicales y su vinculación a gráficos, induciendo el aprendizaje de la forma musical, hasta llegar a la simbolización.

\section{IV.4. ESTRATEGIAS COGNITIVAS}

A partir del estudio de los procesos cognitivos implicados en la audición y en relación con las capacidades de la edad testeada, se tomaron en cuenta las estrategias necesarias para responder al test. Estas implican tareas de procesamiento, codificación, recuperación y ejecución de respuesta.

a. Atención holística en la primera aproximación a la audición de los estímulos.

b. Atención focalizada sobre el atributo musical en estudio: la forma: segmentación y agrupamiento.

Comportamientos encubiertos implicados:

I. almacenamiento de los agrupamientos en la MCP

II. confrontación de los agrupamientos seleccionados con los esquemas contenidos en MLP

\footnotetext{
${ }^{44}$ En Mayor et al, 1995
} 
III. representación de los agrupamientos en algún tipo de formato mental.

c. Comportamiento explícito: traducción a otros formatos: kinéticos y verbales.

d. Confrontación comparativa de los agrupamientos conformados de acuerdo a criterios de igualdad, semejanza o contraste.

e. Confrontación de los agrupamientos construidos y la representación concretosimbólica de los gráficos de figuras geométricas, demandados por el test (primera parte).

f. Traducción de los agrupamientos construidos a representaciones gráficas concreto-simbólicas a través de figuras geométricas (segunda parte del test).

Algunas de las preguntas que los investigadores realizan respecto de las estrategias de aprendizaje s se refieren a cómo se adquieren, integran y automatizan en la realización de una tarea (Wenstein y Meyer, 1998) ${ }^{45}$. La realización de estrategias correctas caracteriza la modalidad de aprendizaje experto.

Las sesiones inter-test con el grupo experimental intentaron desarrollar estrategias reforzadas por el suministro de variedad de ejemplos que permitieran acrecentar la práctica y la construcción de imágenes pertinentes con cada ejemplo musical.

\section{IV.5. ESTRATEGIAS METACOGNITIVAS}

\footnotetext{
${ }^{45}$ En Wittrock y Baker, 1998
} 
La audición musical entendida como un tipo de aprendizaje en los términos expuestos requiere el desarrollo de estrategias que se caracterizan por ser conscientes, controladas, autorreguladas y autodirigidas, si bien las representaciones sobre las que opera el pensamiento se hallan en un continuo (entre lo implícito y lo explícito, lo inconsciente y lo conciente, entre otras).

Las investigaciones muestran que los sujetos pueden mejorar su capacidad para aprender usando selectivamente estrategias motivacionales y metacognitivas, con lo cual cobra importancia el concepto de autoaprendizaje (Zimmerman, 1989) ${ }^{46}$, el que es entendido como el proceso en el cual los aprendices son participantes activos en su propio proceso de aprendizaje, con una retroalimentación informativa auto-orientada que permite el control del proceso a través de la autoestima, la autorrealización y el auto-refuerzo (Mayor et al, 1995).

La realización del test puede entenderse como una experiencia de autoaprendizaje, que conduce a partir de los ejemplos seleccionados y en relación a gráficos analógicos pautados, la comprensión de la forma musical. En este proceso interviene un cúmulo de experiencias previas del sujeto como nivel representacional particular, pero resulta fundamental la actitud individual entendida como su disposición motivacional y afectiva, la cual es resultante de las características particulares del sujeto en cuanto a su sentido de auto-estima, autorrealización y autorefuerzo.

"La teoría del aprendizaje social de Bandura $(1982,1986,1989)$ se basa en la interdependencia de los factores personales, conductuales y ambientales para dar cuenta del desarrollo humano; el autoaprendizaje, consecuentemente, está influido por factores cognitivos y emocionales que actúan en forma recíproca con los factores ambientales y los eventos conductuales, destacando en todo ello el papel de los procesos de autocontrol y autoeficiencia" (Mayor et al, 1995:36).

\footnotetext{
${ }^{46}$ En Mayor et al, 1995
} 
Gardner (1997) explica las diferencias individuales respecto de la simbolización dentro de un mismo nivel de desarrollo, atendiendo a la intersección de lo cognitivo y lo afectivo, proponiendo la consideración de diferentes "estilos cognitivos", como modo particular en que cada sujeto aborda una problemática planteada.

Según Mayor et al (1995) los componentes principales del aprendizaje son el conocimiento, la motivación y la metacognición. De esta manera las estrategias involucradas en el aprendizaje son cognitivas, emocional/motivacional y metacognitivas.

Las diferencias individuales en la resolución de una tarea como el test, pueden relacionarse con los estilos atribucionales. Las personas que atribuyen sus logros a causas internas, como el propio esfuerzo y habilidad, manifiestan mejores resultados y en general aprovechan más un entrenamiento específico. Las personas que atribuyen el éxito a causas externas como la suerte o la tarea a realizar, presentan desempeños menores e inclusive suelen evitar la tarea (Borkowski y Krause, 1985; Heckhausen, 1987) ${ }^{47}$.

Los estilos atribucionales están relacionados con el concepto de motivación. Los sujetos intrínsecamente motivados pueden estar más dispuestos a realizar el esfuerzo mental implicado en el aprendizaje. Los comentarios anecdóticos de las sesiones tanto con el grupo experimental como con el control, ilustran este punto en el sentido de la buena disposición que todos los niños mostraban al momento de ejecutar instrumentos, realizar percusión corporal y comentarios de las audiciones realizadas. Sin embargo al proponerles realizar nuevamente el test (en ocasión del post-test) algunos de los niños manifestaron su predilección por otras actividades de la clase de música, mientras otros se mostraban dispuestos y entusiasmados a realizarlo nuevamente. Esto nos permite prever el tipo de disposición para la tarea y la falta de motivación en su realización.

Las razones para ello pueden ser múltiples, pero si caracterizamos la audición musical como un tipo de aprendizaje que utiliza abstracciones, simbolizaciones y pensamiento reflexivo, requiere por lo tanto atención y concentración sostenida.

\footnotetext{
${ }^{47}$ En Mayor et al, 1995
} 
Atendiendo a las características de la edad testeada esto es posible, siempre que se encuentren motivados a realizar la tarea. 


\section{CAPÍTULO V}

\section{METODOLOGÍA}

En este capítulo se describe la Lógica de la Investigación en términos de los supuestos metodológicos, las variables y constructos utilizados para el diseño experimental, la conformación y características de la muestra y los paneles convocados, el diseño y características del test, los puntajes asignados a los diversos desempeños en el test, la secuencia didáctica creada para el tratamiento inter-test y los repertorios utilizados.

\section{V.1. LÓGICA DE LA INVESTIGACIÓN}

\section{V.1.1.Hipótesis}

Se considera que:

Sujetos de igual edad y sin formación sistemática musical previa presentarán diferentes niveles de representación y diferencias interindividuales en términos del:

- grado de desempeño en el reconocimiento auditivo de la estructura formal y su representación gráfica,

- grado de progreso en un entrenamiento específico sobre el tema en estudio,

- grado de aprovechamiento post- intervención pedagógica. 


\section{V.1.2. Variables}

Se diseñaron las variables A y B. La variable A indaga la habilidad para realizar segmentaciones en el discurso musical a partir de la audición, infiriendo los grupos perceptivos que constituyen la forma musical y a partir de ello relacionarlos con un gráfico analógico constituido por formas geométricas. La habilidad que intenta indagar la variable A se presenta en tres instancias de discriminación con diferente grado de complejidad, lo cual se traduce en tres sub-variables. Esta variable pertenece a la primera parte del test. La variable B examina la habilidad para graficar a través de figuras geométricas la forma musical a partir de la audición. Se establecen tres sub-variables de acuerdo a las posibilidades de respuestas posibles y pertenecen a la segunda parte del test.

Variable A: Reconocer auditivamente la correspondencia entre forma musical y gráfico

Sub-variables: A1: dos frases iguales o diferentes

A2: tres frases iguales o diferentes

A3: tres frases iguales diferentes o parecidas

Variable B: Reconocer auditivamente la forma musical y graficar

Sub-variables; B1: Resolución total. Reconocimiento de repetición, variación y contraste entre los agrupamientos

B2: Resolución parcial. Reconocimiento de repetición y contraste entre los agrupamientos, sin advertir la variación.

B3: Sin Resolución. No reconocimiento de repetición, variación y contraste entre los agrupamientos. 


\section{V.1.3. Muestra}

Conformada por 26 sujetos $(\mathrm{N}=26)$, alumnos de $5^{\circ}$ año de la Escuela de Educación Primaria de gestión estatal 11 de Septiembre. La misma está ubicada en el Departamento Rawson de la Provincia de San Juan. La distribución de los alumnos en grupos experimental y control se realizó mediante un sorteo realizado ante las autoridades del establecimiento, quedando designado el curso $5^{\circ} \mathrm{B}$ como grupo experimental y $5^{\circ} \mathrm{C}$ como grupo control. Las maestras eran las mismas para los dos quintos, una de ellas dictaba matemática y naturales, la otra lengua y sociales. Las docentes expresaron que ambos cursos eran de similar a rendimiento.

Todos los alumnos presentes en cada curso participaron al momento de realizarse el Pre-test, Post-test y sesiones inter-test, sin embargo, conforman la muestra los sujetos presentes en todas las instancias. La Dirección del establecimiento con la autorización de la Supervisión de Educación Musical, permitió la realización de las sesiones en días y horarios extras a los establecidos para las clases regulares de música. Los niños participantes del estudio no conocían el investigador hasta el momento del sorteo.

\section{V.2. DESARROLLO EXPERIMENTAL}

Para el desarrollo experimental de este proyecto se elaboró un test sobre el atributo "forma musical" y se sometió a control por medio de un panel de expertos y otro panel de niños entrenados de la misma edad de la muestra.

Posteriormente se realizaron las sesiones experimentales bajo el formato Pre-test, Post-test, entre las cuales el grupo experimental recibió tres sesiones de entrenamiento específico sobre el tema y el grupo control recibió tres sesiones cuyo desarrollo siguió las pautas de la planificación suministrada para este estudio por una docente de música del 
área. Ambos grupos estuvieron a cargo de la investigadora de este proyecto durante el desarrollo de las sesiones inter-test.

\section{V.2.1. Descripción del Test Forma Musical}

\section{V.2.1.1. Consideraciones respecto a las partes del test.}

El test está dividido en dos partes. (Ver Anexo 1 Test impreso)

La Primera Parte consta de tres ítems y cada ítem contiene tres ejemplos para realizar (9 ejemplos musicales)

La metodología a utilizar en la Primera Parte consiste en establecer a partir de la audición una relación entre el ejemplo musical escuchado y un gráfico que representa a través de figuras geométricas los agrupamientos iguales, diferentes o similares.

Primer ítem. Presenta tres ejemplos de dos agrupamientos perceptivos: iguales o diferentes. Para cada ejemplo musical aparecen dos gráficos: uno real y un distractor, y el sujeto indica mediante una cruz el gráfico que según sus formas geométricas corresponde con la forma del ejemplo escuchado. Las posibilidades formales que pueden establecerse son: $\mathrm{a}-\mathrm{a} / \mathrm{a}-\mathrm{b}$.

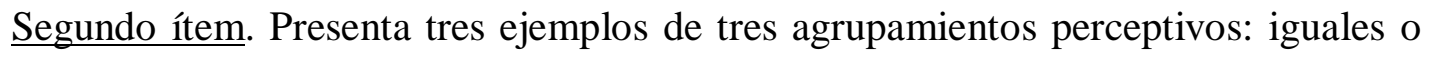
diferentes. Para cada ejemplo musical aparecen tres gráficos: uno real y dos distractores, y el sujeto indica mediante una cruz el gráfico que según sus formas geométricas corresponde con la forma del ejemplo escuchado. Las posibilidades formales que pueden establecerse son: $a-a-b / a-b-b / a-b-a$

Tercer ítem. Presenta tres ejemplos de tres agrupamientos perceptivos: iguales, diferentes o similares. Para cada ejemplo musical aparecen tres gráficos: uno real y dos distractores, y el sujeto indica mediante una cruz el gráfico que según sus formas 
geométricas corresponde con la forma del ejemplo escuchado. Como en este ítem aparece la posibilidad del agrupamiento "similar", este se representa mediante un punto dentro de la forma geométrica. Las posibilidades formales que pueden establecerse son: $a-a^{\prime}-b / a-b-b^{\prime} /$ a-b-a'.

La Segunda Parte consta de un ítem y este contiene tres ejemplos para realizar. Se realiza en una hoja separada de la primera parte. Al terminar la primera parte se retiran las hojas, se realiza un breve comentario y descanso como para distender y renovar la atención. A posteriori se entrega la segunda parte.

La metodología a realizar en la Segunda Parte consiste en graficar a partir de la audición los agrupamientos perceptivos presentes en el ejemplo musical escuchado. Cada ejemplo presenta tres agrupamientos y pueden ser iguales, diferentes o similares. La gráfica que se les pide que utilicen corresponde con la utilizada en la primera parte, es decir figuras geométricas.

\section{V.2.1.2. Puntajes asignados}

En la Primera Parte del Test cada ejemplo musical se puntúa con:

- 1 punto: si reconoce a partir de la audición la asociación entre ejemplo musical y gráfico

- 0 punto: si no reconoce a partir de la audición la asociación entre ejemplo musical y gráfico

Puntaje máximo por cada item: 3 puntos

Puntaje máximo de la Primera Parte del Test: 9 puntos

En la Segunda Parte del Test cada ejemplo musical se puntúa con:

- 2 puntos: si reconoce y grafica en la ubicación correcta los agrupamientos iguales, diferentes y variados. 
- 1 punto: si solo reconoce y grafica en la ubicación correcta los agrupamientos iguales y diferentes, sin advertir la variación.

- 0 punto: cuando no reconoce ni grafica en la ubicación correcta los agrupamientos iguales, diferentes o variados.

Puntaje máximo de la Segunda Parte: 6 puntos

\section{Puntaje total del Test: 15 puntos.}

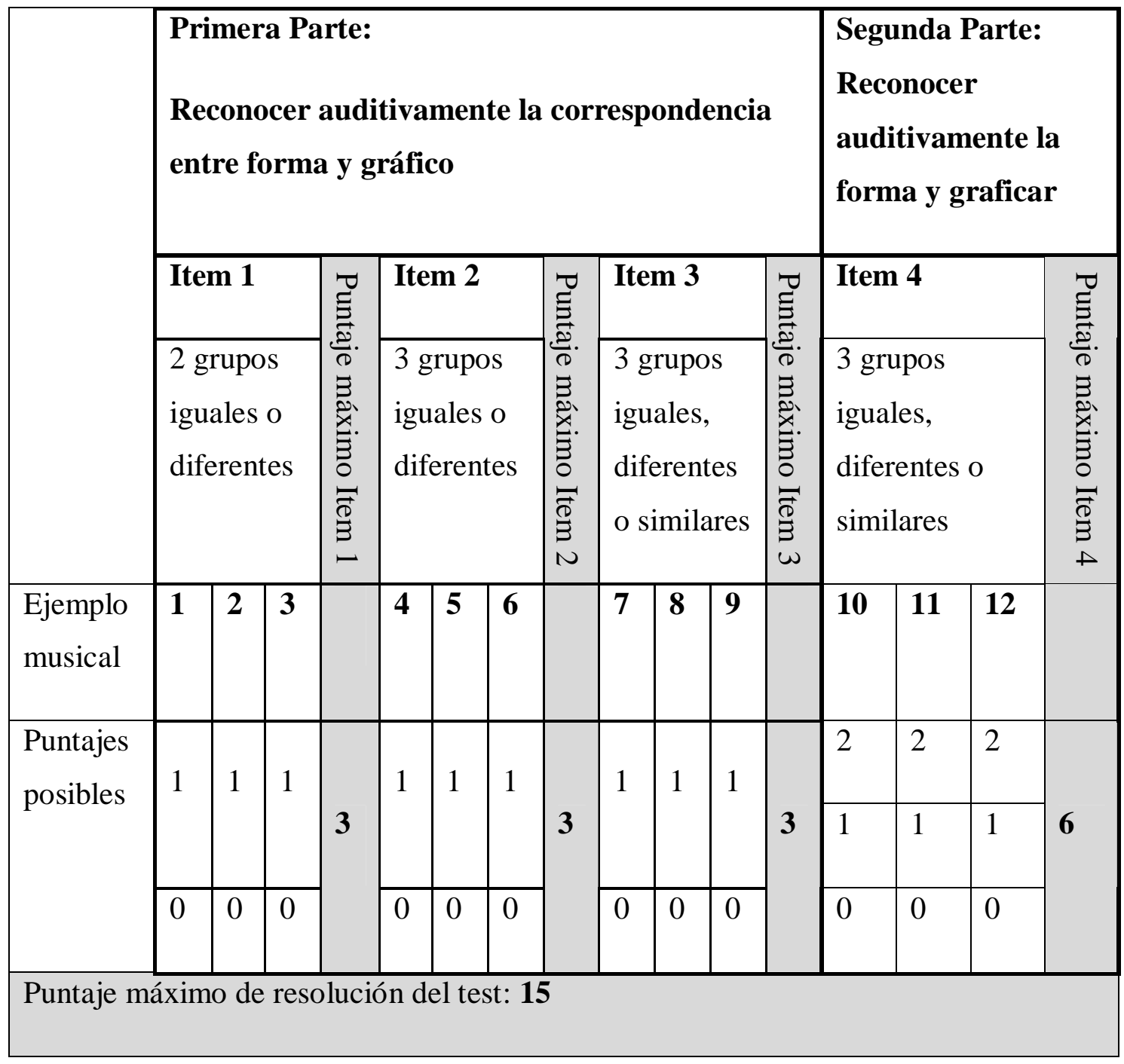




\section{V.2.1.3. Criterios de selección y realización de los ejemplos musicales.}

Los ejemplos musicales fueron elegidos o compuestos especialmente para el test y se corresponden con los siguientes criterios:

e. Música instrumental

f. Agrupamientos perceptivos claramente diferenciados por características rítmico- melódicas y tímbricas. Agrupamientos perceptivos claramente similares por variación rítmico- melódica.

g. Agrupamientos relacionados de forma independiente

h. Igual extensión en todos los agrupamientos: 8 tactus

i. Duración aproximadamente similar: de 6 a 8 segundos en los ejemplos de dos agrupamientos y de 12 a 16 segundos en los ejemplos de tres agrupamientos.

j. Tempo moderado

Los ejemplos realizados especialmente para el test fueron compuestos melódicamente por la autora del proyecto. A posteriori sobre las melodías originales se realizan versiones con arreglos armónicos e instrumentales cuya creación, mezcla y edición digital se produjo en formato MIDI con el programa editor y procesador de sonido REASON 5 a cargo de un especialista en el área ${ }^{48}$.

Los ejemplos elegidos e insertados en el test fueron:

- $\quad$ Ejemplo 2: Merrie Melodies. Looney Tunes. Tema de Apertura. Fragmento.

- Ejemplo 3: Haendel. Concierto para órgano N¹3 Op.4. El cucú y el ruiseñor. Allegro. Fragmento.

- $\quad$ Ejemplo 6: Collegium Musicum. Danza Indoeuropea №5. Fragmento.

${ }^{48}$ Sr. Eduardo Varela 
- $\quad$ Ejemplo 10: Tradicional EEUU. Oh Susana. Fragmento. Versión arreglada y procesada digitalmente en REASON 5 formato MIDI.

(Escuchar Anexo Audio Ejemplos Musicales del Test)

\section{V.2.1.4. Cuestiones a evaluar}

Qué grado de realización del test permite distinguir entre entrenamiento (del grupo experimental) y el conocimiento por enculturación?

En qué medida colaboró la instrucción específica sobre las estrategias en la realización del post-test?

Podría establecerse una tendencia a través de los resultados individuales respecto a la aplicación de las estrategias entrenadas?

Es posible representar el conocimiento musical en un lapso de tiempo limitado como es el del entrenamiento del grupo experimental?

En qué medida colabora en el proceso de traducción a formato representacional grafico la respuesta construida (tener el dibujo a la vista, primera parte del test) o la respuesta a construir (tener que graficarlo directamente desde el estímulo musical, segunda parte del test)?

\section{V.2.2. Paneles Convocados}

Panel de expertos y Panel de niños entrenados

Los paneles de expertos y de niños entrenados fueron convocados para resolver el test, previo a su implementación en los grupos experimental y control, bajo la misma modalidad en que se implementaría con ellos. 
El panel de expertos estuvo integrado por cinco profesores que dictan la asignatura Lenguaje Musical en diferentes niveles de la Carrera Intérprete Musical del Departamento de Música de la UNSJ. La convocatoria al grupo de expertos obedeció a la necesidad de evaluar el test en los términos de fiabilidad de los criterios de selección de los ejemplos musicales.

El panel de niños entrenados estuvo integrado por doce alumnos del II Ciclo Módulo B de la Carrera Intérprete Musical del Departamento de Música de la UNSJ. La elección de este curso respondió a la correspondencia con las edades de los grupos experimental y control, por ello su convocatoria intentó evaluar la fiabilidad del test respecto a las posibilidades de resolución de la edad testeada.

\section{V.2.3. Diseño de la prueba experimental}

Formato: Pre-test, Post-test

Tratamiento: Además de las sesiones destinadas a pre-test y post-test, se realizaron tres sesiones inter-test, con diferente tratamiento entre grupo experimental y control, de cuarenta minutos cada una e impartidas en ambos grupos por la investigadora responsable del proyecto. La planificación para cada una de las tres sesiones del grupo control fue proporcionada por una educadora musical ${ }^{49}$ de otro establecimiento con experiencia en quinto año. Se le solicitó su colaboración a través de facilitar tres de las planificaciones que normalmente desarrolla para trabajar el contenido forma musical. Estas planificaciones fueron desarrolladas con el grupo control por la investigadora del trabajo.

Las planificaciones para las sesiones del grupo experimental fueron desarrolladas enfatizando un entrenamiento direccional, multisensorial (auditivo, kinésico, visual) y concreto, a través de traducir la variedad de ejemplos musicales en diferentes formatos

\footnotetext{
${ }^{49}$ Profesora Universitaria en Educación Musical Luci Ferrarini
} 
representacionales, concluyendo en la simbolización a través de distintas grafías analógicas: figuras geométricas, arcos, números y letras.

Cronograma: Los cinco encuentros se realizaron con una frecuencia de dos por semana desde el 25 de octubre al 7 de noviembre de 2013. Las sesiones se realizaban de manera continuada. El grupo experimental en la segunda parte del primer módulo horario hasta su finalización, indicado por el timbre del recreo. El grupo control en la primera parte del segundo módulo al terminar el primer recreo.

Lugar: en el salón de clases habitual, el cual disponía de bancos individuales con suficiente espacio entre ellos para trabajar de manera independiente y áreas libres para la realización de ejecuciones y desplazamientos.

A continuación se describen las características de la implementación del test y las sesiones inter-test con el grupo experimental.

\section{V.2.3.1. Implementación del Test}

Situación de la prueba: al iniciar la experiencia los alumnos se disponían en hileras de bancos separados para trabajar individualmente sin posibilidad de observar las respuestas de otros compañeros. Se les solicitaba que guardaran los útiles pertenecientes a otras asignaturas y que tuvieran a mano lápiz y goma. Se les entregaba la primera parte del test consistente en tres hojas, una para cada punto de la primera parte.

Con el test a la vista se leía la consigna del primer punto, aclarando los recuadros donde debían consignar la respuesta y la necesidad de elegir solo una posibilidad. Se les explicaba que podían colocar su nombre en la hoja del test o un seudónimo, pero que tanto en el pre-test como en el post-test debían mantener la denominación elegida. Se les advertía del carácter no evaluativo del test, haciendo hincapié en que las respuestas que pudieran consignar nos servirían para comprender las resoluciones posibles en chicos de su edad. 
Sin más explicaciones que la relativa a la cantidad de audiciones por ejemplo (tres en total) y del tiempo que tendrían entre ellas para pensar y escribir su respuesta, se procedía a la realización de la primera parte del test. Se recogían las hojas, se les daba unos minutos para distraerse mientras se organizaba el material recolectado y se procedía a entregar la segunda parte del test. Se les explicaba que el procedimiento era similar al anterior pero que en ese caso debían ellos graficar valiéndose de las mismas figuras geométricas que se utilizó en la primera parte del test, aclarando que no es la única manera, sino que respondía a la necesidad de unificar la manera de expresar las respuestas.

Equipamiento para la prueba: Netbook HP, equipo de amplificación Ciclos SF-2201 PMPO watt 2000 y test impreso para cada sujeto.

\section{V.2.3.2. Sesiones con el Grupo Experimental}

Criterios de selección de los ejemplos para las sesiones: Los ejemplos musicales utilizados durante el desarrollo de las sesiones con el grupo experimental fueron seleccionados según los criterios establecidos para la realización del test. En el test la cantidad máxima de agrupamiento era de tres y algunos de los abordados en las sesiones contenían cuatro, con la finalidad de intensificar en el entrenamiento el trabajo de la memoria. En general se seleccionó música instrumental, en tempo moderado, agrupamientos claramente diferenciados, de 8 tactus, relacionados de forma independiente.

Descripción de las sesiones con el Grupo Experimental: El desarrollo de cada sesión consistió en la presentación de ejemplos musicales y una secuenciación de actividades que partió de la audición y a través de indicios focalizaba la atención en los agrupamientos perceptivos proponiendo una serie de acciones tendientes a reforzar las estrategias cognitivas implicadas en la representación y simbolización de la forma musical. 


\section{LA COMPRENSIÓN DE LA ESTRUCTURA MUSICAL. \\ LA REPRESENTACIÓN UTILIZADA EN NIÑOS ENTRE 10 Y 11 AÑOS.}

Proveer de indicios durante la audición implica "conciliar palabras y gestos interpolados con precisión temporal" (Furnó, 2005:87). Estos colaboran en concentrar la atención en el rasgo musical objeto de estudio y funcionan como andamiaje, en el sentido en que lo propone Bruner, como estrategias docentes que orientan el pensamiento del sujeto en la construcción del conocimiento (Bruner, 1995) ${ }^{50}$.

A partir de la música se propusieron diferentes modalidades de representación externa que colaborasen en la representación interna. Algunas de estas modalidades fueron comunes para todos los ejemplos musicales abordados, creando una secuencia de trabajo que finalizaba en cada caso con propuestas diferentes de ejecución. Estas aportaban una dinámica particular a cada ejemplo propuesto, un formato representacional diferente y la posibilidad de corroborar el grado de comprensión de los sujetos a partir de sus desempeños en tales propuestas. Entre ellas se encuentraban: desplazamientos en el espacio, desplazamiento de objetos, percusión corporal, juegos de manos y ejecución instrumental, atendiendo y representando en cada caso a la estructura formal de la música.

Respecto a las modalidades comunes trabajadas en todos los casos se destacó el indicar levantando la mano el inicio de cada grupo, indicar audiblemente, dibujar con arcos en el aire acompañando el transcurrir temporal de los agrupamientos, trasladar esos arcos a la gráfica siguiendo la música en tiempo real como modalidad de transición, a través del movimiento, entre la abstracción temporal de la música y la gráfica concreta de su simbolización. Otras modalidades fueron el canto, capitalizando la pregnancia perceptiva del contorno melódico y la verbalización de las características de cada agrupamiento a través de la comparación de los mismos, reflejando las apreciaciones en gráficos con figuras geométricas, letras y números, sobre los arcos ya propuestos.

La sesión finalizaba con dos ejemplos musicales a modo de control evaluativo. Para cada uno de ellos los sujetos debían advertir a partir de la audición la forma y graficar utilizando cualquiera de las modalidades de simbolización trabajadas durante la sesión.

\footnotetext{
${ }^{50}$ En Furnó (2005)
} 
Para ello se les entregaba una hoja y al finalizar el trabajo la regresaban al evaluador. Las evaluaciones corregidas eran entregadas a la clase siguiente con una devolución de las dificultades encontradas y una puesta en común sobre las estrategias posibles de utilizar.

Instrumentos Informáticos: Los fragmentos utilizados como ejemplos fueron editados con el programa Adobe Audition 3.0 versión 2007. En algunos casos se grabaron dos versiones, una, la del fragmento específico para determinar la forma y otra con el fragmento repetido sin solución de continuidad para el trabajo de ejecución sobre la música grabada en tiempo real.

Materiales: tizas de colores, pelota e instrumentos: sonajas, palo de agua, celestín triángulos, claves, cajas chinas, bombo, bongó y pandero.

Equipamiento: Netbook HP, equipo de amplificación Ciclos SF-2201 PMPO watt 2000 y cañón proyector HP.

\section{V.2.3.2.1. Primera Sesión: 29 de Octubre de 2013}

La primera sesión comenzó rescatando la analogía entre el lenguaje hablado y el musical a través de la posibilidad de segmentar el discurso en ideas o frases musicales. Continuó con la secuenciación prevista para cada ejemplo finalizando el trabajo sobre cada uno con la propuesta de ejecución específica. La sesión finalizó con el control evaluativo. Las obras propuestas para esta instancia fueron:

- Dvorak. Sinfonía N99 del Nuevo Mundo Allegro con fuoco Fragmento A Á

- Tradicional España. Sarian sun sun. A A B. Extraído del cancionero "Para divertirnos cantando" de V.H. de Gainza (1973). Versión arreglada y procesada digitalmente en REASON 5 formato MIDI.

Ejemplos musicales: Escuchar Anexo Audio "Ejemplos Musicales Primera Sesión Grupo Experimental". 
Estructura de la Primera Sesión: El desarrollo detallado se encuentra en el Anexo 2 "Planificación Primera Sesión Grupo Experimental"

\begin{tabular}{|c|c|c|c|}
\hline Ejemplo Musical & Forma & $\begin{array}{l}\text { Formato } \\
\text { Representacional } \\
\text { manifiesto }\end{array}$ & Simbolización \\
\hline $\begin{array}{l}\text { Tradicional "El juego de la Oca" } \\
\text { (versión arreglada y procesada } \\
\text { digitalmente en REASON } 5 \\
\text { formato MIDI) }\end{array}$ & A A & \multirow{5}{*}{$\begin{array}{l}\text { Auditivo musical } \\
\text { Verbal } \\
\text { proposicional } \\
\text { Visual }\end{array}$} & \multirow[t]{5}{*}{$\begin{array}{l}\text { Arcos, figuras } \\
\text { geométricas, letras y } \\
\text { números. }\end{array}$} \\
\hline $\begin{array}{l}\text { "Bizet. Ópera Cármen. Suite } \mathrm{N}^{\circ} 1 . \\
\text { Los Toreadores, fragmento" }\end{array}$ & $\mathrm{A} \mathrm{A}$ & & \\
\hline $\begin{array}{l}\text { "Tchaikovsky. } \quad \text { Suite } \\
\text { Cascanueces, Op.71A Danza } \\
\text { China" fragmento }\end{array}$ & $\mathrm{ABAB}$ & & \\
\hline $\begin{array}{l}\text { "Tchaikovsky. Suite El } \\
\text { Cascanueces, Op.71A Obertura } \\
\text { Miniatura" fragmento }\end{array}$ & $\mathrm{A} \mathrm{A}^{\prime}$ & & \\
\hline $\begin{array}{l}\text { Offenbah. Can Can de la ópera } \\
\text { Orfeo en los infiernos, fragmento }\end{array}$ & $\mathrm{A} \mathrm{A}^{\prime}$ & & \\
\hline
\end{tabular}

\section{V.2.3.2.2. Segunda Sesión: 31 de Octubre de 2013}

La segunda sesión comienzó con la devolución de las evaluaciones de cierre realizadas la primera sesión. El desarrollo continuó de manera similar al de la sesión precedente en relación a la secuenciación pedagógica, los materiales, equipamiento utilizados y la propuesta de ejecución diferente para cada ejemplo musical propuesto. En esta sesión se abordó la posibilidad de reagrupar los agrupamientos perceptivos, advirtiendo la característica jerárquica y recursiva de la estructura formal. También se indicó la 
posibilidad de "medir" los agrupamientos, determinando su extensión y corroborando su equilibrio formal.

Al finalizar la sesión se realizó el control evaluativo a través de los siguientes ejemplos:

- Saint Saens. Carnaval de los animales. Fósiles, fragmento AA'

- Haendel Sinfonía en Do $1^{\circ}$ mov. fragmento AAB

Ejemplos musicales: Escuchar Anexo Audio "Ejemplos Musicales Segunda Sesión Grupo Experimental".

Estructura de la Segunda Sesión: El desarrollo detallado se encuentra en el Anexo 3 "Planificación Segunda Sesión Grupo Experimental"

\begin{tabular}{|c|c|c|c|}
\hline Ejemplo Musical & Forma & $\begin{array}{l}\text { Formato } \\
\text { Representacional } \\
\text { manifiesto }\end{array}$ & Simbolización \\
\hline $\begin{array}{lr}\text { Bizet. } & \mathrm{La} \\
\text { Artesiana. } & \text { Suite } \\
\mathrm{N}^{\circ} \text { 1 Carrillón } & \end{array}$ & $\mathrm{A} \mathrm{A}^{\prime}$ & \multirow{4}{*}{$\begin{array}{l}\text { Auditivo musical } \\
\text { Verbal o proposicional } \\
\text { Visual } \\
\text { Kinético }\end{array}$} & \multirow{4}{*}{$\begin{array}{l}\text { Arcos, figuras } \\
\text { geométricas, letras y } \\
\text { números. }\end{array}$} \\
\hline $\begin{array}{l}\text { Tchaikovsky. Suite } \\
\text { El Cascanueces. } \\
\text { Marcha }\end{array}$ & $\begin{array}{lrr}\mathrm{a} & \mathrm{a} & \mathrm{b} \\
8 & 8 & 16 \\
& & \\
\text { A } & \mathrm{B}\end{array}$ & & \\
\hline $\begin{array}{l}\text { Banda de la } \\
\text { película "El Golpe" }\end{array}$ & $\begin{array}{l}a b a b^{\prime} a b \\
\text { A B A }\end{array}$ & & \\
\hline $\begin{array}{l}\text { Carnavalito "La } \\
\text { Humahuaqueña" }\end{array}$ & A A B B & & \\
\hline
\end{tabular}




\section{V.2.3.2.3. Tercera Sesión: 5 de Noviembre de 2013.}

Al inicio de esta sesión se realizó las devolución de las evaluaciones de control de la segunda sesión. A continuación se entregó una guía de audición impresa a cada sujeto. (Ver Anexo 4 "Guía de Audición")

La guía proponía determinar a través de la audición la forma musical relacionándola con distintos tipos de gráficos analógicos a través de figuras geométricas, arcos, corchetes e imágenes. En algunos casos debían completar los gráficos incompletos del ítem siguiendo la propuesta gráfica realizada por la guía y en otros casos realizarlos completamente eligiendo la simbolización a utilizar. La guía contenía nueve ejemplos distribuidos en dos páginas.

Al finalizar el trabajo en cada ejemplo se presentaba un power point con animación en tiempo real sobre la música, como formato representacional multimodal. (Ver Anexo 5 "Presentaciones multimodales Tercera Sesión")

Los ejemplos musicales abordados en la guía fueron:

- Tradicional. Carnavalito "La Humahuaqueña" versión Los Nocheros

- Pro Música $N^{\circ} 10$ "Con la música a todas partes” Track 10 Danza

- Carnavalito Simple. Creado, arreglado y procesado digitalmente en REASON 5 formato MIDI

- Vivaldi. Concierto para Violín "La Primavera", $1^{\circ}$ movimiento.

- Grieg. Suite Peer Gynt. $N^{\circ} 1$, op. 46. Danza de Anitra

- Bizet. Ópera Carmen. Aragonesa

- Pro Música N5. "El Pro Música de Rosario le canta a los niños del mundo" Track 01 Danza de los Moros. AA'BB'AA'

- Bahms. Danza Húngara N5,

- Pro Música $\mathrm{N}^{\circ} 10$ “Con la Música a todas partes” Track 06 Canción para un árbol de río

Ejemplos musicales: Escuchar Anexo Audio "Ejemplos Musicales Tercera Sesión Grupo Experimental". 


\section{CAPÍTULO VI}

\section{RESULTADOS}

Este capítulo muestra los resultados comparando los desempeños manifestados en pre y post-test entre grupo experimental (GE) y grupo control (GC). Se presentan a través de cinco puntos: i) análisis de la variable A, ii) análisis de la variable $\mathrm{B}$, iii) comparación variable A y B, iv) desarrollo general de cada grupo y v) resultados generales. Para la elaboración de este capítulo se contó con el asesoramiento de una experta en el área ${ }^{51}$.

En el primer punto se presentan los resultados obtenidos en la primera parte del test que pertenecen a la variable $A$, a través de sus sub-variables en términos de promedios de resolución. A continuación se presenta el desarrollo de cada sub-variable en particular y de la variable A en general.

Se entiende por desarrollo la tasa o índice de crecimiento entre pre y post-test en cada grupo y para cada aspecto a considerar (cada sub-variable, cada variable y el test en general). Incluimos el análisis de la tasa de desarrollo debido a las características particulares que presentaron ambos grupos, ya que el grupo control partió en el pre-test con un puntaje significativamente mayor al del grupo experimental y en general mantuvo mayores puntajes en el post-test. Por lo cual el promedio de resolución de cada grupo a partir de los puntajes obtenidos, no mostraba comparativamente el progreso en el aprendizaje entre ambos grupos. El análisis del desarrollo intenta evaluar justamente este aspecto.

\footnotetext{
${ }^{51}$ Dra. Susana Ozán.
} 
En el segundo punto se presentan los resultados obtenidos en la segunda parte del test que pertenecen a la variable $\mathrm{B}$, siguiendo los pasos del análisis realizado para la variable A. El tercer punto presenta la comparación de los valores medios obtenidos en cada grupo y la dispersión de los mismos, la comparación de ambas variables en cada grupo y con respecto a los resultados obtenidos a partir del panel convocado de niños entrenados. Se verifica el nivel de significación en el aumento del rendimiento medio entre pre y posttest mediante estadístico de pruebas pareadas. El cuarto punto describe el desarrollo general de cada grupo y su comportamiento respecto a las diferencias de puntajes y desarrollo obtenidos. Finalmente se presentan resultados generales.

\section{VI.1. ANÁLISIS DE LA VARIABLE A}

\section{VI.1.1. Comparación de sub-variables de A}

El cuadro 1 muestra el promedio de resolución de la muestra en cada sub-variable de A, expresado en porcentaje.

Cuadro 1

\begin{tabular}{|l|l|l|l|l|l|l|}
\hline \multicolumn{2}{|l|}{ PRE-TEST } & \multicolumn{2}{l|}{ POST-TEST } \\
\hline & A1 & A2 & A3 & A1 & A2 & A3 \\
\hline Grupo Experimental & 54 & 33 & 29 & 88 & 57 & 47 \\
\hline Grupo Control & 57 & 44 & 33 & 86 & 63 & 66 \\
\hline
\end{tabular}


Gráfico 1

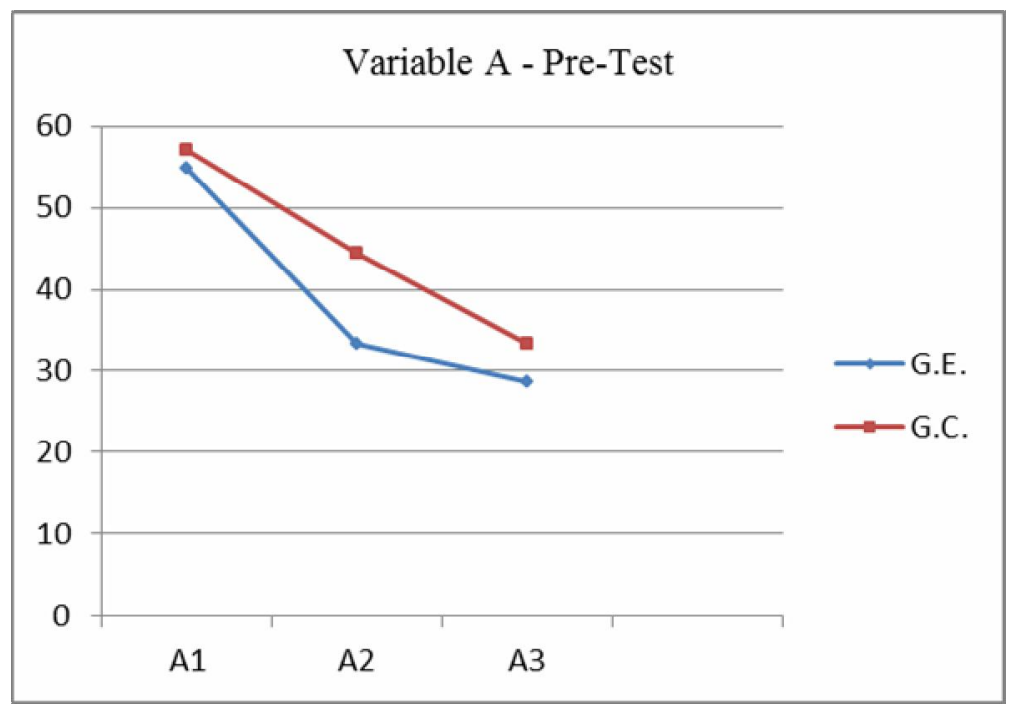

El grafico 1 muestra el comportamiento en las sub-variables de A, durante el PreTest: para ambos grupos, una disminución del desempeño desde A1 a A3, con una mejor resolución en la discriminación auditiva de los ejemplos musicales de dos frases (A1). Resultó más complejo la discriminación auditiva en ejemplos musicales de tres frases (A2) y en mayor medida en la variación de frase (A3).

\section{Gráfico 2}

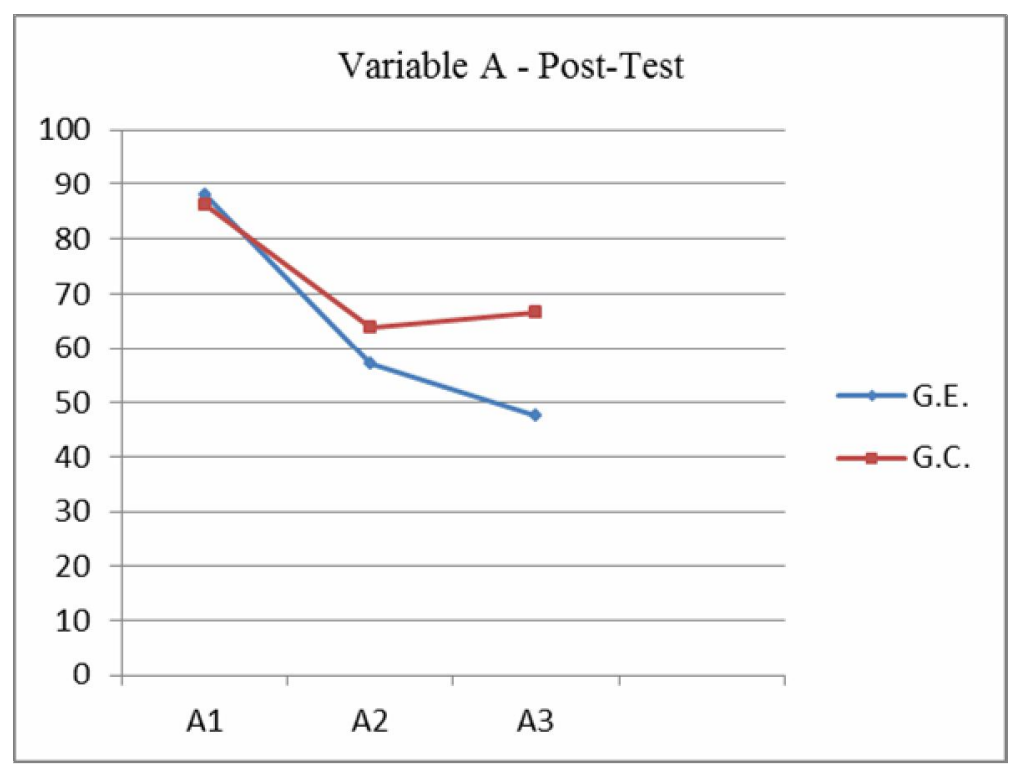


El gráfico 2 muestra el comportamiento de cada sub-variable de A durante el PostTest. Se observa un mejor desempeño en ambos grupos (respecto al Pre-Test), manteniéndose en general la misma relación de dificultad entre las sub-variables en el grupo experimental y mejorando el desempeño para la sub-variable A3 en el grupo control.

El cuadro 2 muestra el promedio de resolución de cada grupo respecto a la variable A en general y la relación entre pre y post-test.

Cuadro 2

\begin{tabular}{|l|l|l|}
\hline \multicolumn{2}{|c|}{ VARIABLE A } \\
\hline & PRE-TEST & POST-TEST \\
\hline Grupo Experimental & 38,88 & 64,28 \\
\hline Grupo Control & 55,86 & 72,21 \\
\hline
\end{tabular}

Gráfico 3

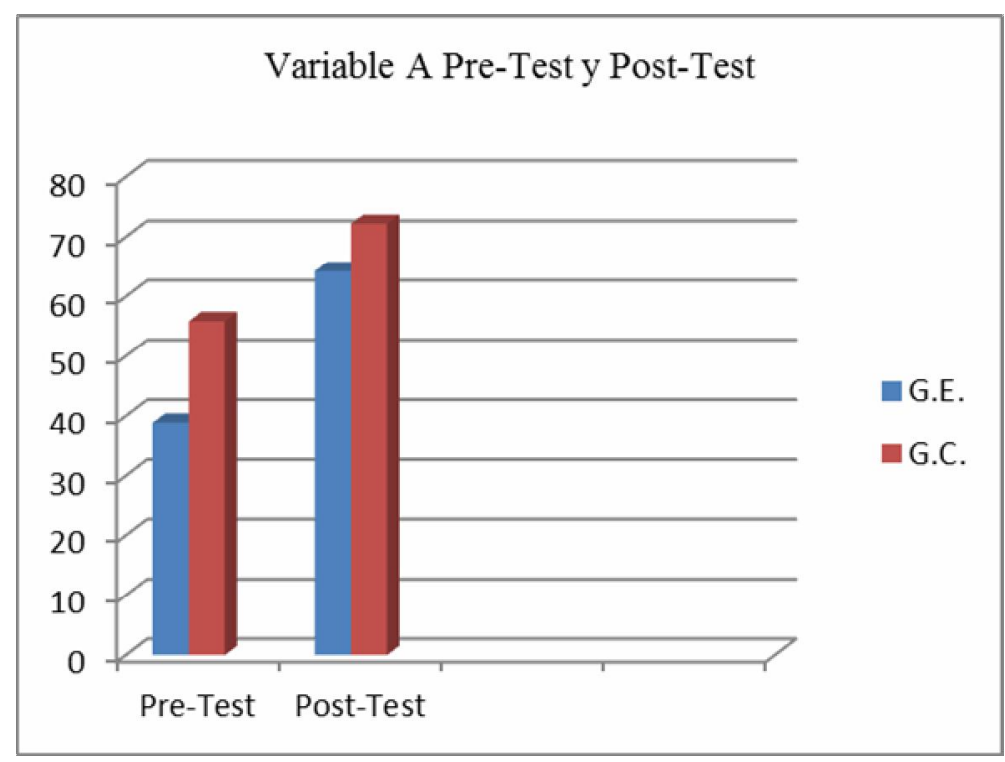


El gráfico 3 muestra el promedio de resolución general de la variable A entre pre y post-test en ambos grupos. Se observa un mejor desempeño en el post-test.

\section{VI.1.2. Desarrollo de las Sub-Variable de A}

A continuación se analiza la variación en el desempeño entre el Pre-Test y Post-Test para cada una de las sub-variables de A, en grupo experimental y control. Como se observa en el gráfico 3 cada grupo parte de diferente grado de resolución en la tarea: el grupo control muestra mayor puntaje y por lo tanto mayor promedio de resolución. Para indagar el crecimiento relativo desde el nivel del cual parte cada grupo en el pre-test, se calcula la Tasa de Desarrollo para cada una de las Sub-variables de A. Las cifras indican promedio de resolución expresado en porcentaje para cada sub-variable y la tasa de desarrollo indica promedio de crecimiento entre pre y post-test expresado también en porcentaje.

Cuadro 3

\begin{tabular}{|l|c|c|c|}
\hline \multirow{2}{*}{\multicolumn{1}{|c|}{ GRUPO EXPERIMENTAL }} & \multicolumn{3}{c|}{ VARIABLE A } \\
\cline { 2 - 4 } & A1 & A2 & A3 \\
\hline PRE-TEST & 54 & 33 & 28 \\
\hline POST-TEST & 88 & 57 & 47 \\
\hline TASA DE DESARROLLO & 60 & 71 & 66 \\
\hline
\end{tabular}


Cuadro 4

\begin{tabular}{|l|c|c|c|}
\hline \multicolumn{1}{|c|}{ GRUPO CONTROL } & \multicolumn{3}{c|}{ VARIABLE A } \\
\cline { 2 - 4 } & A1 & A2 & A3 \\
\hline PRE-TEST & 57 & 44 & 33 \\
\hline POST-TEST & 86 & 63 & 66 \\
\hline TASA DE DESARROLLO & 50 & 43 & 100 \\
\hline
\end{tabular}

Gráfico 4

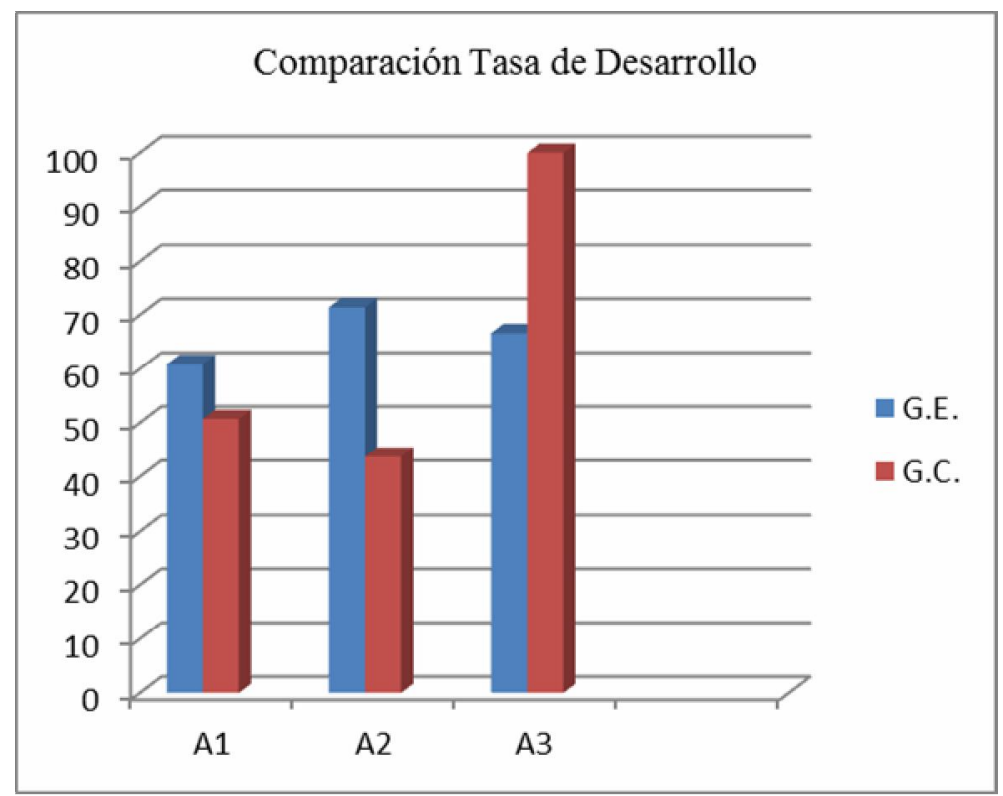

El gráfico 4 muestra un mayor crecimiento en la resolución de las sub-variables A1 y A2 en el grupo experimental entre Pre y Post-Test. Sin embargo en la sub-variable A3 aparece un mejor rendimiento en la resolución de la tarea en el grupo control. 


\section{VI.1.3. Desarrollo de la Variable A}

El cuadro 5 muestra el promedio general del desempeño en la resolución de las actividades planteadas en la variable A, y el desarrollo logrado por cada grupo entre PreTest y Post-Test. Se puede apreciar que en general el mejor desarrollo lo realizó el grupo experimental.

Cuadro 5

\begin{tabular}{|l|c|c|c|}
\hline \multicolumn{4}{|c|}{ VARIABLE A } \\
\hline & PRE-TEST & POST-TEST & TASA DE DESARROLLO \\
\hline GRUPO EXPERIMENTAL & 38 & 64 & $65 \%$ \\
\hline GRUPO CONTROL & 44 & 72 & $60 \%$ \\
\hline
\end{tabular}

\section{VI.2. ANÁLISIS DE LA VARIABLE B}

Dado el tipo de tarea requerida en la segunda parte del Test que corresponde a la variable B en la que se solicita al sujeto que reconozca auditivamente la forma musical y además la grafique (a diferencia de la Variable A que solo reconocen y aparean con un gráfico ya realizado), se presenta la posibilidad de varios tipos de respuesta para un mismo ejemplo, lo que representa distintos puntajes. 
- 2 puntos: si reconoce y grafica en la ubicación correcta los agrupamientos iguales, diferentes y variados.

- 1 punto: si solo reconoce y grafica en la ubicación correcta los agrupamientos iguales y diferentes, sin advertir la variación.

- 0 punto: cuando no reconoce ni grafica en la ubicación correcta los agrupamientos iguales, diferentes o variados.

\section{VI.2.1. Comparación de las Sub-Variables de B}

Para considerar esta variedad de respuestas en el análisis de la Variable B, se establecieron tres sub-variables:

B1: Resolución total (considerando el porcentaje de la muestra que obtuvo puntaje 2)

B2: Resolución parcial (considerando el porcentaje de la muestra que obtuvo puntaje 1)

B3: Sin Resolución (considerando el porcentaje de sujetos que no lograron resolver la actividad, puntaje 0 )

Cuadro 6

\begin{tabular}{|l|c|c|c|c|c|c|}
\hline & \multicolumn{3}{|c|}{ PRE-TEST } & \multicolumn{3}{c|}{ POST-TEST } \\
\cline { 2 - 7 } & B1 & B2 & B3 & B1 & B2 & B3 \\
\hline Grupo Experimental & 23 & 35 & 40 & 30 & 40 & 28 \\
\hline Grupo Control & 25 & 27 & 47 & 30 & 41 & 27 \\
\hline
\end{tabular}




\section{Gráfico 5}

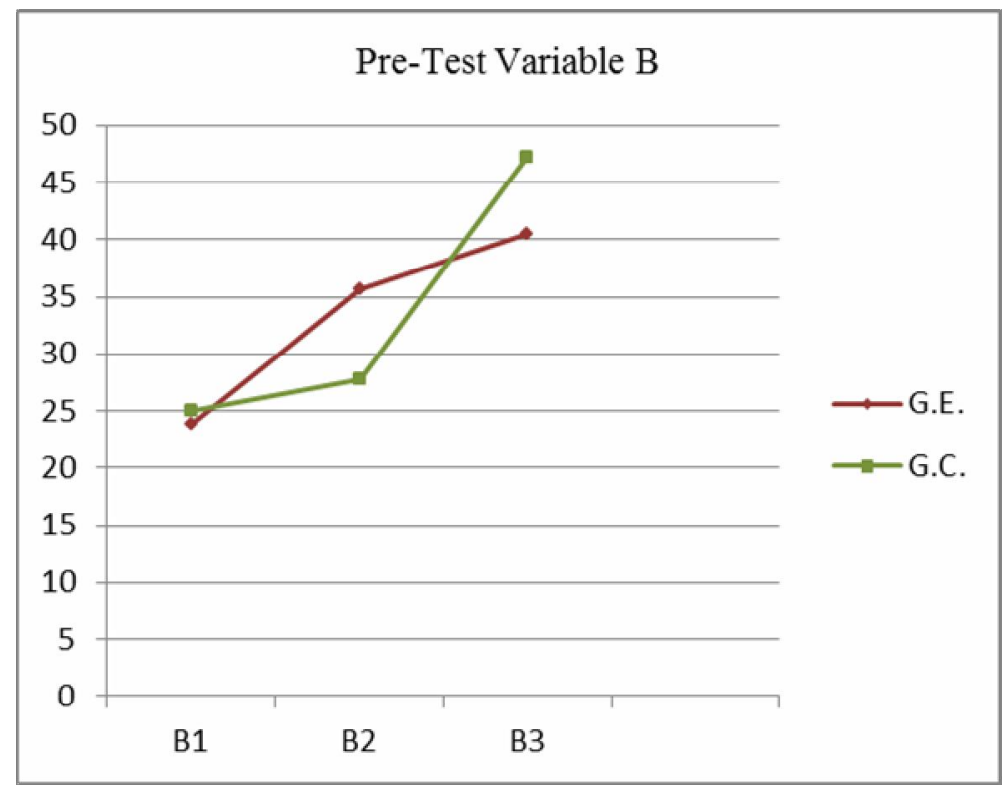

El gráfico 5 muestra un comportamiento similar en ambos grupos durante el Pre-Test, en el que la mayor cantidad de sujetos obtuvo puntaje 0 , en menor cantidad los que obtuvieron puntaje1, es decir la resolución parcial y el grupo más reducido es el que logró obtener el mayor puntaje, es decir la resolución total.

\section{Gráfico 6}

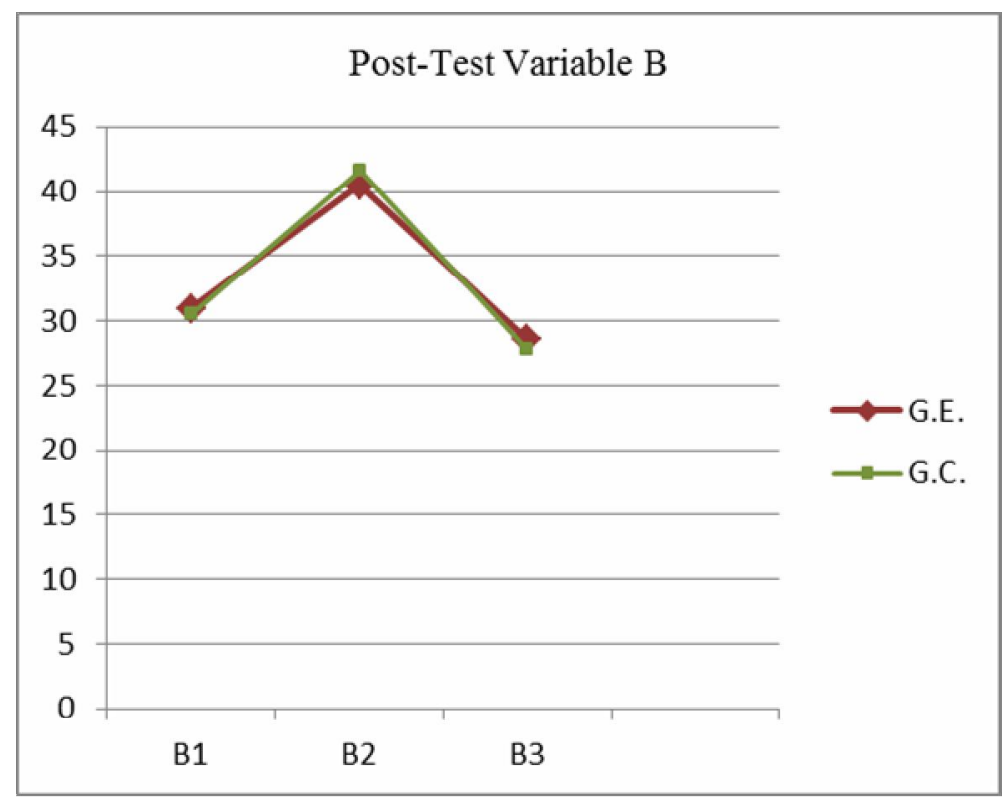


El gráfico 6 muestra que durante el Post-Test ambos grupos presentan una resolución similar en cuanto a los porcentajes de la muestra que obtienen resolución total, parcial y no lo resuelven, siendo mayor el número de sujetos que obtuvo la resolución parcial y menor grupo que no lo resolvió.

Por lo tanto se observa un mejor desempeño en el Post-Test respecto al Pre-Test, ya que aumenta la cantidad de sujetos que obtienen la resolución total y parcial, y menor el número de sujetos que no logra resolverlo.

\section{VI.2.2. Desarrollo de la Variable B}

El cuadro 7 muestra el promedio de resolución general de la variable B para cada grupo en el Pre y Post-Test, y el crecimiento entre ambos.

Cuadro 7

\begin{tabular}{|l|l|l|c|}
\hline \multicolumn{5}{|c|}{ VARIABLE B } \\
\hline & PRE-TEST & POST-TEST & TASA DE DESARROLLO \\
\hline GRUPO EXPERIMENTAL & 41 & 51 & 22 \\
\hline GRUPO CONTROL & 38 & 51 & 32 \\
\hline
\end{tabular}


Gráfico 7

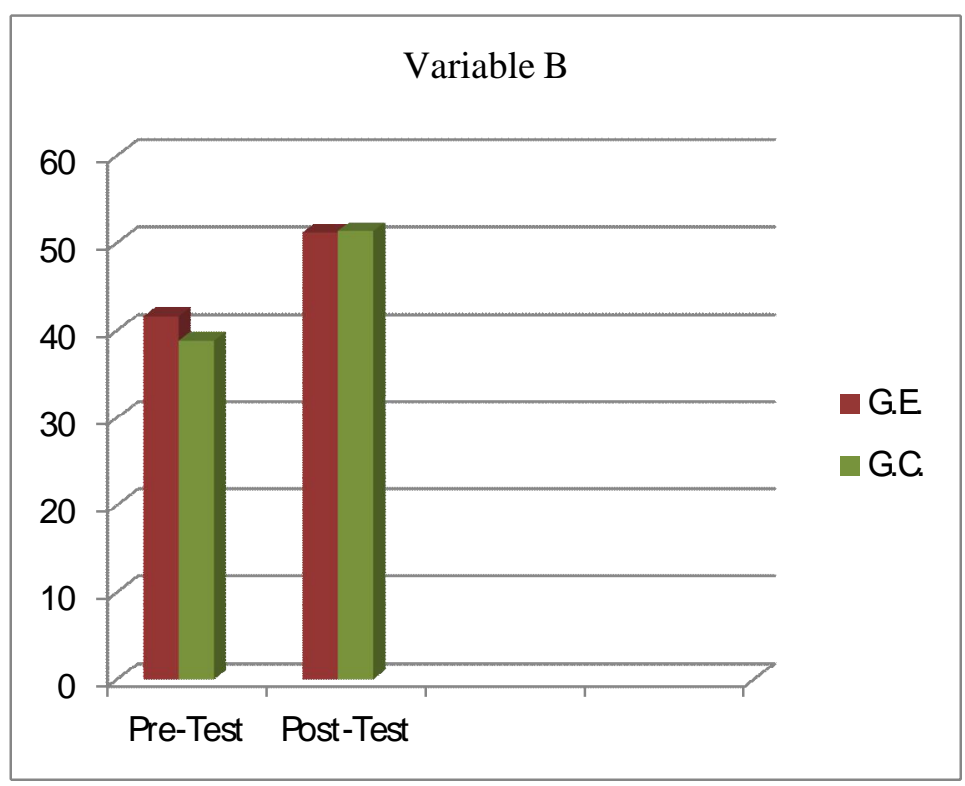

En ambos grupos (Gráfico 7) el promedio de resolución es mayor durante el PostTest, aunque el grupo control muestra una mayor tasa de desarrollo (ver Cuadro 7).

\section{VI.3. COMPARACIÓN VARIABLE A Y B}

\section{VI.3.1. Comparación valores medios}

\section{VI.3.1.1. Valores Medios sub-variables de A}

Cuadro 8

\begin{tabular}{|c|c|c|c|c|c|c|c|c|}
\hline \multirow{3}{*}{ 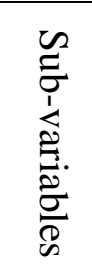 } & \multicolumn{4}{|c|}{ GRUPO EXPERIMENTAL } & \multicolumn{4}{|c|}{ GRUPO CONTROL } \\
\hline & \multicolumn{2}{|c|}{ Pre-test } & \multicolumn{2}{|c|}{ Post-test } & \multicolumn{2}{|c|}{ Pre-test } & \multicolumn{2}{|c|}{ Post-test } \\
\hline & Media & Desv.Típ. & Media & Desv.Típ. & Media & Desv.Típ. & Media & Desv.Típ. \\
\hline A1 & 1,64 & ,929 & 2,64 & ,497 & 1,93 & 1,207 & 2,58 & ,900 \\
\hline A2 & 1,00 & ,784 & 1,71 & 1,069 & 1,29 & 1,069 & 1,92 & 1,084 \\
\hline A3 & ,86 & ,770 & 1,43 & ,938 & 1,07 & ,730 & 2,00 & 1,206 \\
\hline
\end{tabular}


En el cuadro 8 se observa que los valores medios son en general más altos para el grupo control, sin embargo, este grupo también muestra una mayor dispersión de la media, lo que implica que no es una muestra homogénea, sino que existen puntajes que han desviado el promedio.

\section{VI.3.1.2. Valores medios de B}

Cuadro 9

\begin{tabular}{|c|c|c|c|c|c|c|c|c|}
\hline \multirow{3}{*}{$\begin{array}{l}\text { : } \\
\stackrel{0}{0} \\
\frac{\sigma}{\sigma}\end{array}$} & \multicolumn{4}{|c|}{ GRUPO EXPERIMENTAL } & \multicolumn{4}{|c|}{ GRUPO CONTROL } \\
\hline & \multicolumn{2}{|c|}{ Pre-test } & \multicolumn{2}{|c|}{ Post-test } & \multicolumn{2}{|c|}{ Pre-test } & \multicolumn{2}{|c|}{ Post-test } \\
\hline & Media & Desv.Típ. & Media & Desv.Típ. & Media & Desv.Típ. & Media & Desv.Típ. \\
\hline B & 2,63 & 1,500 & 3,07 & 1,592 & 2,71 & 1,939 & 3,08 & 1,505 \\
\hline
\end{tabular}

En la variable B, los valores medios son más estables entre ambos grupos, sobre todo en el post-test, aunque el grupo control presenta la mayor desviación de la media en el pre-test, lo que supone, que el mayor promedio de resolución de la muestra es producto de algunos puntajes más altos y no la característica general del grupo, sino de algunos sujetos que (en este caso) elevan el promedio de la muestra. 


\section{V.3.2. Comparación de desarrollo entre variable A y B}

Cuadro 10

\begin{tabular}{|l|c|c|c|c|c|c|}
\hline & \multicolumn{3}{|c|}{ VARIABLE A } & \multicolumn{3}{c|}{ VARIABLE B } \\
\hline & $\begin{array}{c}\text { PRE- } \\
\text { TEST }\end{array}$ & $\begin{array}{c}\text { POST- } \\
\text { TEST }\end{array}$ & $\begin{array}{c}\text { Tasa de } \\
\text { Desarrollo }\end{array}$ & $\begin{array}{c}\text { PRE- } \\
\text { TEST }\end{array}$ & $\begin{array}{c}\text { POST- } \\
\text { TEST }\end{array}$ & $\begin{array}{c}\text { Tasa de } \\
\text { Desarrollo }\end{array}$ \\
\hline $\begin{array}{l}\text { GRUPO } \\
\text { EXPERIMENTAL }\end{array}$ & 38 & 64 & 65 & 41 & 51 & 22 \\
\hline GRUPO CONTROL & 44 & 72 & 60 & 38 & 51 & 32 \\
\hline
\end{tabular}

Gráfico 8

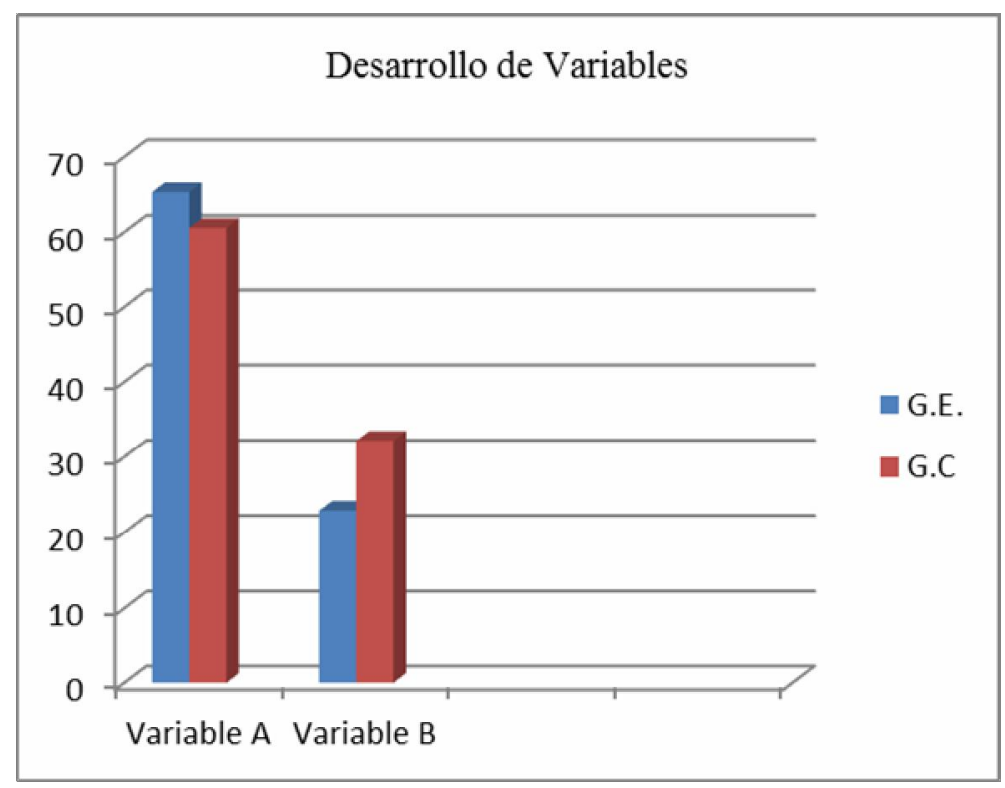


El promedio de resolución para cada variable en cada grupo presenta características diferentes. En el grupo experimental el promedio de resolución para la variable A en el pretest es menor que en la variable $\mathrm{B}$, en cambio en el grupo control el promedio de resolución para la variable A en el pre-test es mayor que en la variable B. Este comportamiento cambia en el post-test y tanto el grupo experimental como el grupo control presentan un mayor nivel de resolución para la variable A en el post-test que para la variable B, lo que puede sugerir una mayor dificultad en la tarea planteada por la variable B.

De esta manera, ambos grupos muestran un mejor desempeño en el post-test en ambas variables, como lo evidencian los gráficos 3 y 7 . Sin embargo el mayor crecimiento se produjo en la variable $\mathrm{A}$, lo cual puede sugerir que las tareas planteadas en los ítems pertenecientes a la variable A resultaron de menor dificultad.

\section{VI.3.3. Desempeños alcanzados por los grupos experimental, control y panel de niños}

\section{Gráfico 9}

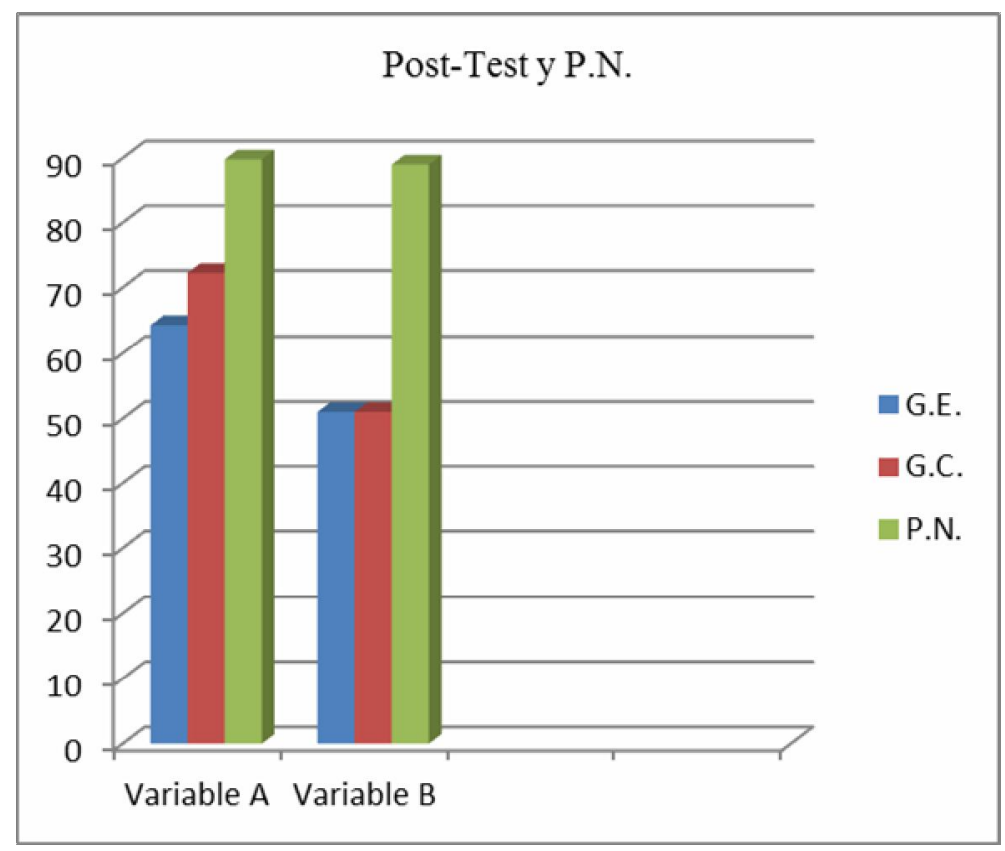


El gráfico 9 muestra los promedios de resolución de los grupos experimental y control durante el post-test, como muestra de los desempeños alcanzados comparándolos con el promedio de resolución del panel de niños entrenados. Se observa en los grupos experimental y control un menor desempeño en la variable B, sin embargo el panel muestra idéntica resolución en ambos tipos de tareas: las propuestas en la variable A y en B.

\section{VI.3.4. Comparación de desempeños en distintos aspectos del test}

Para ampliar las observaciones realizadas anteriormente se propone el siguiente análisis.

Dado que las sub-variables de A y B tienen diferente criterio para evaluar los desempeños. El cuadro 11 compara el promedio de resolución de las sub-variables de A y la variable B en general, Se intenta estimar el grado de dificultad que presenta cada item en relación a las características formales y de tipo de tarea.

Cuadro 11

\begin{tabular}{|l|c|c|c|c|}
\hline & \multicolumn{4}{|c|}{ GRUPO EXPERIMENTAL } \\
\hline & A1 & A2 & A3 & B \\
\hline Pre-Test & 54 & 33 & 28 & 41 \\
\hline Post-Test & 88 & 57 & 47 & 51 \\
\hline
\end{tabular}


Gráfico 10

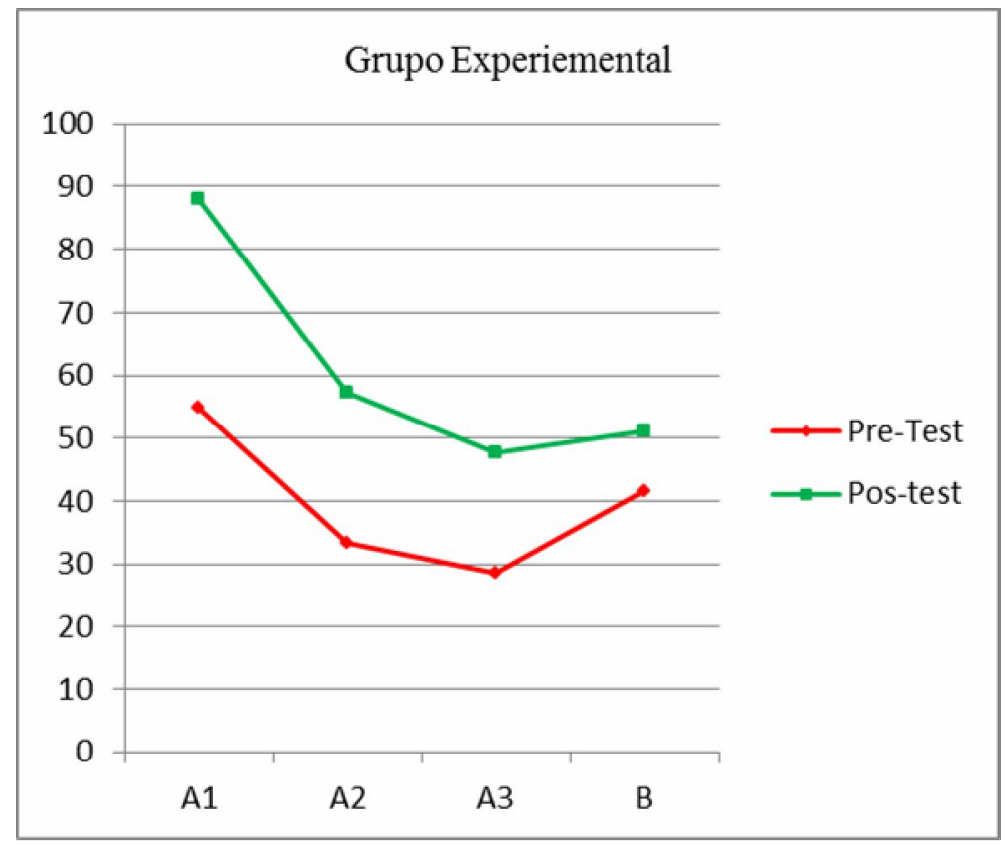

El grupo experimental muestra en general mejor desempeño en el post-test y un nivel de dificultad semejante entre pre y post-test. Las sub-variables de A evidencian un nivel de dificultad creciente y $\mathrm{B}$ parece tener un nivel de dificultad intermedio entre A2 y A3 en el post-test. De hecho B presenta ejemplos musicales con características similares a los utilizados en A2 y A3. Este resultado podría estar indicando que no existe una diferencia significativa entre discriminar auditivamente y relacionar con un gráfico o discriminar auditivamente y graficar, en tanto se remitan a características formales semejantes. 


\section{Cuadro 12}

\begin{tabular}{|l|c|c|c|c|}
\hline & \multicolumn{4}{|c|}{ GRUPO CONTROL } \\
\hline & A1 & A2 & A3 & B \\
\hline Pre-Test & 57 & 44 & 33 & 38 \\
\hline Post-Test & 86 & 63 & 66 & 51 \\
\hline
\end{tabular}

Gráfico 11

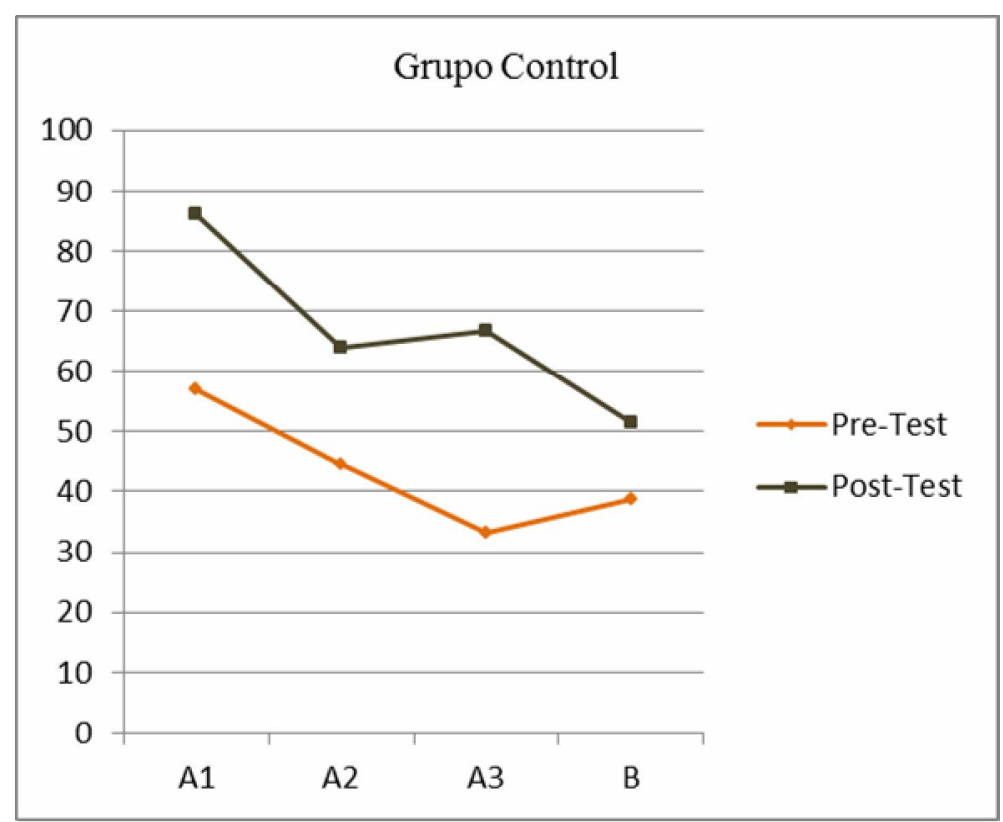

El grupo control muestra también un mejor desempeño en el post-test, aunque muestran un comportamiento diferente las sub-variables de A y B entre pre y post-test. En el pre-test las sub-variables de A evidencian un nivel de dificultad creciente y B parece tener un nivel de dificultad intermedio entre A2 y A3 (este comportamiento es similar al post-test del grupo experimental, aunque con puntajes menores). Sin embargo en el posttest la variable B muestra el menor porcentaje de resolución, lo que podría estar indicando 
que para el grupo control (sin entrenamiento específico) la tarea propuesta por la variable $\mathrm{B}$, discriminar auditivamente y graficar, resultó más compleja, que las tareas propuestas por A.

\section{VI.3.5. Comparación de muestras pareadas}

Para conocer el nivel de significación que tienen los resultados en cuanto a las diferencias obtenidas entre pre y post-test para grupo experimental y control, se aplica la prueba estadística: prueba $t$ - Student para muestras pareadas con el Sftware SPSS.

Este tipo de pruebas se utiliza para muestras dependientes como ocurre en este caso, ya que las observaciones se realizan sobre los mismos individuos.

A continuación se comparan los rendimientos medios en cada instancia (pre y posttest) para cada variable. El nivel de significación de la prueba es 0.05

Cuadro 13

Prueba de muestras pareadas Grupo Experimental

\begin{tabular}{|cc|c|c|c|c|c|c|}
\hline & & \multicolumn{3}{|c|}{ Diferencias relacionadas } & t & Sig. (bilateral) \\
\cline { 3 - 7 } & & Media & Desviación típ. & $\begin{array}{c}\text { Error típ. de la } \\
\text { media }\end{array}$ & & \\
\hline Par 1 & A1T - A1P &,- 929 & 1,141 &, 305 & $-3,045$ & 13 &, 009 \\
Par 2 & A2T - A2P &,- 643 & 1,336 &, 357 & $-1,800$ & 13 &, 095 \\
Par 3 & A3T - A3P &,- 643 & 1,216 &, 325 & $-1,979$ & 13 &, 069 \\
\hline
\end{tabular}


Valor crítico $\mathrm{t}=-1.77$ para un nivel de significación del 5\% (0.05).

Esto muestra que en el Grupo Experimental, el rendimiento medio de la variable A ha aumentado en el post-test de manera significativa. El análisis en la variable B muestra que no es significativo el aumento en el rendimiento medio entre pre y post-test para el grupo experimental.

Gráfico 14

Prueba de muestras pareadas Grupo Control

\begin{tabular}{|lc|c|c|c|c|c|c|}
\hline & \multicolumn{3}{|c|}{ Diferencias relacionadas } & t & gl & Sig \\
\cline { 3 - 6 } & Media & Desviación típ. & $\begin{array}{c}\text { Error típ. de la } \\
\text { media }\end{array}$ & & . (bilateral) \\
\hline Par 1 & A1T - A1P &,- 667 &, 985 &, 284 & $-2,345$ & 11 &, 039 \\
Par 2 & A2T - A2P &,- 500 & 1,087 &, 314 & $-1,593$ & 11 &, 139 \\
Par 3 & A3T - A3P &,- 833 & 1,467 &, 423 & $-1,968$ & 11 &, 075 \\
Par 4 & BT - B3P &,- 417 & 2,151 &, 621 &,- 671 & 11 &, 516 \\
\hline
\end{tabular}

Valor crítico $\mathrm{t}=-1.79$ para un nivel de significación del 5\% (0.05).

Esto muestra que en la variable A, del grupo control, el rendimiento medio ha aumentado de manera significativa en el post.

En la variable B se observa que el rendimiento medio entre el pre y post-test no presenta cambios significativos.

Comparando los valores p de grupo experimental y control:

\begin{tabular}{|c|c|}
\hline 0,336 & Experimental \\
\hline 0,516 & Control \\
\hline
\end{tabular}


Se observa que en general el grupo experimental presenta una mejora más significativa en el rendimiento entre pre y post-test.

Nivel de significación $\alpha$; Probabilidad de cometer Error Tipo I (por lo tanto, la probabilidad de cometer este error es pequeña).

\section{VI.3.6. Análisis de desempeño respecto a cada ejemplo musical}

Se analiza a continuación el desempeño en cada ejemplo musical presentado en el test y la diferencia de resolución entre pre y post-test en grupo experimental y control. Finalmente se realiza una comparación entre los desempeños alcanzados en el post-test por ambos grupos y el panel de niños entrenados.

El cuadro 15 muestra las diferentes características formales de los ejemplos, su vinculación a cada variable y el tipo de tarea que debían realizar sobre ellos.

\section{Cuadro 15}

\begin{tabular}{|c|c|c|c|}
\hline $\begin{array}{l}\text { Ejemplo } \\
\text { Musical }\end{array}$ & Características formales & $\begin{array}{c}\text { Tipo de } \\
\text { tareas }\end{array}$ & Variables \\
\hline Ejemplo 1 & dos frases iguales (AA) & \multirow{6}{*}{ 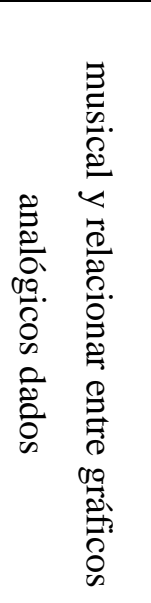 } & \multirow{3}{*}{ A1 } \\
\hline Ejemplo 2 & dos frases diferentes $(\mathrm{AB})$ & & \\
\hline Ejemplo 3 & dos frases iguales (AA). & & \\
\hline Ejemplo 4 & tres frases iguales o diferentes (ABB) & & \\
\hline Ejemplo 5 & tres frases iguales o diferentes (ABA) & & A2 \\
\hline Ejemplo 6 & tres frases iguales o diferentes (AAB). & & \\
\hline
\end{tabular}


LA COMPRENSIÓN DE LA ESTRUCTURA MUSICAL.

LA REPRESENTACIÓN UTILIZADA EN NIÑOS ENTRE 10 Y 11 AÑOS.

\begin{tabular}{|c|c|c|c|}
\hline Ejemplo 7 & tres frases iguales, diferentes o parecidas ( $\left.\mathrm{ABA}^{\prime}\right)$ & & \\
\hline Ejemplo 8 & tres frases iguales, diferentes o parecidas ( $\left.\mathrm{AA}^{\prime} \mathrm{B}\right)$ & & $\mathbf{A 3}$ \\
\hline Ejemplo 9 & tres frases iguales, diferentes o parecidas ( $\left.\mathrm{ABB}^{\prime}\right)$. & & \\
\hline Ejemplo10 & Tres frases iguales o diferentes ABA & \multirow{3}{*}{ 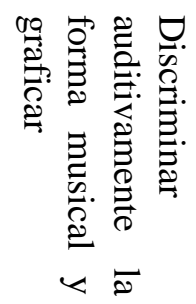 } & \multirow{3}{*}{ B } \\
\hline Ejemplo11 & Tres frases iguales, diferentes o parecidas $\mathrm{AA}^{\prime} \mathrm{B}$ & & \\
\hline Ejemplo12 & Tres frases iguales, diferentes o parecidas $\mathrm{ABB}^{\prime}$ & & \\
\hline
\end{tabular}

Gráfico 12

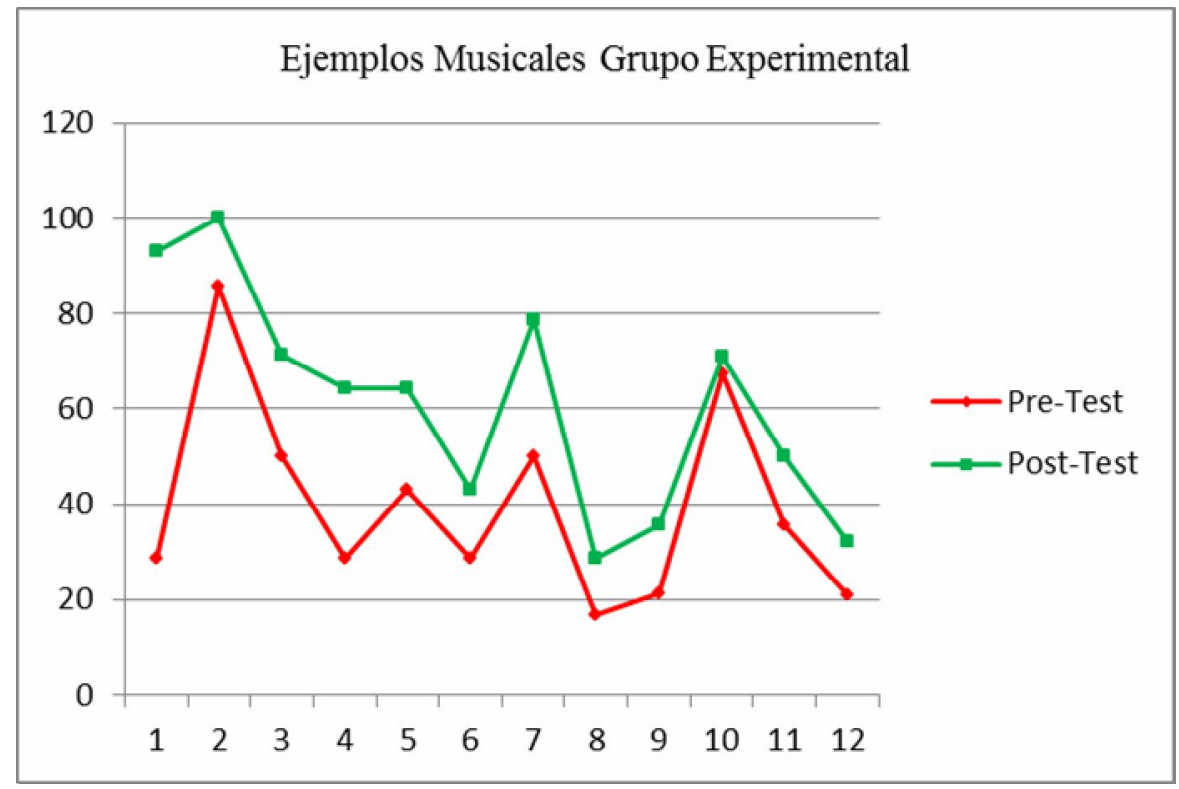

En el gráfico 12 se observa que el grupo experimental muestra un mejor desempeño en el post-test, con un tipo de respuesta similar en cuanto a la dificultad que pareciera representó cada ejemplo entre pre y post-test, es decir, en general, la resolución de la tarea mejoró pero cada ejemplo mantuvo su relación de dificultad respecto a los otros (salvo el ejemplo 1 en el pre-test lo cual puede deberse a la sorpresa que representa el inicio del test) 
En general A1 muestra el mejor desempeño (ejemplos 1,2 y 3), le sigue A2 (ejemplos 4,5 y 6). A3 muestra el mayor margen de desempeño, con un puntaje mayor a A2 (ejemplo7) y menor (ejemplo 8). B se encuentra dentro del rango de desempeños de A3.

Las líneas más irregulares aparecen en A3 y B. Estas comparten el tipo de estructura formal en sus ejemplos donde además de los grupos contrastantes (A y B) aparece la variación de los mismos.

El ejemplo de más fácil resolución para ser el ejemplo 2 (A1) y el de más difícil resolución el ejemplo 8 (A3).

En general los ejemplos de más alta resolución, como "picos" en el trazado de la línea son: 2 (A1) y en un nivel más bajo 7 (A3) y 10 (B)

\section{Gráfico 13}

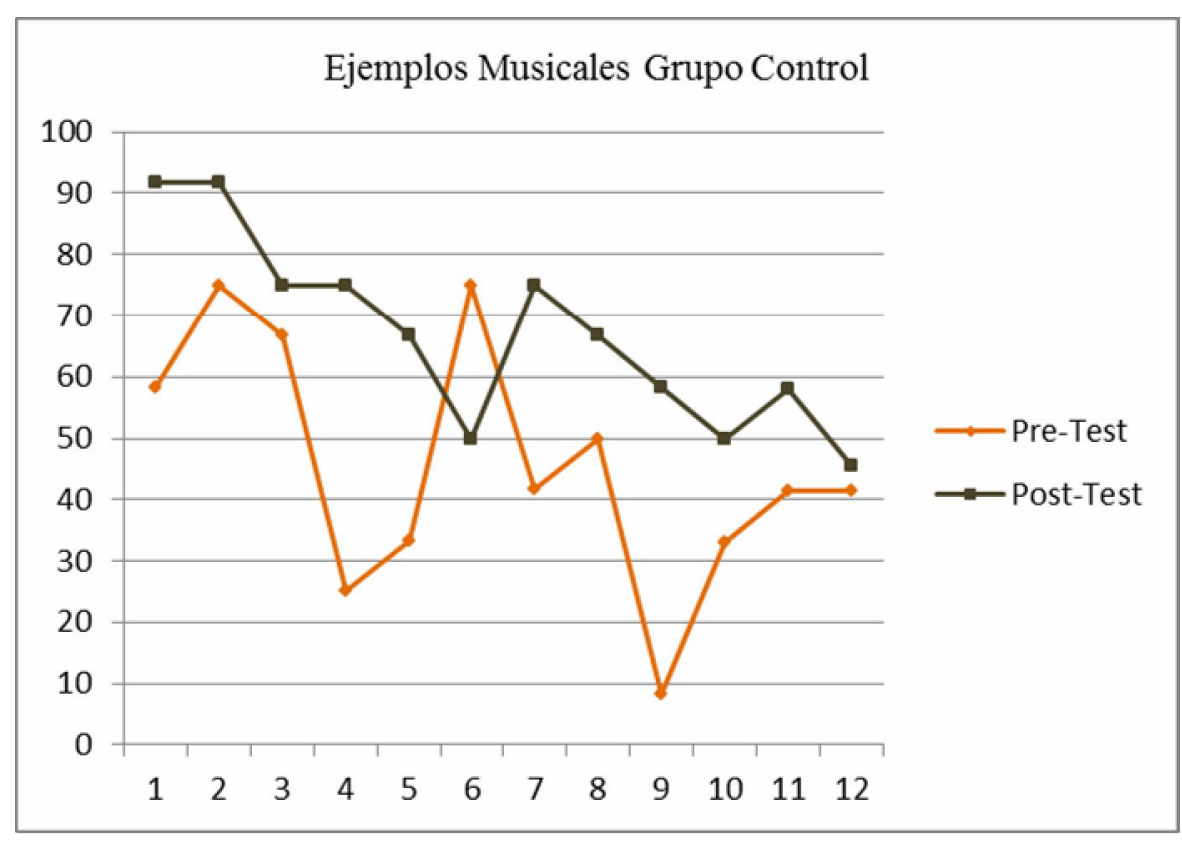

El grupo control muestra en general mayor desempeño en el post-test. Durante el pre-test se observa un comportamiento irrgular en el patrón de respuestas y durante sl posttest aparece un comportamiento similar al grupo experimental mostrando en general un 
desempeño decreciente, sin embargo pueden enmarcarse las respuestas dentro de los mismos rangos para $\mathrm{A} 2, \mathrm{~A} 3$ y $\mathrm{B}$.

El ejemplo de más fácil resolución para ser los ejemplos 1 y 2 (A1) y el de más difícil resolución el ejemplo 12 (B).

En general los ejemplos de más alta resolución, como "picos" en el trazado de la línea son: 1 y 2 (A1), en un nivel más bajo 7 (A3) y en un nivel más bajo aún11 (B)

Gráfico 14

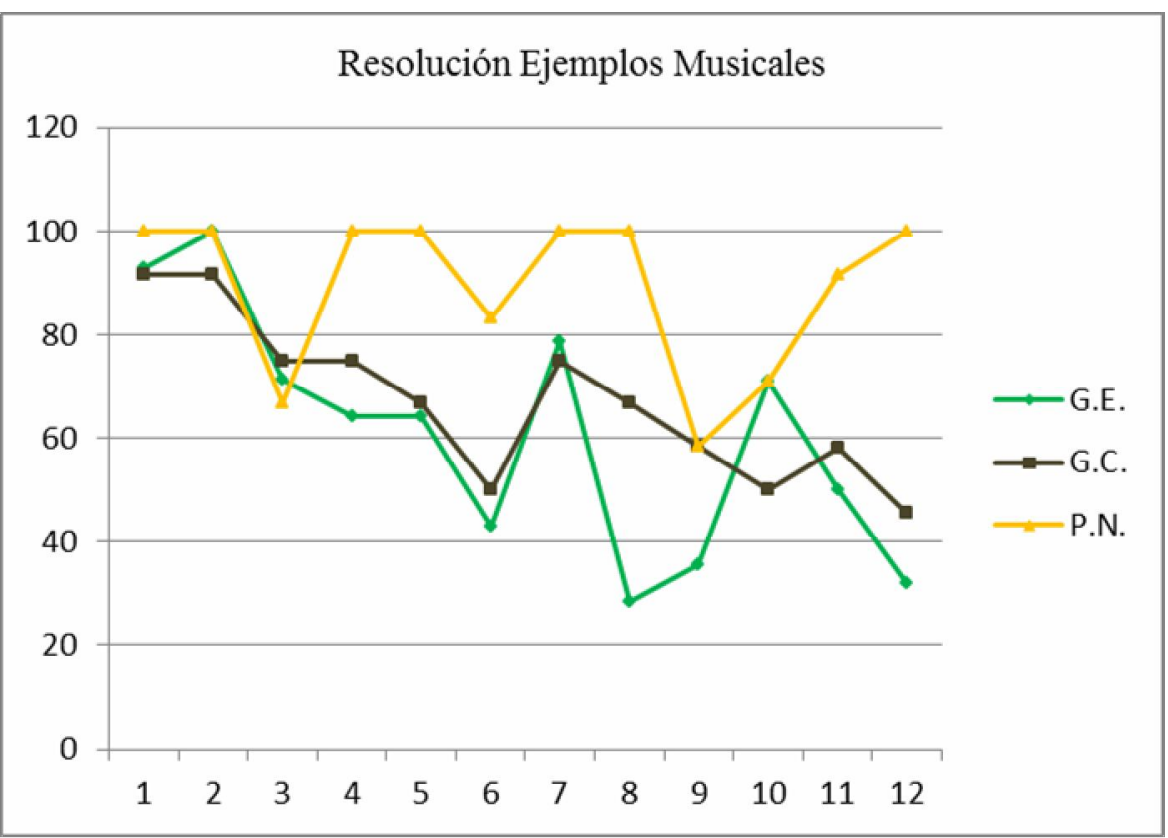

Los desempeños del panel de niños entrenados muestran que a excepción de los ejemplos 3, 9 y 10, los desempeños son altos, lo que podría evidenciar que la diferencia en las respuestas, cuando existe suficiente práctica, se relacionan a las características del ejemplo y no al tipo de tarea o a la estructura formal o extensión. 
En comparación con los grupos experimental y control durante el post-test, estos presentan cierta tendencia decreciente en el nivel de resolución y con mayor irregularidad en las respuestas. En general A1 parece ser de más fácil resolución, le sigue A2, A3 y B que se encuentran en el mismo rango de resolución.

\section{VI.4. DESARROLLO GENERAL DE CADA GRUPO}

El cuadro 12 muestra el promedio de resolución general (primera y segunda parte) en el Pre y Post-Test para ambos grupos y la tasa de desarrollo general para cada uno de ellos.

Cuadro 16

\begin{tabular}{|c|c|c|c|}
\hline & Pre-Test & Post-Test & Tasa de crecimiento \\
\hline Grupo Experimental & $40 \%$ & $59,04 \%$ & $47,60 \%$ \\
\hline Grupo Control & $44 \%$ & $63,88 \%$ & $45,18 \%$ \\
\hline
\end{tabular}

Se observa que los promedios de resolución son menores para el grupo experimental, sin embargo su crecimiento es mayor considerando los desempeños iniciales. 


\section{VI.4.1. Análisis de los grupos según rangos de puntajes}

Cuadro 17

\begin{tabular}{|l|c|l|c|}
\hline Grupo Experimental & $\begin{array}{l}\text { Puntajes bajos } \\
\text { Entre 0-5 }\end{array}$ & $\begin{array}{l}\text { Puntajes } \\
\text { medios } \\
\text { Entre 6-10 }\end{array}$ & $\begin{array}{l}\text { Puntajes Altos } \\
\text { Entre 11-15 }\end{array}$ \\
\hline $\begin{array}{l}\text { Porcentaje de la muestra que obtiene } \\
\text { estos puntajes en PRE-TEST }\end{array}$ & $43 \%$ & $57 \%$ & $0 \%$ \\
\hline $\begin{array}{l}\text { Porcentaje de la muestra que obtiene } \\
\text { estos puntajes en POST-TEST }\end{array}$ & $8 \%$ & $57 \%$ & $35 \%$ \\
\hline
\end{tabular}

Cuadro 18

\begin{tabular}{|l|c|l|c|}
\hline Grupo Control & $\begin{array}{l}\text { Puntajes bajos } \\
\text { Entre 0-5 }\end{array}$ & $\begin{array}{l}\text { Puntajes } \\
\text { medios } \\
\text { Entre 6-10 }\end{array}$ & $\begin{array}{l}\text { Puntajes Altos } \\
\text { Entre 11-15 }\end{array}$ \\
\hline $\begin{array}{l}\text { Porcentaje de la muestra que obtiene } \\
\text { estos puntajes en PRE-TEST }\end{array}$ & $34 \%$ & $41 \%$ & $25 \%$ \\
\hline $\begin{array}{l}\text { Porcentaje de la muestra que obtiene } \\
\text { estos puntajes en POST-TEST }\end{array}$ & $9 \%$ & $41 \%$ & $50 \%$ \\
\hline
\end{tabular}

Analizando los cuadros 17 y 18 se observa que en el GE los puntajes bajos y medios decrecen y los puntajes altos aumentan. Los puntajes bajos decrecen más que en GC y los puntajes altos crecen más que en el GC. 
El GC se comporta diferente. Muestra un crecimiento en los puntajes altos, aunque menor que en el GE que no tiene puntajes altos en el pre-test. Los puntajes medios se mantienen y los puntajes bajos decrecen pero en menor medida que en el GE.

\section{Gráfico 15}

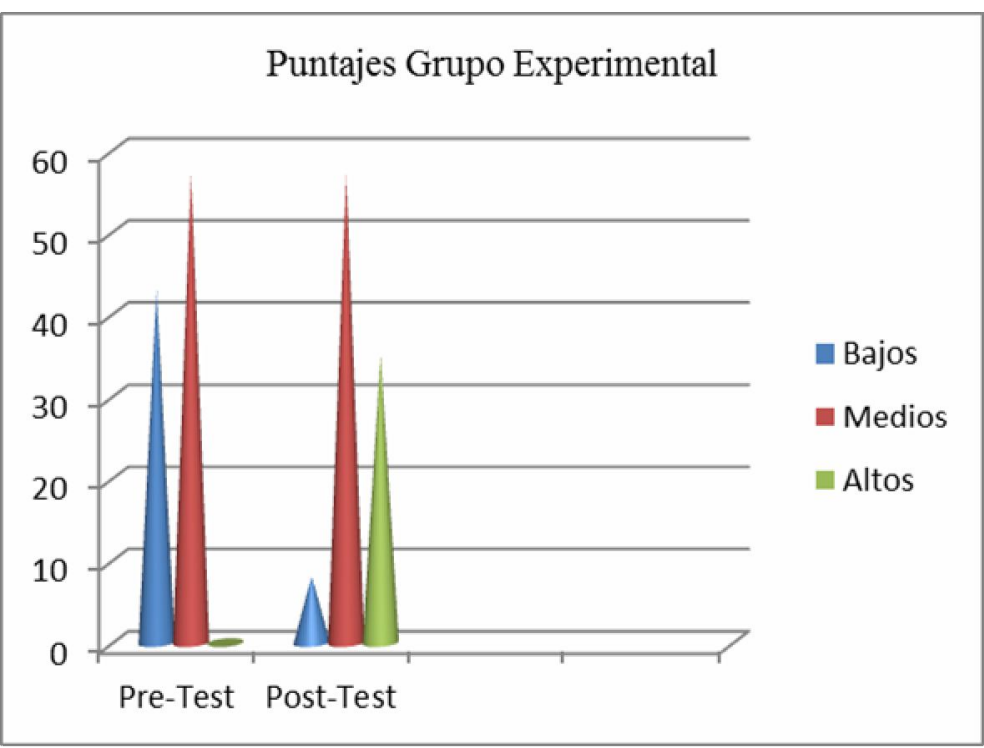

Gráfico 16

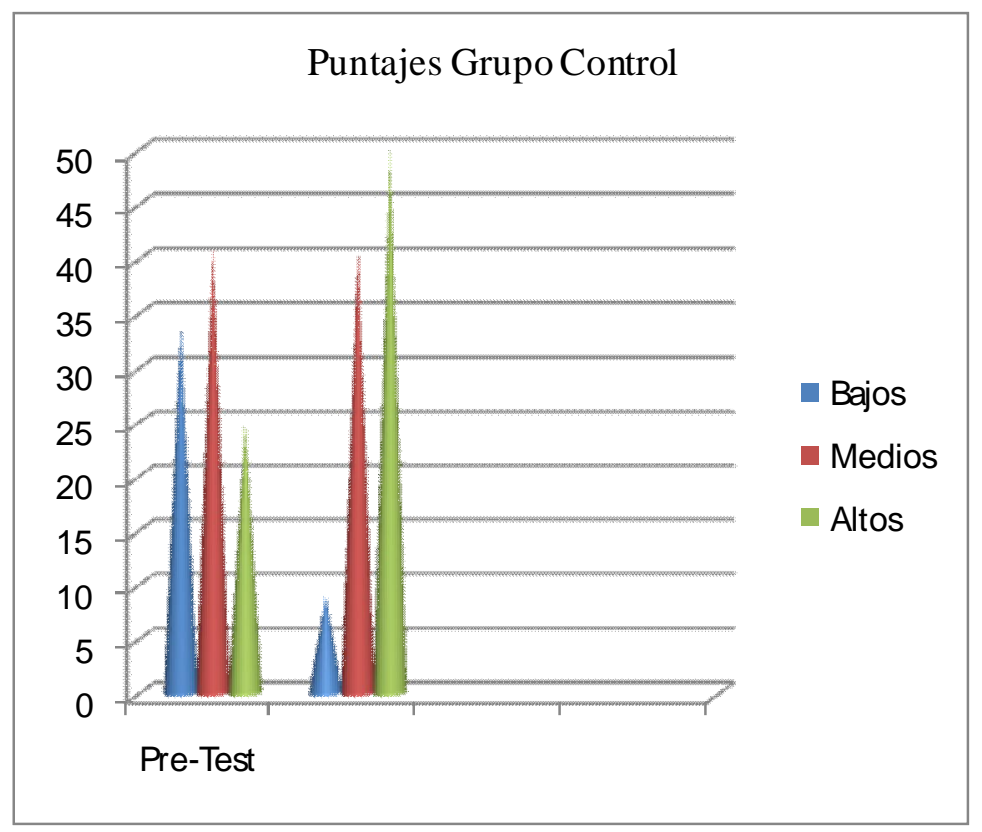


Los gráficos 15 y 16 muestran cómo permanecen constantes los puntajes medios. El grupo control muestra mayor porcentaje de puntajes altos, aunque comienza teniendo puntajes en este rango. El grupo experimental muestra menor porcentaje de puntajes altos pero dado que comienza de cero en este rango su crecimiento es mayor en este aspecto. Los puntajes bajos decrecen en ambos grupos, en mayor medida en el grupo experimental.

\section{VI.4.2. Análisis de los grupos según nivel de desarrollo}

Cuadro 19

\begin{tabular}{|c|c|c|c|}
\hline & DESARROLLO NEGATIVO & \multicolumn{2}{|c|}{ DESARROLLO POSITIVO } \\
\hline \multirow{2}{*}{$\begin{array}{l}\text { GRUPO } \\
\text { EXPERIMENTAL }\end{array}$} & \multirow{2}{*}{$28 \%$} & \multirow{2}{*}{$72 \%$} & $\begin{array}{l}70 \% \text { entre } 30 \text { y } 100 \% \text { de } \\
\text { desarrollo }\end{array}$ \\
\hline & & & $\begin{array}{l}30 \% \text { entre } 200 \text { y } 257 \% \\
\text { de desarrollo }\end{array}$ \\
\hline \multirow{2}{*}{$\begin{array}{l}\text { GRUPO } \\
\text { CONTROL }\end{array}$} & \multirow{2}{*}{$25 \%$} & \multirow{2}{*}{$75 \%$} & $\begin{array}{l}77 \% \text { entre } 1 \text { y } 100 \% \text { de } \\
\text { desarrollo }\end{array}$ \\
\hline & & & $\begin{array}{l}23 \% \text { entre } 133 \text { y } 267 \% \\
\text { de desarrollo }\end{array}$ \\
\hline
\end{tabular}

El análisis de los desempeños individuales arroja que existen en ambos grupos sujetos que obtienen menor puntaje en el post-test: $28 \%$ en el grupo experimental y $25 \%$ en el grupo control. Los mismos se encontraban entre los puntajes medios bajos de resolución en el pre-test. El resto de los sujetos cuyo desempeño creció en el post-test muestra diferentes desarrollos. 
Una tasa de desarrollo elevada no indica un puntaje elevado, sino un crecimiento elevado en relación al desempeño del cual partió. Los sujetos con mayores puntajes no tienen una tasa de desarrollo alta porque partieron de un puntaje elevado y el crecimiento en este estudio tiene un límite: los 15 puntos establecidos por el test.

La tasa de desarrollo intenta mostrar de manera general la posibilidad de superación entre pre y post-test.

\section{Gráfico 17}

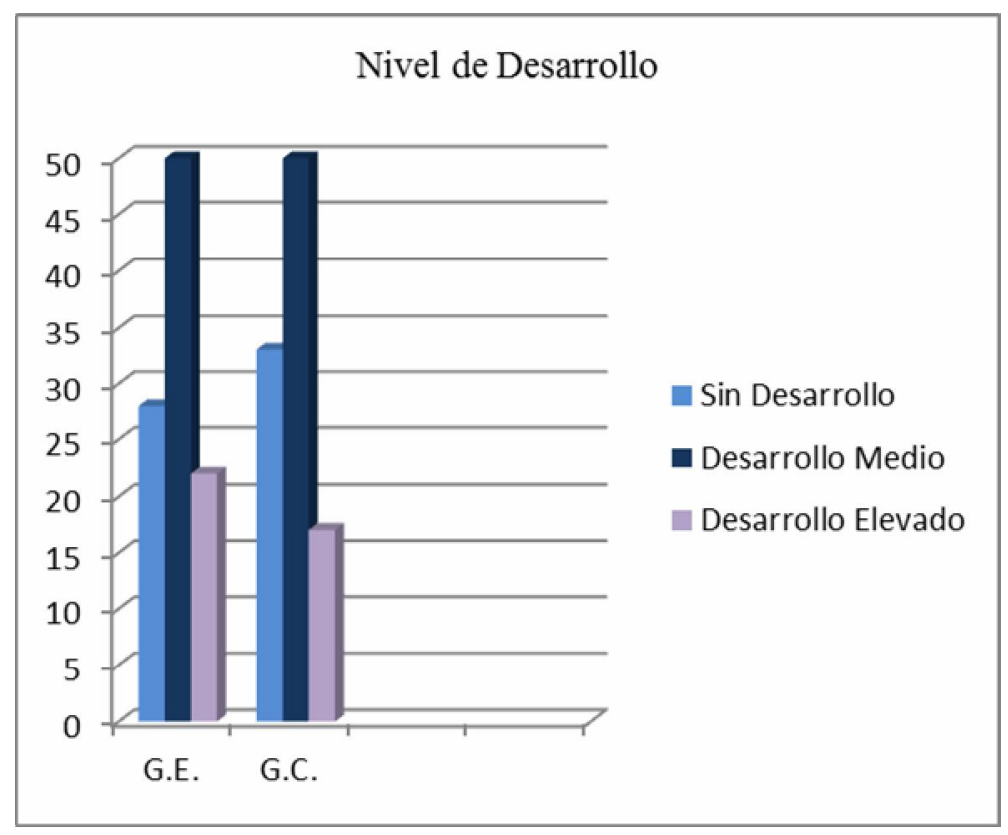

El gráfico 17 muestra la dinámica de desarrollo en cada grupo. El desarrollo medio es el más elevado y semejante en ambos grupos.

El grupo experimental muestra un mayor porcentaje de la muestra que se encuentra en el rango de desarrollo elevado en comparación al grupo control.

El grupo control muestra un porcentaje más elevado de la muestra en relación al grupo experimental que se encuentra dentro del rango sin desarrollo. 


\section{VI.5. RESULTADOS GENERALES}

La experiencia mostró la adecuación a los criterios de representación elegidos para el test, tanto en el grupo experimental como en el grupo control. Un dato de relevancia es que ambos grupos carecían de formación sistemática previa. Gran parte de los resultados de la representación corporal forman parte de los registros anecdóticos de la prueba. En tal sentido es difícil determinar en qué medida la respuesta es producto de la representación individual y cuando es influenciada por la observación de los otros niños. En cambio en la representación gráfica las respuestas pudieron estimarse individualmente

El Post-Test presenta mayor porcentaje de resolución para ambos grupos. El grupo control presenta los mayores promedios de resolución (puntajes más altos) en el pre y posttest. Las similitudes y diferencias observadas en los grupos control y experimental suscitan interesantes interrogantes

El grupo experimental presenta promedios de resolución más bajos, pero su crecimiento es en general mayor que el del grupo control, lo que se evidencia estadísticamente en la comparación de pruebas pareadas, mediante el nivel de significación del aumento en el rendimiento medio entre pre y post-test.

Las respuestas obtenidas muestran diferencias en torno a un mismo atributo cuando es requerido utilizar una respuesta suministrada y cuando es necesario construir la respuesta.

En cuanto al promedio de resolución de cada variable, en general es mayor la variable A, lo que podría asumirse como de más fácil resolución que B. El valor crítico en la variable A para el nivel de significación muestra en ambos grupos un aumento significativo entre pre y post-test. En cambio la variable B no muestra estadísticamente un aumento significativo en el promedio de resolución entre pre y post-test. 
En el análisis de comparación con el panel de niños entrenados, ambas variables presentan en este grupo igual promedio de resolución, lo que podría evidenciar que la práctica posibilita la comprensión de la estructura formal independientemente del tipo de tarea.

$\mathrm{Al}$ analizar la variable $\mathrm{A}$ en cada una de sus sub-variables, se evidencia que la que desvía el promedio hacia una más alta resolución es A1, porque A2 y A3 están más cercanas a la resolución que presenta B.

Podría encontrarse una relación en este sentido al realizar un análisis detallado de cada sub-variable de A en comparación con B, lo que podría estar evidenciando una tendencia de resolución. La misma es más notoria en el post-test en ambos grupos e indicaría que:

A1 presenta mayor promedio de resolución, lo que sugiere que resulta menos complejo discriminar auditivamente y relacionar con gráficos la estructura formal de dos agrupamientos, siendo el de más alta resolución el ejemplo 2 dentro de A1, es decir los grupos perceptivos contrastantes $(\mathrm{AB})$.

A2 presenta un promedio de resolución menor que A1 y mayor que el resto de las sub-variables en el grupo experimental e igual a A3 y B en grupo control. Los ejemplos musicales de A2 presentan una estructura formal de tres agrupamientos iguales o contrastantes.

A3 y B se encontrarían en el mismo rango de resolución en ambos grupos. Aunque suponen diferente tarea los ejemplos musicales de la sub-variable A3 y B presentan una estructura formal de tres agrupamientos iguales, contrastantes y con variación.

En la comparación de la resolución de cada ejemplo entre ambos grupos con el panel de niños entrenados, se evidencia que en el caso de estos, en general presentan una resolución alta y más constante, lo que mostraría nuevamente que en sujetos con mayor cantidad de práctica, la naturaleza de la tarea no es el motivo de la dificultad sino la comprensión de la estructura. 
Aunque la tendencia general es a mejorar en el post-test, se presenta un $28 \%$ (en GE) y un $25 \%$ (en GC) que no evidencia progreso entre el pre y post-test e inclusive retrocede.

En ambos grupos los puntajes medios tienden a mantenerse, los altos a ascender y los bajos a decrecer.

Si bien el porcentaje mayor de sujetos $72 \%$ (en GE) y 75\% (en GC) logró un crecimiento en la resolución del test entre pre y post-test, no se observa una relación entre el puntaje obtenido y el nivel de desarrollo. Aparecen sujetos con un tasa de desarrollo individual elevada y puntajes medios o bajos. O sujetos con tasa de desarrollo baja y puntajes altos porque su desempeño comenzó siendo alto. Sin embargo la tasa de desarrollo permite apreciar en general el aumento en el promedio de resolución entre pre y post-test lo que se evidencia en ambos grupos.

En este trabajo resultó significativa la diferencia inicial entre grupo experimental y control. Ambos grupos crecieron en su resolución durante el post-test, pero pareciera que dicho crecimiento resultó proporcional al nivel del cual partieron. 


\section{CAPÍTULO VII}

\section{CONCLUSIONES}

Este trabajo asumió el desafío de realizar las sesiones experimentales en el ámbito de la escuela común, con niños sin entrenamiento musical previo e indagar las posibilidades de representación de la forma musical a partir de la audición. Los grupos naturales conformados participaron de las sesiones en el contexto de las situaciones áulicas cotidianas, con la variedad de componentes que pueden influir en el proceso de enseñanza aprendizaje, pero en la realidad en la que éste se desarrolla.

Los intereses de este estudio se dirigieron hacia la comprensión de la forma musical a partir de la audición en niños entre 10 y 11 años sin entrenamiento musical previo, en relación a i) la naturaleza de la tarea y las complejidades estructurales propuestas en los ejemplos del test, ii) las diferentes modalidades representacionales en el tratamiento experimental y la resolución del test.

El diseño de esta investigación partió del supuesto que la música genera diferentes modos de representación, que son formas de conocimiento particulares en cada sujeto y que a través de la intervención pedagógica musical esas representaciones "naturales" pueden asumir diferentes formatos de traducción de la sintaxis musical.

Los resultados obtenidos nos permiten avanzar en torno a la temática en relación a la implicancia que tiene el nivel representacional del sujeto en la construcción del conocimiento y utilización de estrategias para simbolizarlo o darlo a conocer, como así también la incidencia de la naturaleza da la tarea en su resolución y el rol de la experiencia en tal sentido. Finalmente enfatizar la importancia de las habilidades cognitivas y sus componentes metacognitivos así como la motivación intrínseca para la identificación y simbolización de la forma musical a partir de la audición. 
La música como lenguaje que transcurre en el tiempo, compromete el ejercicio de la memoria en la formación de representaciones mentales. Las distintas modalidades que puede asumir la experiencia musical favorecen la memorización y condicionan la comprensión musical, de naturaleza fuertemente transmodal. "Los sentidos (visual, auditivo y kinésico) pueden ser usados para crear o recrear una experiencia en la mente que recupera el hecho físico al que representa" (Connolly y Wiliiamon, 2004). ${ }^{52}$ Los resultados muestran que la utilización de la modalidad visual a través de gráficos analógicos en el test, colaboró, no solo en la memorización, sino en la comprensión de la forma musical. Los niños pudieron lograr un promedio de resolución del 40\% (el GE) y $44 \%$ (el GC) en el pre-test, sin haber realizado previamente una tarea de este tipo.

El reconocimiento de la forma musical por parte de niños sin entrenamiento musical formal, corrobora la realidad psicológica del constructo "agrupamiento perceptivo". "La estructura de agrupamiento es el elemento básico de la comprensión musical" (Lerdahl y Jackendoff 1983-2003:14). En este sentido resulta de interés la selección y realización de ejemplos utilizados en el test, que tuvo en cuenta la saliencia perceptiva de los grupos, la extensión similar, y la duración en términos de presente psicológico como espacio de tiempo posible de ser procesado. El panel de expertos convocados evaluaron los ejemplos obteniendo un $98,66 \%$ de promedio de resolución y el panel de niños entrenados obtuvo un $89,44 \%$.

Cada variable representa tareas de diferente naturaleza. La variable A indaga la habilidad de reconocer auditivamente la correspondencia entre forma musical y gráfico. La variable B analiza el desempeño para reconocer auditivamente la forma musical y graficarla sin referencias visuales. La decisión de este diseño en dos partes de diferentes tareas en el test se debió al interés de verificar el aporte de las investigaciones que manifiestan que la naturaleza de la tarea influye en el nivel de resolución de los sujetos (Hargreaves, 1998; Sternberg, 1987). Investigaciones previas de la autora de este trabajo en relación a los tipos de tarea con respecto al ritmo, mostraron diferencias significativas en la resolución de cada

\footnotetext{
${ }^{52}$ En Malbrán, 2006 ${ }^{\mathrm{a}}$
} 
una (Ortega, Graffigna, 2013). Los resultados en la comparación de ambas variables muestran un mayor promedio de resolución para la variable A en pre y post-test para grupo control y en el post-test para grupo experimental. Asimismo presenta una mayor tasa de desarrollo la variable A (65\% para el GE y $60 \%$ para el GC) en contraste con la variable B (22\% para el GE y $32 \%$ para el GC). Este análisis mostraría que la tarea de reconocer auditivamente la forma musical en relación a gráficos propuestos resulta menos compleja que reconocer auditivamente la forma y graficarla, resultado que confirmaría escritos previos que delimitan la diferencia de dificultad entre seleccionar la respuesta a construirla (Bloom, 1971; DeVega, 1998).

Una observación más detallada del desempeño en relación con el conocimiento de las estructuras formales en ejemplos propuestos para cada una de las variables, muestra otros datos emergentes del análisis. Para ver la estructura formal de los ejemplos utilizados en cada sub-variable de A y de la variable B ver capítulo VI página 118.

La variable que consiste en reconocer auditivamente ejemplos musicales de dos agrupamientos y relacionarlo a gráficos propuestos (A1) tanto en el pre-test como en el post-test y en ambos grupos, fue la de mayor promedio de resolución, por lo cual podemos considerar que resultó más accesible reconocer y relacionar los ejemplos musicales con un gráfico de dos agrupamientos en lugar de tres. El incremento de la información que suscita un ejemplo tripartito respecto de uno bipartito compromete la capacidad de la memoria de trabajo.

Los ejemplos seleccionados para dicha variable (A1) al analizar comparativamente los resultados se observa que el de mayor promedio de resolución en ambos grupos fue el de grupos diferentes $(\mathrm{AB})$ y el de menor promedio de resolución fue el de grupos idénticos (AA) los que se presentaban con cambio dinámico (p-f). Esto sugeriría un aparente conflicto cognitivo ya que la introducción de una variable expresiva (f-p) pareciera poner en duda la claridad para la resolución del problema en términos de la variable estructura.

Investigaciones previas han dado cuenta de la dificultad para que los niños realicen categorizaciones en el campo del sonido (Furnó, 2003, 2005, Furnó, Valles, 2013). 
Otro dato de interés es que tuvo dificultades para resolver la tarea el $44 \%$ de la muestra del panel de niños entrenados, siendo que respondieron con el 100\% de aciertos para los otros dos ejemplos de la misma variable (A1).

La variable que analiza la estructura formal en ejemplos de tres agrupamientos iguales o diferentes en relación a gráficos propuestos (A2) presenta un promedio de resolución menor que A1 y mayor que el resto de las sub-variables en el grupo experimental e igual a las dos restantes variables (A3 y B) en el grupo control.

Los resultados muestran que ambos grupos comparten la resolución eficaz en la variable $\mathrm{A} 1$ que en las dos restantes (A3 Y B). Aunque suponen diferente tarea los ejemplos musicales de la sub-variable A3 y B presentan una estructura formal de tres agrupamientos iguales, contrastantes y con variación. Tales resultados corroboran investigaciones previas en el sentido que la naturaleza de la tarea incide en los desempeños, pero la experiencia alcanzada en la tarea modifica esa incidencia (Hargreaves, 2008; Levitin, 2008; Schön, 2012).

Si bien el test propone dos partes con diferente tipo de tarea, la primera con respuesta construida y la segunda con respuesta a construir, no se solicita aquí a los sujetos realizar gráficos espontáneos, sino las figuras geométricas que se presentaron en la primera parte, es decir un ejercicio de transferencia de lo aprendido en un nuevo contexto (obras diferentes). De esta manera la modalidad de trabajo que propone el test, le permite al sujeto llegar a graficar a partir de la audición con las convenciones propuestas, en lugar de producir la respuesta eligiendo sus propios modos de simbolización.

El análisis general de los resultados muestra un mejor desempeño en el post-test para ambos grupos, aun cuando el grupo control no recibió un entrenamiento específico. Resultado que pone en evidencia lo estipulado por Bruner (1984) respecto de que el mismo test es vehículo para aprender reglas y convenciones mientras "se juega". En este sentido Gardner (1971) advirtió que los niños pueden mejorar significativamente la habilidad para ejecutar una tarea durante la misma sesión experimental (Hargreaves, 1998:96). 


\section{LA COMPRENSIÓN DE LA ESTRUCTURA MUSICAL. \\ LA REPRESENTACIÓN UTILIZADA EN NIÑOS ENTRE 10 Y 11 AÑOS.}

Las consideraciones precedentes también se relacionan con la modalidad de trabajo propuesta por el test cuya resolución se constituyó en un aprendizaje por descubrimiento guiado (Ausubel, Novak y Hanesian, 1978) ${ }^{53}$. El papel del mediador en este tipo de aprendizaje no es exclusivamente presencial, ya que el texto escrito puede desarrollar esas funciones (Mayor, 1995). En este sentido la secuencia de actividades propuestas por el test pudo guiar el conocimiento previo del sujeto a través de los ejemplos musicales y su vinculación a gráficos, induciendo el aprendizaje de la forma musical, hasta llegar a la simbolización.

Es posible que el mayor progreso en el post-test a partir de los datos suministrados por el test, estén relacionados con estrategias metacognitivas de control, supervisión y autoevaluación de la tarea. Los sujetos que desarrollan este tipo de habilidades son más eficientes en la resolución de tareas (Mayor, 1995; Malbrán, 2006a). La elección del tipo de estrategia a utilizar puede ser natural (Cooper, 1980) ${ }^{54}$ pero es susceptible de modificarse por medio de la enseñanza (Brown y Campione, 1978; Buterfield, 1981) ${ }^{55}$.

Las estrategias que se intentaron reforzar en las sesiones experimentales a través de diversidad de ejemplos y modalidades representacionales, evidentemente colaboraron para que el grupo experimental tuviera en general un mejor desempeño en el post-test, lo que permite suponer que ayudó a configurar un nivel de representación mayor al que tenían al momento del pre-test sobre el atributo forma musical. Estudios previos muestran que se alcanza una considerable flexibilidad y modificabilidad en la selección de estrategias, de la mano de la instrucción (Brown y Campione, 1978; Buterfield, 1981) ${ }^{56}$. Los resultados muestran un desarrollo general entre pre y post-test del 47,69\% para el grupo experimental.

\footnotetext{
${ }^{53}$ En Mayor et al, 1995

${ }^{54}$ En Sternberg, 1987

${ }^{55}$ En Sternberg, 1987

${ }^{56}$ En Sternberg, 1987
} 
Un resultado llamativo en este estudio fue que el grupo control, que no recibió entrenamiento específico, pudo conseguir un $45,18 \%$ de desarrollo entre pre y post-test. Consideramos que este progreso se relaciona con su nivel representacional al momento del pre-test. Según Sloboda ${ }^{57}$ (1993) "el modo en que las personas se representan la música determina cuanto de bien la pueden recordar y ejecutar". Dado que la música suscita representaciones y procesos no directamente observables se infiere su existencia por "el modo en cómo la gente escucha, memoriza, interpreta instrumentalmente, crea y reacciona ante la música." ${ }^{58}$ Podríamos suponer que habría una relación entre el nivel de representación que un sujeto tiene sobre el hecho musical y su desempeño en relación al mismo. Bamberger (1986) argumentó que los niños con potencialidad musical tienen múltiples representaciones internas de la misma pieza de música y pueden moverse libremente de un tipo de representación a otra ${ }^{59}$.

Las diferencias sustantivas entre la competencia de entrada del grupo control respecto del grupo experimental se manifiestan en el análisis de los resultados. El G.C. resuelve el pre test con un promedio del $44 \%$, mientras que en el G.E. el nivel de partida es con un promedio de resolución del $40 \%$ de respuestas correctas. Estas diferencias se mantienen en el post-test: el GC el alcanza un 63,88 \% de promedio de resolución, mientras que en el GE obtiene un $59 \%$. Esto sugeriría que el constructo forma demanda habilidades cognitivas de amplio espectro y es dependiente del desarrollo de competencias puestas en juego en otras habilidades cognitivas. Los resultados analizados sugerirían que los estudiantes de más importante desarrollo (background) como los del GC, cultivan dichas pericias en otras áreas del conocimiento. Dichas habilidades de operación del pensamiento les permiten actuar efectivamente a partir de indicios tan mínimos como los suministrados en el pre- test, ya que las diferencias entre pre y post resultaron significativas.

\footnotetext{
${ }^{57}$ En Musumeci, 1995

${ }^{58}$ En Robledo Barros y otros, 2003

${ }^{59}$ En Winner, 2003
} 
En este sentido, podemos analizar las diferencias entre ambos grupos desde dos puntos de vista:

- $\quad$ El nivel de representación al momento del Pre-test (de acuerdo al desempeño manifestado) y su incidencia en desempeños futuros (el post-test)

- $\quad$ La incidencia del entrenamiento específico, el cual colabora en desarrollar el nivel de representación, pero es dependiente del nivel de representación del cual parte el entrenamiento.

De acuerdo a la experiencia musical adquirida en un medio determinado, la educación musical recibida, como así también factores biológicos, la decodificación de la información del discurso musical no es la misma para todos los individuos (Zenatti, 1991). "La decodificación de símbolos de contenidos significativos se basa en las experiencias previas" (Malbrán, 2006b:1).

Hay acuerdo general en describir la representación de un conocimiento como un proceso que se presenta en distintos niveles o modalidades (Bruner, 1995, Karmiloff-Smith 1992). El conocimiento implícito que un sujeto tiene sobre la forma musical, adquirido por enculturación, se encuentra almacenado en la memoria a largo plazo como esquema. La mente explora la información almacenada y redescribe esas representaciones en diferentes formatos hasta alcanzar un conocimiento explícito (Karmiloff-Smith 1992). Las diferencias presentes desde el comienzo entre grupo experimental y control pueden relacionarse con el nivel de representación promedio en cada uno de los grupos.

De acuerdo a los resultados podríamos considerar que el mayor nivel de representación del grupo control le permitió no sólo obtener mejor puntaje en el pre-test, sino capitalizar esta experiencia para alcanzar mejores resultados en el post-test. De esta manera el test se convierte en un dispositivo de integración multimodal (auditiva-visual) que opera como soporte cognitivo para configurar un mayor nivel de representación sobre la forma musical y por lo tanto se constituye en un medio para alcanzar una mayor comprensión sobre el objeto de estudio aun en sujetos sin aprendizaje musical formal. 
La resolución del test depende del nivel de representación del sujeto y de acuerdo a dicho nivel de representación, el mismo test puede convertirse en un medio para hacer explícitas las representaciones que el sujeto posee respecto de la forma musical, pudiendo mejorar los desempeños durante el post-test.

Respecto al grupo experimental podemos argumentar que el entrenamiento específico sobre un contenido, aportando experiencias multimodales y cantidad de práctica, colabora en el desarrollo representacional de dicho contenido, pero es dependiente del nivel de representación con el cual se inició el entrenamiento, sobre todo si este se desarrolla en un breve tiempo.

Otro resultado sugestivo refiere al grupo de sujetos que no evidencian progreso entre el pre y post-test e inclusive retroceden, $28 \%$ (en GE) y un $25 \%$ (en GC). "La implicación del estudiante es decisiva en su propio progreso" (Malbrán, 2006b:1). Estudios previos relativos a las diferencias individuales en la resolución de una tarea, como puede ser el test, concede importancia a los estilos atribucionales, los que se ponen en juego en procesos de autoaprendizaje (Mayor, 1995; Malbrán, 2006a).

En el autoaprendizaje, los sujetos son participantes activos de su propio proceso de aprendizaje y ponen en juego el desarrollo de sus propias estrategias motivacionales y metacognitivas (Zimmerman, 1989) ${ }^{60}$. Las estrategias metacognitivas otorgan mayor eficacia al proceso y la motivación provee persistencia en la tarea. La audición musical requiere atención sostenida, abstracción, simbolización y pensamiento reflexivo. "Existe consenso en que la música es una construcción de la mente, un juego de representaciones involucradas tanto en la recepción como en la producción" (Malbrán, 2006a:1). En este sentido se "necesita administrar el tiempo, mantener la concentración y la motivación" (Hallam, 1997:13-14) ${ }^{61}$.

\footnotetext{
${ }^{60}$ En Mayor et al, 1995

${ }^{61}$ Citado por Malbrán, 2006 ${ }^{\mathrm{a}}: 1$
} 


\section{LA COMPRENSIÓN DE LA ESTRUCTURA MUSICAL. \\ LA REPRESENTACIÓN UTILIZADA EN NIÑOS ENTRE 10 Y 11 AÑOS.}

La comprensión de la forma musical a través de la audición requiere el desarrollo de estrategias cognitivas como la atención, la memoria y la representación de modo de establecer nexos entre la música y los distintos formatos que pueden acompañarla con las diferentes competencias aportadas por el sujeto. Estos procesos son vistos como transmodales y su desarrollo puede depender del nivel representacional particular que posea el sujeto, el cual puede modificarse de la mano de la enseñanza. La mediación pedagógica puede guiar el proceso representacional a través de distintas modalidades de expresión y representación orientando las intuiciones implícitas en un tránsito que va del mundo interior, implícito y difícilmente objetivable a un mundo con producciones y simbolizaciones explícitas.

\section{VII.1. APORTES POTENCIALES}

Los nuevos enfoques de la cognición musical, aportan conocimiento a la pedagogía al momento de considerar las múltiples instancias que confluyen en la audición, siguiendo estrategias basadas en la masa crítica acumulada. Esto implica que el trabajo de análisis auditivo en la clase de música, a través de su discurrir temporal debiera integrar:

- $\quad$ acciones corporales de traducción del estímulo tales como canto, percusión corporal y ejecuciones instrumentales.

- $\quad$ integraciones multisensoriales basadas en la congruencia entre imágenes, gráficos, presentaciones multimedias y estímulos sonoros.

- $\quad$ verbalizaciones, narraciones, descripciones, performances de movimientos, juegos dramáticos, representaciones miméticas generadas por la música.

La concurrencia de actividades descriptas ha intentado poner de manifiesto los múltiples aspectos de representaciones que sobre el contenido musical abordado, se supone 
existen en el sujeto. Se considera que a partir de esta dialéctica entre cada música, cada individuo y cada contexto, comienza una construcción del conocimiento en términos de categorías aislables y susceptibles de análisis riguroso. Abordarlas en permanente comunicación con lo sentido, lo experimentado, otorga significación a la conceptualización teórica, concediendo sentido a la experiencia.

\section{VII.2. REFLEXIONES FINALES}

El estudio realizado ha intentado generar diferentes modalidades del aprendizaje significativo y por descubrimiento guiado. Se utilizaron en las distintas experiencias múltiples iniciativas prácticas de producción musical y de reconocimiento auditivo, impulsando la configuración de abstracciones, simbolizaciones y ejercicio del pensamiento reflexivo. Durante el desarrollo de las clases un registro anecdótico del investigador fue el paulatino incremento de la concentración, implicación en la tarea y atención sostenida de los niños participantes. Creemos que el diseño de la tarea fue acertada al:

- Presentar la música a través de formatos multi-representacionales, que colaboran en la comprensión. En este sentido el mismo test se convirtió en el medio de acercamiento entre la experiencia del sujeto y la forma musical.

- Contemplar la individualidad de cada sujeto, al corroborar cómo es que construye su conocimiento a partir de incidencias tales como, el nivel de representación que posee, su implicación en la tarea y su nivel de experiencias previas.

- Considerar el impacto sensible que la música, como lenguaje altamente emocional puede provocar en el sujeto, como forma de favorecimiento del aprendizaje; indudablemente sobrevuelan en la actuación las capacidades cognitivas, sin embargo, los aspectos motivacionales- afectivos fueron esenciales para un aprendizaje efectivo y un compromiso por la tarea. 
- Favorecer el reconocimiento auditivo de la forma musical en niños sin entrenamiento musical, atendiendo a que los ejemplos utilizados sean seleccionados sobre a) la base del conocimiento de las capacidades perceptivas y cognitivas de la edad en cuestión y sobre la realidad perceptiva de la estructura musical formal en conjunción con presentaciones multimodales y b) la simplicidad/ complejidad de los fragmentos musicales, en términos de su construcción interna (música tonal, pulsada) y la extensión temporal de los mismos.

- $\quad$ Promover la realización de diferentes tareas desde la audición en relación a la forma musical es interdependiente con la experiencia previa del sujeto y habilidades cognitivas de amplio espectro que trascienden el contenido musical para insertarse en competencias demandadas por la escuela en su conjunto.

- $\quad$ Proponer el uso de formatos multimodales diversificados. La entrada de información congruente por diferentes vías sensoriales aporta y acrecenta el nivel de desarrollo representacional lo que permite acceder a tareas de mayor demanda cognitiva.

- $\quad$ Aportar al encuentro entre investigación y realidad del aula. La experiencia mostró el interés del cuerpo docente de la escuela por participar en un proyecto de investigación universitaria y acortó la brecha entre ambas instituciones. Emprendimientos de este tipo incrementan la validez ecológica de la investigación y aportan a la docencia diferentes visiones del tratamiento del conocimiento.

El reconocimiento de la forma de una obra musical es una construcción que demanda "fluidez de circulación" en la relación oído-cuerpo-mente. Se trata de advertir la estructura subyacente entre relaciones sonoras ordenadas en el tiempo, lo que implica procedimientos mentales a altísima velocidad que permiten identificar si una relación de sonidos es repetición de otras porque se la escuchó antes, si es nueva, si es parecida pero no igual a una anterior... Por ende, se trata de una ida y vuelta entre lo que se escucha, se recuerda y se abstrae de la música que se está escuchando. El meollo de la cuestión es que tal construcción es al momento. Estos tipos de desarrollos en tiempo real son frecuentes en 
el mundo cibernético contemporáneo, pero no son frecuentes en otras áreas de conocimiento escolar, lo que señala uno de los aportes de la música a la escuela.

Los resultados sorprendentes del grupo control motivan para estudios posteriores.

- ¿Es que entonces los niños de hoy progresan en su manejo del conocimiento a partir de mínimos indicadores...? Esto es...Con una pista... lo resuelvo.

- $\quad$ ¿Es que la pericia para operar con la play station, el celular, la tablet, y demás recursos, están demandando a los niños juegos con la mente en alta velocidad y tornándolos operativos para aplicar lo percibido o recibido como información inmediatamente en un nuevo contexto?

- ¿Es que dada la velocidad con que incorporan nuevas estrategias o nuevos contenidos, si deseamos obtener diferencias entre dos grupos como los de la muestra se trata de diseñar estrategias de mayor extensión en el tiempo, mayor complejidad y mayor demanda cognitiva. ¿O será que por las nuevas performances cibernéticas han variado los tiempos para el aprendizaje de los conocimientos por insight, ensayo error, descubrimiento y aproximaciones sucesivas?

- ¿ ¿Es que dada la comprobación de que los niños del GC avanzaron entre pretest y pos-test como si hubieran recibido prácticas específicas porque aportaron habilidades cognitivas de otros campos del conocimiento (dado que no poseían experiencia musical sistemática previa) se trata de conciliar certeramente las habilidades que demandan las diversas disciplinas como un todo, independientemente del objeto de estudio particular de cada una de ellas?

En el campo de la investigación se considera que se trata de ampliar el campo del conocimiento por medio de herramientas confiables y que los resultados que confirmen o 
rechacen la hipótesis son igualmente apreciables para la meta del crecimiento en una disciplina si arrojan nuevas luces, interrogantes y avenidas de indagación. En este caso los interrogantes finales que arroja nuestro breve estudio surgen tanto del grupo experimental como del grupo control. En tal sentido un punto crítico de análisis posterior debiera permitirnos conocer las razones por las cuales en ambos grupos hubo niños que igualaron sus bajos desempeños en ambos test o más aún retrocedieron. Es decir, nuestras preocupaciones se centran tanto en los puntos más altos de la curva como en los más bajos.

La realidad psicológica de los niños es una plataforma cambiante año a año. La indagación de sus procedimientos y estrategias mentales probablemente genere importantes cambios en nuestras mentes docentes. Es hora de estar a la altura de ellos para hacer del encuentro en el aula una verdadera escuela de interacción enriquecedora y descubrimiento permanente. 
LA COMPRENSIÓN DE LA ESTRUCTURA MUSICAL.

LA REPRESENTACIÓN UTILIZADA EN NIÑOS ENTRE 10 Y 11 AÑOS.

\section{REFERENCIAS}

Altenmüller, E. (2002). Neurología de la Percepción Musical. Mente y Cerebro. Barcelona: $\mathrm{N}^{\circ} 2$, Año I, 48-54.

Álvarez González, M. (2009). Datos blandos para las ciencias duras: El camino de la Psicología a las Neurociencias. Buenos Aires: Paidós.

Arias Gómez, M. (2007). Música y Neurología. En Neurología Vol 22 No1 (pp 39-45). Consulta http://www.jbyg.com/descarga/neurologia.pdf [Consultado enero 2012]

Barquero Jiménez, M. S. (2008) Música y Cerebro [en línea]. Circunvalación del Hipocampo. [Consulta: enero 2013]. Disponible en: http://www.hipocampo.org/originales/original0002.asp. [Consultado enero 2012]

Basso, G. (2006). Percepción auditiva. Buenos Aires: Universidad Nacional de Quilmas Editorial.

Bigand, E. (1991) Hacia una formalización de los procesos implicados en la comprensión musical. Revista Comunicación, Lenguaje y Educación 9. pp.71-88

Bigand, E. y Lalitte, P (2007) El Cerebro y la Música Contemporánea. Mente y Cerebro, Barcelona, 22: 20-25.

Bigand, E. (2011). Pensar el aprendizaje de la música hoy a la luz de los descubrimientos recientes en psicología y en neurociencias cognitivas. Reseña de Conferencia en la ARIAM lle-de France por Guadalupe Segalerba. Boletín SACCoM Vol 3, No2.

Bloom, B. (1971). Taxonomía de los objetivos de la educación: la clasificación de las metas educacionales: manuales I y II. Traducción de Marcelo Pérez Rivas. Buenos Aires: Centro Regional de Ayuda Técnica. Agencia para el Desarrollo Internacional (A.I.D).

Bruner, J. (1995). Desarrollo cognitivo y educación. Madrid: Morata.

Burcet, I. (2010). El rol de la alfabetización musical en el desarrollo de habilidades de análisis por audición. En F. Shifres y R. Herrera (Eds.). Actas del Seminario Adquisición y desarrollo del lenguaje musical en la enseñanza formal de la música. SACCoM, pp. 57-61.

Carlsen, J.; Laden, B. (1996) Las representaciones mentales en la música. Eufonía Año II No5. GRAO.

Chion, M. (1993). La audiovisión. Buenos Aires: Paidós. 
Cross, I. (2007). Música, Cultura y Evolución. Faculty of Music. University of Cambridge. http://www.musicam.ac.uk/-cross/

De Vega, M. (1998[1984]). Introducción a la Psicología Cognitiva. Madrid: Alianza.

Dierssen, M. (2004) La música y la mente humana: neurobiología de la experiencia musical. En http://www.agenciaelvigia.com.ar/mente.htm. [Consultado en enero 2013].

Domingo Curto, J. M. (2005). La cultura en el laberinto de la mente. Aproximación filosófica a la "Psicología Cultural" de Jerome Bruner. Buenos Aires: Niño y Dávila.

Dowling, W. (1994) El Contorno melódico en la escucha y el recuerdo de melodías. En Musical Perception. Ed. Rita Aiello. Traducción Silvia Malbrán. Oxford University Press. New York.

(1998) Conocimiento procedimental y conocimiento declarativo en educación y cognición musical. Trad. Isabel Cecilia Martínez. Orpheotrom .Estudio e investigación. Nº 4. Conservatorio A. Ginastera. Bs As. Pp.23-40.

Dumarier, E. (1992) Percepción-aprehensión y Percepción-comprensión. Psyhcologie esprimental de la perception. Paris: Press Universitaires de France.

Eisner, E. (1987): Procesos cognitivos y curriculum. Una base para decir lo que hay que enseñar. Barcelona: Martínez Roca.

Furnó, S. (2003) La formación de conceptos musicales. Cuadernos interamericanos de Investigación en Educación Musical. Volumen II. Número 6. Universidad Autónoma de México.

(2005). La formación Auditiva del Oyente Reflexivo. Actas de las I Jornadas de Educación Auditiva. Fac. de Bellas Artes. UNLP. (pp. 27-45)

Gainza, V. H. de (edit). (1990). Nuevas Perspectivas de la Educación Musical. Buenos Aires: Guadalupe.

Gardner, H. (1987) Arte, mente y cerebro. Una aproximación cognitiva a la creatividad. Buenos Aires: Paidós.

Gagné, E. (1985). La Psicología Cognitiva del Aprendizaje Escolar. Madrid: Visor.

Gogni Grandmontagne, A. (1995). La Psicología y los contenidos académicos (Cap 1). En Psicodidáctica y aprendizajes escolares. Ed Universidad del País Vasco: Bilbao.

Gómez, D. y Gutierrez, M. (2010) Efectos de la percepción de dos estilos musicales sobre el nivel y localización de la actividad electroencefalográfica en músicos pertenecientes a contextos.... [en línea]. Cuadernos de Música, Artes Visuales y Artes Escénicas Colombia. Vol 5, No1 (pp. 33-50). 


\section{LA COMPRENSIÓN DE LA ESTRUCTURA MUSICAL. LA REPRESENTACIÓN UTILIZADA EN NIÑOS ENTRE 10 Y 11 AÑOS.}

http://www.academia.edu/1393964/Efectos_de_la_percepcion_de_dos_estilos_musi cales_sobre_el_nivel_y_localizacion_de_la_actividad_electroencefalografica_en_m usicos pertenecientes a contextos [Descargado enero de 2013]

Hargreaves, E. (2008). Música y desarrollo psicológico. Barcelona: Grao.

Imberty, M. (1990). Développement linguistique et musical de l'enfant l'age préscolaire et escolaire. Naissaence e développement, Paris:PUF. Traducción Silvia Furnó.

Jacquier, M y Pereira Ghiena, A. (2010). El rol del cuerpo en el aprendizaje del lenguaje musical. Reflexiones acerca del aporte de la cognición corporizada. En F. Shifres y R. Herrera (Eds.). Actas del Seminario Adquisición y desarrollo del lenguaje musical en la enseñanza formal de la música (pp. 67-72) Buenos Aires: SACCoM.

Karmiloff Smith, A. (1992). Beyond Modularity. [Más allá de la Modularidad. La ciencia cognitiva desde la perspectiva del desarrollo. (J. Gómez Crespo y M. Núñez Bernardos traductores) Madrid. Alianza. 1994] Cambridge, MA, The MIT Press

Lakoff, G. y Johnson, M. (1980). Metaphors We Live By. Chicago: University of Chicago Press.

Leman, M. (2008). Embodied Music Cognition and Mediation Technology. [Cognición Musical Corporeizada y Tecnologías de Mediación (SACCoM trad.) Buenos Aires: 2011] Cambridge: the MIT Press.

Lerdahl, F. y Jackendoff, R. (2003[1983]). Teoría Generativa de la Música Tonal. Madrid: Akal.

Levitin, D. (2006). This is your brain on music. The science of a human obsession. U.S.A: Penguin Group.

López Cano, R. (2004). Elementos para el estudio semiótico de la cognición musical. Teorías cognitivas, esquemas, tipos cognitivos y procesos de categorización. SITEM (Universidad de Valladolid) Seminario de Semiología Musical UNAM. En http:/www.geocities.com/lopezcano [Descargado en noviembre 2013]

(2005). Los cuerpos de la música. Introducción al dossier Música, Cuerpo y Cognición. TRANS Revista Transcultural de Música. N9. Sociedad de Etnomusicología (SIbE). Barcelona. España. http://redalyc.uaemex.mx [Descargado en enero 2014]

(2007). "Semiótica, semiótica de la música y semiótica cognitiva enactiva. Notas para un manual de usuario". Texto didáctico. [Descargado junio 2009]

(2011). "Música, mente y cuerpo. De la semiótica de la representación a una semiótica de la performatividad". En Marita Fornaro (Ed). De cerca, de lejos. Miradas actuales en Musicología de/sobre América Latina. Montevideo. 
Universidad de la República. Comisión Sectorial de Educación permanente. Escuela Universitaria de Música (en prensa). [Descargado enero 2014)

Malbrán, S. (1997) Música y Metaudición: algunas reflexiones para su estudio. Orpheotron $\mathrm{N}^{\mathrm{o}} 2$

Malbrán, S. y Robledo Barros, R. (2005). La estructura de agrupamiento. Un estudio con músicos. $5^{\circ}$ Encuentro Latinoamericano de Educación Musical. Santiago de Chile.

Malbrán, S. y Furnó, S. (2005). Vinculaciones entre investigación y Didáctica Musical. Ficha de circulación interna. Maestría en Psicología de la Música. UNLP. Facultad de Bellas Artes. Seminario de Psicología aplicada a la Educación Musical.

Malbrán, S. R. (2005). Relaciones temporales y cognición musical. Extraído de la Tesis Doctoral: Organización Temporal y Sincronía Rítmica. Facultad de Humanidades y Ciencias de la Educación. Universidad Nacional de la Plata.

(s/f). Teoría Musical y Psicología de la Música: Nuevas Visiones para la Pedagogía. En Creatividad en Educación Musical. Fundación Marcelino Botín

"Integración de modalidad cruzada en las Artes temporales" Ficha de estudio. U.N.L.P. y U.B.A.

(2006a) Estrategias metacognitivas en la preparación musical profesional. Un desafío. En Actas de la Conferencia Universidad Católica Argentina.

(2006b). La formación auditiva como proceso cognitivo. Eufonía, 36.

(2007). El oído de la mente. Madrid. Akal.

(2008). Ritmo Musical y Sincronía. Un programa de Investigación aplicada con Proyecciones Psicopedagógicas. Buenos Aires. Editorial de la Universidad Católica Argentina.

(s/f) La representación en música. Hacia la construcción del "Oído de la mente" En Escritos sobre Audición. Lenguaje, tecnologías, producciones. Libro 2. Comp. Susana Espinosa. Ed. UNLa.

(2010). El modelo cross modal aplicado a las artes temporales. En Días, M. y Riaño, E. (Editores). Voz, cuerpo y acción: un espacio para la música. Editorial Universidad de Cantabria. Santander.

Malbrán, S. y García Malbrán, E. (2010) Lenguaje Musical y Didáctica: Sonido y Estructura Sonora. En Riaño, E y Díaz, M. (Coord) Fundamentos Musicales y Didácticos en Educación Infantil. (pp.77-108). Santander: PUbliCan. Ediciones Universidad de Cantabria. 
Martínez, I. (2006). Atención auditiva a niveles más profundos de la estructura subyacente. En Actas de la V Reunión Anual de SACCOM, pp. 89-97.

Martínez, I. y Epele, J. (2012) “¿Cómo se construye la experiencia intermodal del movimiento y la música en la danza? Relaciones de coherencia en la performance y en la recepción de frases de música y de movimiento”. Cuadernos de Música, Artes Visuales y Artes Escénicas, vol. 7, núm. 2, pp. 65-82

Mayor, J., Suengas, A. y González Márquez, J. (1995). Estrategias Metacognitivas. Madrid: Editorial Síntesis.

Musumeci, O. (1995). El test de Bentley como predictor del rendimiento musical de los alumnos ingresantes al Conservatorio de Morón. CIEM, 2(6), pp. 37-44.

Peñalba, A. (2005). El cuerpo en la música a través de la teoría de la Metáfora de Johnson: análisis crítico y aplicación a la música. Revista Transcultural de Música, $\mathrm{N}^{\circ}$. http://www.sibetrans.com/trans/articulo/176/el-cuerpo-en-la-musica-a-traves-de-lateoria-de-la-metafora-de-johnson-analisis-critico-y-aplicacion-a-la-musica [Descargado junio 2012]

(2008). El cuerpo en la Interpretación Musical. Tesis Doctoral. Universidad de Valladolid. Facultad de Educación y Trabajo Social. http://uvadoc.uva.es/handle/10324/55 [Última consulta 20-08-2012]

Pérez, D; (2005). "El problema mente-cuerpo ayer y hoy", VERTEX Revista Argentina de Psiquiatría. Vol. XVI: 345-351

Reybrouck, M. (2005). Body, Mind and Music: Musical Semantics between Experimental Cognition and Cognitive Economy. TRANS Revista Transcultural de Música. $\mathrm{N}^{\circ} 9$. Sociedad de Etnomusicología (SIbE). Barcelona. España. http://redalyc.uaemex.mx [Descargado junio 2012]

Romo, M. (1997). Psicología de la creatividad. Barcelona: Paidós.

Sebastini, A. y Malbrán, S. (2003). Las habilidades musicales "clave": un estudio con músicos de orquesta. Actas de la III Reunión Anual de SACCoM.

Shifres, F. (2004). Contribuciones de la Teoría Musical y la Psicología de la Música al Desarrollo Auditivo de los Músicos Profesionales. I Jornadas de Investigación en disciplinas Artísticas y Proyectuales. Facultad de Bellas Artes. UNLP. La Plata.

(2005). Reconsiderando las relaciones entre música y modularidad para la educación auditiva. En F. Shifres (Ed.) Actas de las I Jornadas de Educación Auditiva, pp. 143-155. La Plata: CEA. Facultad de Bellas Artes, UNLP

(2006). Comprensión transmodal de la expresión musical. En Shifres, F. y Vargas, G. (Eds.) Sonido, Imagen y Movimiento en la Experiencia Musical $V$ Reunión de SACCoM. Buenos Aires: SACCoM, pp. 157-177. 
(2008) Música, transmodalidad e intersubjetividad. Estudios de Psicología, vol. 29, núm. 1: 7-30.

Schön, D, Akiva-Kabiri, L. y Vecchi, T. (2012) Psicología de la Música. $1^{\circ}$. Ed. La Plata. Maestría en Psicología de la Música. Traducción Colette O’Haire.

Sloboda, J. (1985). The musical mind. The cognitive Psycology of Music.Oxford: Clarendon Press

(1986). ¿Qué es la habilidad?. En Angus Gellatly (Comp). La Inteligencia Hábil. El desarrollo de las capacidades cognitivas. Buenos Aires. Aiqué.

Sternberg, R. (1987). Inteligencia Humana, II. Cognición, personalidad e inteligencia. Buenos Aires: Paidós.

Swanwick, K. (1991). Música, Pensamiento y Educación. Madrid: Morata.

Trainor, L. (2003). Effects of musical training on the auditory cortex in children.. En The Neurociences and Music. Vol. 999. pp. 506-513. [Article Published online january 2006]

Welch, G. (1998a). El desarrollo del canto en el niño. Investigación musical. Hacia un nuevo siglo y una nueva música. Buenos Aires: FEM.

(1998b). El desarrollo musical en la temprana infancia. Boletín del Centro de Investigaciones en Educación Musical. Año 5. ํ⒕ Pp.3-14. Buenos Aires.

(2004). El significado de la voz en la ontogénesis de la comunicación. Key-note for 4ht Annual Meeting of SACCoM. Tucumán, Argentina.

Willems, E. (1964). El Ritmo Musical. Bs. As: Eudeba

Winner, E. (2003). Potencialidad musical. D. Deutch (Ed.) Bulletin of Psychology and the Arts, January, 3.

Wittrock, M. y Baker, E. (Eds.). (1998) Test y Cognición. Investigación cognitiva y mejora de las pruebas psicológicas. Barcelona: Paidós.

Zatorre, R. (2005) Music, the food of neuroscience? Nature, 434: 312-315. Traducción Dra. Nelly Pastoriza para uso exclusive de circulación interna de la Maestría en Psicología de la Música, Facultad de Bellas Artes, UNLP.

Zenatti, A. (1991). Aspectos del Desarrollo Musical del Niño en la Historia de la Psicología del siglo XX. CL y E: Comunicación, Lenguaje y Educación. N $^{\circ}$, pp.57-70. 
LA COMPRENSIÓN DE LA ESTRUCTURA MUSICAL.

LA REPRESENTACIÓN UTILIZADA EN NIÑOS ENTRE 10 Y 11 AÑOS. 


\section{ANEXOS}

\section{ANEXO 1}

\section{TEST}

Atributo: FORMA MUSICAL

\section{Nombre o clave:}

\section{Primera Parte}

a) Los siguientes ejemplos musicales tienen dos partes. ¿Serán iguales o diferentes? Marca en el rectángulo pequeño de la derecha la sucesión de dos formas geométricas que representen las dos partes de la música que escucharás en cada caso.

\section{Ejemplo musical 1}
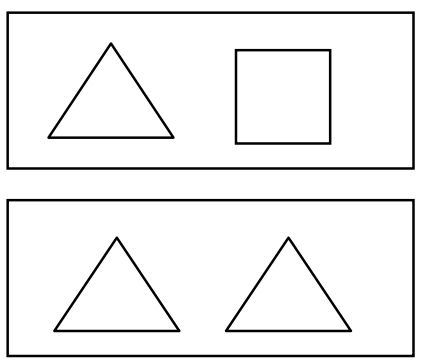

\section{Ejemplo musical 2}
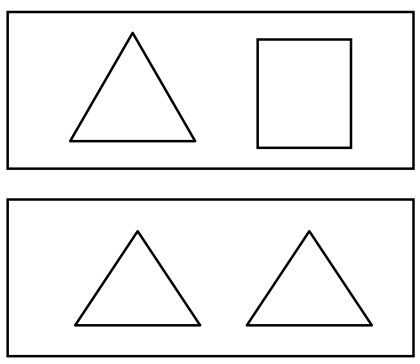

\section{Ejemplo musical 3}
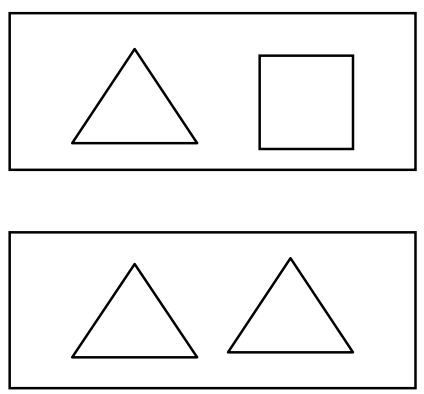
b) Vas a escuchar ejemplos musicales que tienen tres partes. Pueden ser iguales 0 diferentes. Marca en el rectángulo pequeño de la derecha la sucesión de tres formas geométricas que representen las tres partes de la música que escucharás en cada caso.

\section{Ejemplo musical 4}
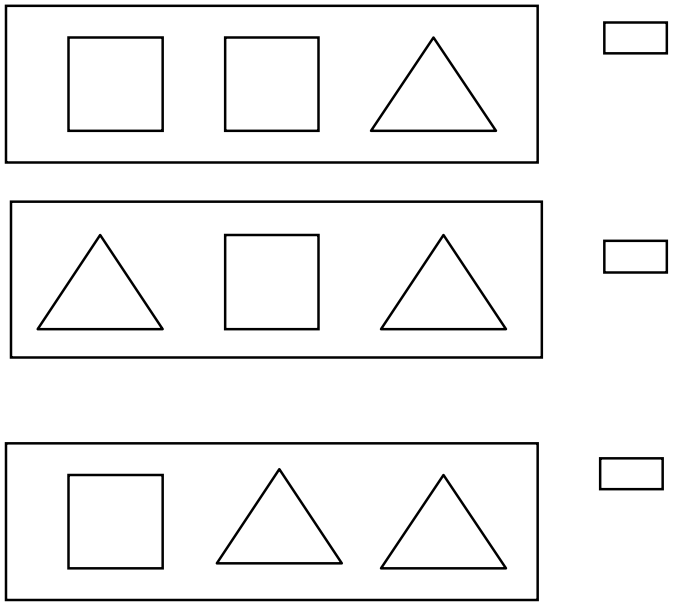

Ejemplo musical 5
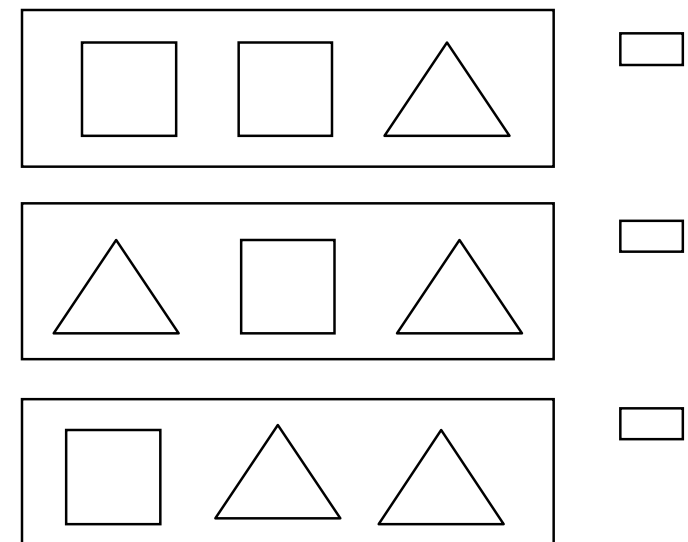

Ejemplo musical 6
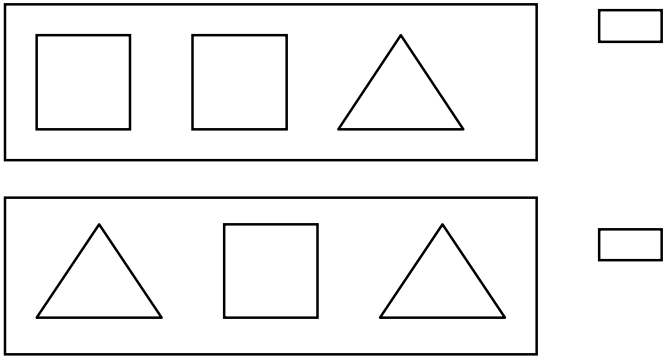
c) Vas a escuchar ejemplos musicales que tienen tres partes. Pueden ser iguales, diferentes o parecidas (con un pequeño cambio)

Marca en el rectángulo pequeño de la derecha la sucesión de tres formas geométricas que representen las tres partes de la música que escucharás en cada caso
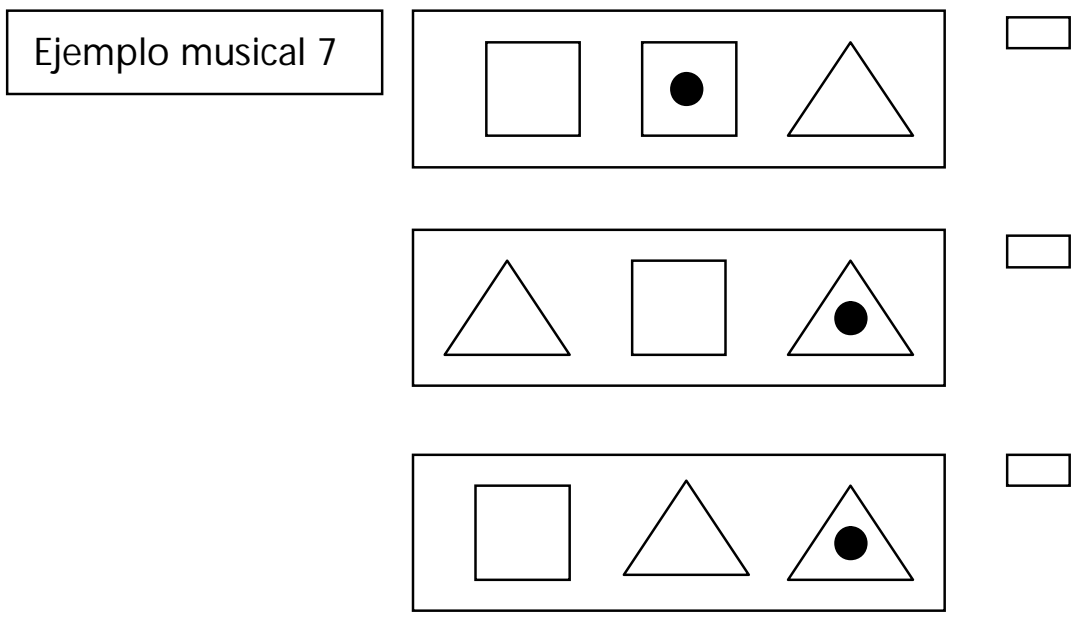

\section{Ejemplo musical 8}
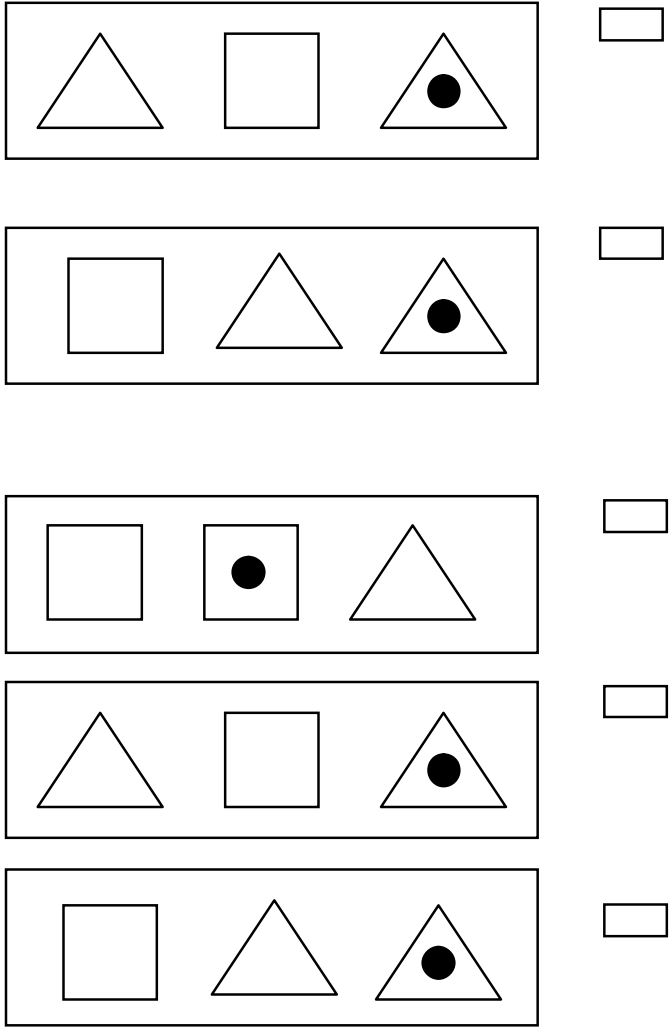

Ejemplo musical 9
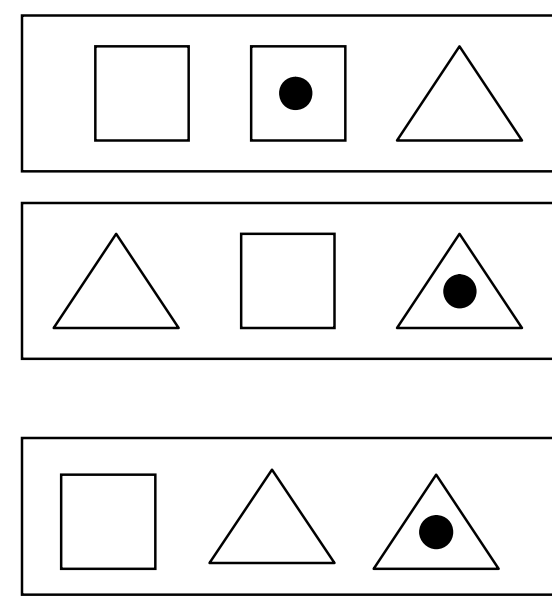
TEST

Atributo: FORMA MUSICAL

Nombre o clave:

\section{Segunda Parte}

d) Vas a escuchar (tres) ejemplos musicales. Grafícalas utilizando figuras geométricas. Si las partes musicales son iguales utilizarás la misma figura, si son diferentes utilizarás figuras geométricas distintas y si tienen un pequeño cambio, utilizarás la forma geométrica que corresponda a la parte cambiada pero le agregarás un punto adentro.

\section{Ejemplo musical 10}

Ejemplo musical 11

Ejemplo musical 12 
LA COMPRENSIÓN DE LA ESTRUCTURA MUSICAL.

LA REPRESENTACIÓN UTILIZADA EN NIÑOS ENTRE 10 Y 11 AÑOS. 


\section{ANEXO 2 \\ PRIMERA SESIÓN GRUPO EXPERIMENTAL}

\section{Forma AA}

\section{Escuchamos el ejemplo 1 "El juego de la Oca"}

La música, al igual que el lenguaje oral, expresa a través de los sonidos ideas, frases, que se articulan en el tiempo construyendo la obra musical. De la misma manera que cuando escuchamos un discurso hablado podemos identificar las frases y darle sentido a lo que nos dicen, cuando escuchamos una melodía podemos también darnos cuenta cuando una frase termina y comienza otra, en nuestra mente vamos anticipando que la frase musical está a punto de cerrar y advertimos que comienza una nueva.

¿Cuantas frases, tiene este ejemplo? Escuchamos nuevamente e indicamos levantando la mano cuando les parece que termina una frase y empieza la próxima

Una vez identificadas las dos frases, las cantamos.

¿Cómo son estas frases entre si: diferentes, parecidas o iguales? Son iguales

En el pizarrón grafico dos arcos mientras canto cada una de las frases, debajo dos figuras geométricas iguales y sobre los arcos dos letras A. Conversamos sobre la analogía de las figuras geométricas y las letras respecto a las frases iguales y la analogía con la lectura común de izquierda a derecha mientras seguimos la temporalidad de la música que vamos escuchando.

Propuesta de juego: Identificar las frases a través de acompañar el devenir temporal de cada una con diferente movimiento.

Dispuestos en círculo pasaremos una pelota acompañando la música (ajustados sincrónicamente al nivel métrico más cómodo para una instancia así que podría ser el acento) durante la primera frase y moviendo los pies en el lugar (ajustados al pulso) durante 
la segunda frase. En este caso se utilizará una grabación que presenta repetidas estas frases de manera indefinida, para darle continuidad al juego.

Escuchamos el ejemplo 2 "Bizet. Ópera Cármen. Los Toreadores, fragmento".

Repetimos el análisis de frases escuchando nuevamente con los ojos cerrados y levantando la mano al término de cada frase. Cantamos y graficamos.

Propuesta de juego:

Juego de manos en parejas. Durante la primera frase uno mantiene las palmas de las manos hacia el frente mientras el compañero realiza los movimientos y en la segunda frase invierten los roles (realizando siempre los mismos movimientos)

\section{Forma AB (ABAB)}

Escuchamos el ejemplo 3 "Tchaikovsky. Suitte El Cascanueces. Danza China, fragmento"

Escuchar nuevamente pidiendo que muevan sus manos de acuerdo a lo que sugiere la música una "Danza con las manos", teniendo en cuenta que mantenemos el mismo tipo de movimiento mientras la música continúa con la misma idea y cambia el movimiento si la música cambia. Por el contrario si la música retoma una idea anterior la representamos con el mismo movimiento.

Intercambiar opiniones respecto a cuantos tipos de movimientos realizamos y lo que eso nos sugiere respecto a las distintas partes de la música.

Escuchar nuevamente y teniendo en cuenta las partes que se advirtieron anteriormente, acompañar el devenir temporal de la música con un gesto de arco realizado espacialmente por la mano, señalando audiblemente donde cerraría cada arco en correspondencia con las partes indicadas. 
En una próxima audición, realizar el mismo ejercicio anterior pero graficando sobre el pizarrón: los arcos (en tiempo real con la música), luego graficar las figuras geométricas y las letras correspondientes.

Mencionar que la música se desarrolla a través del tiempo con duraciones proporcionales y que por lo tanto tiene una métrica, se puede medir. Podemos medir la extensión de cada una de las frases identificadas.

Propongo (marcando, contando y señalando sobre el gráfico) diferentes "escalas de medida" mientras escuchamos la obra (los diferentes niveles métricos) y acordamos el más cómodo. Advertimos que cada frase tiene la misma extensión (dejamos escrito el número debajo de cada parte).

Comentamos que no siempre sucede esto en la música pero cuando es así colabora en la percepción de equilibrio y ayuda a que nuestra mente "calcule" la extensión después de haberla escuchado unos instantes y esa es una de las razones por las cuales podemos anticipar donde terminará y comenzará otra frase.

Propuesta de ejecución:

Un grupo de alumnos realiza ajustes globales en A con sonajas,

Otro grupo de alumnos realiza ajustes puntuales en B con claves, cajas chinas, triángulos.

Primero siguiendo la indicación de la profesora que dará las entradas indicando también en el gráfico y luego sin indicación, guiándose exclusivamente por la audición.

\section{Forma AA'}

\section{Escuchamos Tchaikovsky. Suite Cascanueces. Abertura Miniatura, fragmento.}

Cantar el fragmento junto con la grabación. Preguntar cuantas frases escuchan. Marcar a través de arcos en el aire con las manos las dos frases mientras cantamos junto con la grabación. Preguntar como empiezan cada una de las frases (igual), cantar, preguntar como termina cada una de las frases (diferente), cantar. 
Graficar las dos frases y mencionar que cuando las frases como en este caso cambian solo en una parte de la frase (es decir no son totalmente iguales ni totalmente diferentes) les colocamos la misma letra con una pequeña rayita o se grafica la misma figura geométrica con un pequeño detalle diferente como un punto. Conversar otras posibilidades.

Propuesta de aplicación

Sobre una grabación con las frases $\mathrm{AA}^{\prime}$ repetidas varias veces, cantar la primera parte de cada frase (la que es igual) y palmear el ritmo del primer final (de la segunda parte de la primera frase) y percutir con el lápiz sobre el banco el segundo final (la segunda parte de la segunda frase). Reforzar la consigna indicándola sobre el gráfico realizado anteriormente, los momentos en que se realiza cada acción.

\section{Escuchamos Offenbah. Can Can de la ópera Orfeo en los infiernos, fragmento}

Realizar la misma secuenciación de identificación auditiva, cantar y graficar.

Propuesta de aplicación

Sobre una grabación con las frases $\mathrm{AA}^{\prime}$ repetidas varias veces, dividimos el curso en tres grupos:

Los que ejecutan durante la primera parte de cada frase: marcan con claves los cuatro tiempos de ese fragmento (o con bombo)

Los que ejecutan durante el final de la primera frase (primer final) ritmo con bongó Los que ejecutan durante el final de la segunda frase (segundo final) pulso con pandero

Evaluación de control para la primera clase:

Identificar la cantidad y características de las partes de los siguientes ejemplos musicales y graficar (con arcos, figuras geométricas y/o letras que identifiquen las partes).

- Dvorak. Sinfonía Nº9 del Nuevo Mundo Allegro con fuoco Fragmento A Á 
LA COMPRENSIÓN DE LA ESTRUCTURA MUSICAL.

LA REPRESENTACIÓN UTILIZADA EN NIÑOS ENTRE 10 Y 11 AÑOS.

- Sarian Susum 


\section{ANEXO 3 \\ SEGUNDA SESIÓN GRUPO EXPERIMENTAL}

\section{Escuchamos Ejemplo 1 Bizet. La Artesiana. Suite $\mathbf{N}^{\mathbf{0}} 1$ Carrillón AA'}

En una pequeña rueda de 5 o 6 alumnos tomados de las manos, con la guía de la profesora, giramos siguiendo la música. En un sentido en la frase A y cambiando de sentido en la frase $\mathrm{A}^{\prime}$ incluyendo un saltito en el lugar en el último sonido de esa segunda frase. Para ello utilizamos una grabación donde se repita varias veces $\mathrm{AA}^{\prime}$.

Intercambiamos opiniones respecto al cambio de sentido en el movimiento y de la incorporación del saltito. Concluimos que son dos frases parecidas con un pequeño cambio en el final.

Acompañamos la música con un arco realizado por la mano en un sentido y cambiamos de sentido en la segunda frase incluyendo el ademán de realizar un punto en el aire en la nota final de la segunda frase.

Graficamos los arcos en tiempo real con la música. Agregamos las figuras geométricas y las letras.

\section{Ejemplo 2 Tchaikovsky . Suite El Cascanueces. Marcha A A B y repite A A B}

En una primera audición escuchamos solo AAB. En una nueva audición percutimos en el aire el ritmo (como si pegáramos en la palma imaginaria de un compañero enfrente nuestro, o señalando con el dedo índice o como si dirigiéramos la orquesta marcando el ritmo). Repetimos, ahora intentando también cantar.

¿Cuántos grupos de movimientos realizamos? ¿Cuántas frases tendrá este fragmento, como son entre ellas? Graficamos. Contamos la extensión de cada grupo. Advertimos que B tiene la misma extensión que las dos A juntas (así se equilibran las frases) 
Palmeamos el ritmo de las frases A y cantamos la frase B acompañada de un movimiento pendular con las manos y un punto en el aire en el último sonido de la frase.

Escuchamos nuevamente pero ahora agregando la segunda parte $\mathrm{AAB}^{\prime}$, pidiendo que presten atención a la reaparición de las frases y si lo hacen igual o con algún cambio. Graficamos. Nuevamente palmeamos el ritmo de las frases A y cantamos la frase B acompañada de un movimiento circular con las manos y un punto en el aire en el último sonido de la frase.

Escuchamos el Ejemplo 3 Banda de la película "El Golpe" posiblemente lo escuchen como ab ab’ab.

En una segunda audición propongo que esta música pareciera expresar preguntas y respuestas. ¿Podrían identificarlas? Indiquen levantando las manos dónde termina cada una. Luego propongo que la mitad del curso canta la pregunta, la otra mitad canta la respuesta (con la dirección de la profesora).

Un alumno pasa a graficar al pizarrón los arcos de las distintas frases en tiempo real con la música y con la ayuda de los compañeros que indicarán cuando termina cada frase. Colocamos letra a cada frase, volviendo a cantar si es necesario. Contamos la extensión de cada frase indicada. Advertimos la posibilidad de unir cada pregunta con su respuesta para que queden unidades de sentido completas, quedando ABA. Graficar con figuras geométricas esta forma.

Ya que las unidades mínimas son tres: a-b-b', adjudicamos un grupo instrumental a cada una de estas unidades para ejecutar en tiempo real con la música y ayudándonos si fuese necesario con el gráfico realizado. Pero cada uno de estos grupos se ubicará espacialmente de acuerdo al orden de aparición temporal de la obra: Dos alumnos del grupo a con dos alumnos del grupo b, al lado dos alumnos del grupo a con dos alumnos del grupo b’y a continuación dos alumnos del grupo a con dos alumnos del grupo b. Resaltando que conforman los tres grandes grupos $\mathrm{ABA}$ 
Grupo a: triángulos (negras) y sonajas (corcheas)

Grupo b: bombo (caja challera)

Grupo b’ bombo y vibraslap (celestín)

Escuchamos el Ejemplo 4 Carnavalito "La Humahuaqueña" AABB y repite.

En una primera audición escuchamos solo la primera parte de sikus solista. Luego de la primera audición cantamos, junto a la grabación. Cantamos y levantamos la mano cuando consideramos que termina cada frase. Determinamos la cantidad de frases y graficamos los arcos en el pizarrón. En este caso podemos aprovechar el tema de la dosificación del aire, la respiración al cantar o tocar un instrumento aerófono y su analogía al hablar: generalmente no respiramos en cualquier lugar de la frase sino al terminarla. Cantar nuevamente teniendo en cuenta esto. Otorgarle una letra a cada frase

Propuesta de aplicación con percusión corporal
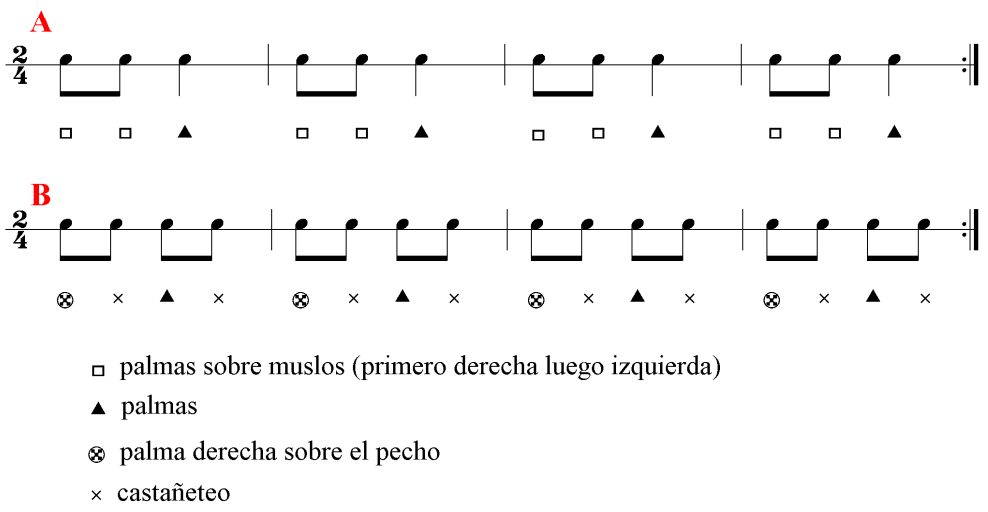

Una vez que se practique la ejecución de la percusión corporal sobre $\mathrm{AABB}$, escuchamos la segunda parte de la grabación donde incorpora más instrumentación. Advertimos que se 
trata de las mismas frases donde en este caso aparece acompañamiento instrumental para el sikus.

Evaluación de control para la segunda clase:

- Saint Saens. Carnaval de los animales. Fósiles, fragmento AA'

- Haendel Sinfonía en Do $1^{\circ}$ mov fragmento AAB 
ANEXO 4

\section{GUÍA DE AUDICIÓN}

Escuela 11 de Septiembre

Nombre:

\section{FORMA MUSICAL}

- Escucha los siguientes ejemplos musicales.

- Identifica las partes y grafícalas en los recuadros correspondientes.

- Al graficar considera las partes iguales, parecidas o diferentes.

\section{Carnavalito "La Humahuaqueña” versión Los Nocheros.}

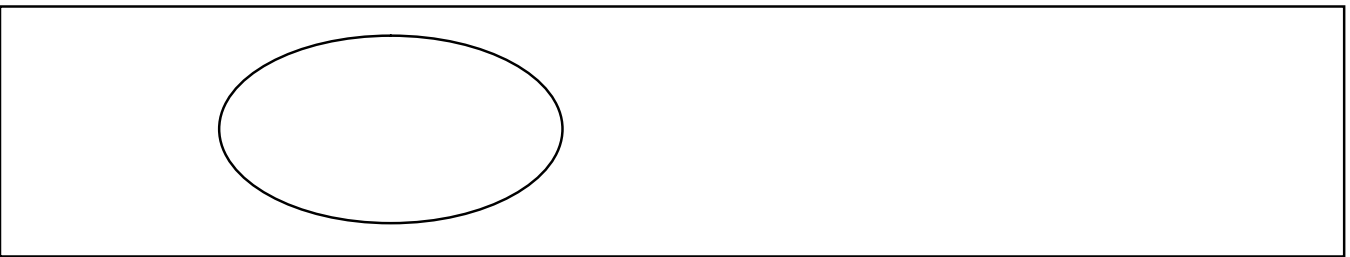

\section{Danza}

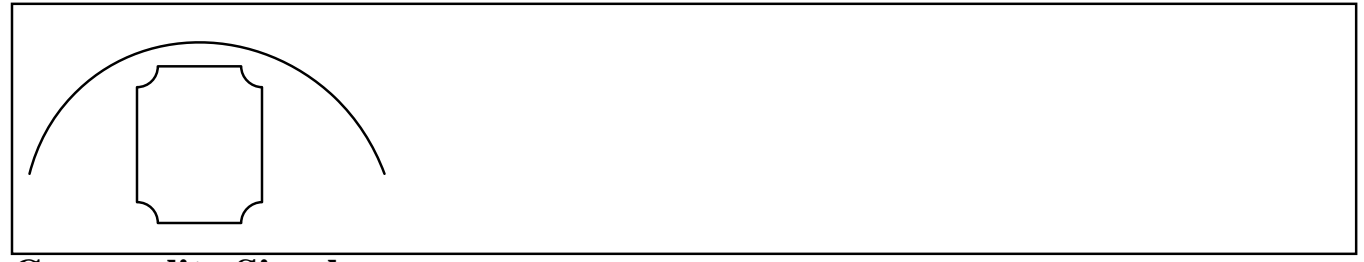

Carnavalito Simple

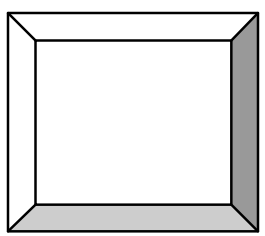

“Vivaldi. Concierto para Violín La Primavera, $1^{\circ}$ movimiento". 
Grieg. Suite Peer Gynt. Danza de Anitra

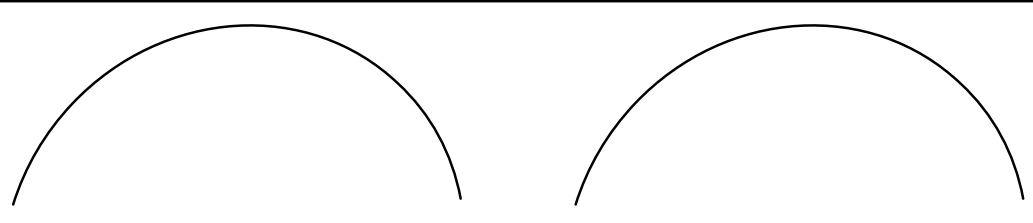

Bizet. Ópera Carmen. Aragonesa

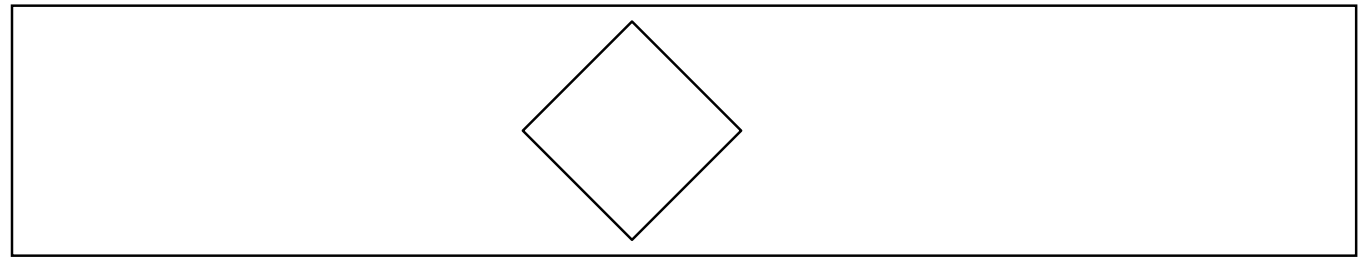

Danza de los Moros

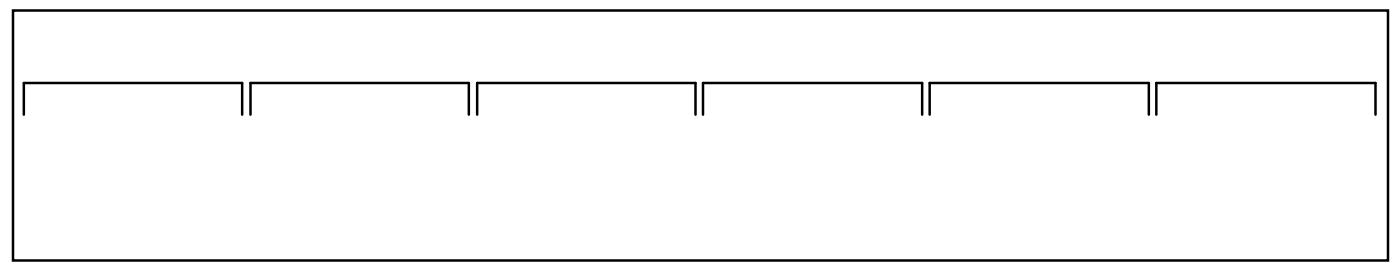

“Brhams. Danza Húngara N5,

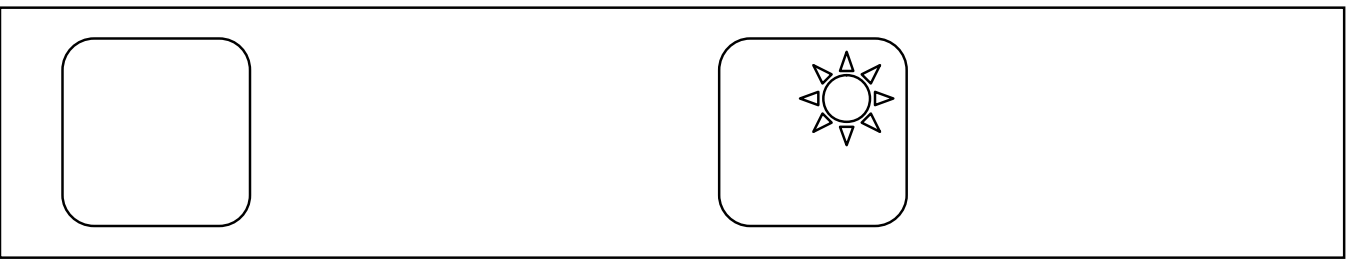

Canción para un árbol de río 


\section{ANEXO 5}

\section{imágenes de "Presentaciones multimodales Tercera Sesión"}

Las siguientes imágenes corresponden a presentaciones formato Power Point con sincronía entre la imagen y la música. Se utilizaron durante la Tercer Sesión con el Grupo Experimental como complemento a la Guía de Audición. Cada una de ellas fue expuesta al finalizar el análisis y gráfico de cada ejemplo propuesto. A través de la congruencia de modalidades auditiva, visual y kinética, este recurso multimodal, a través de su redundancia sensorial, intentó colaborar en la comprensión de la forma musical analizada.

1) Carnavalito "La Humahuaqueña" versión de Los nocheros. Fragmento AA'
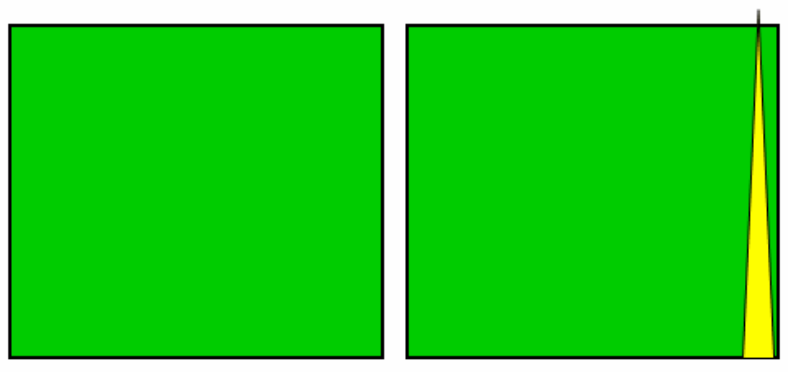

2) Danza

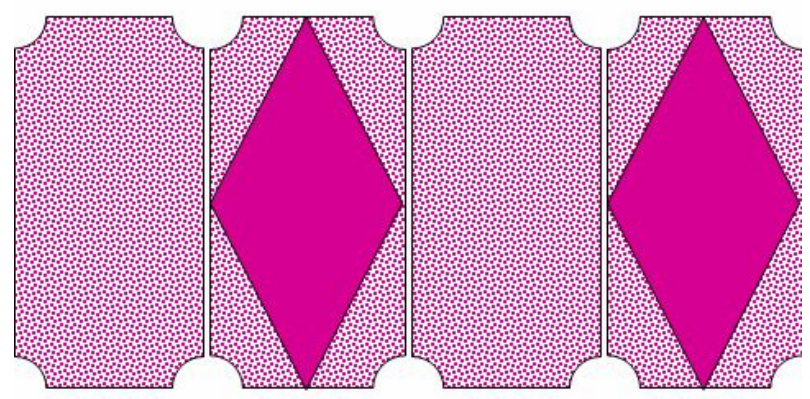


3) Carnavalito Simple
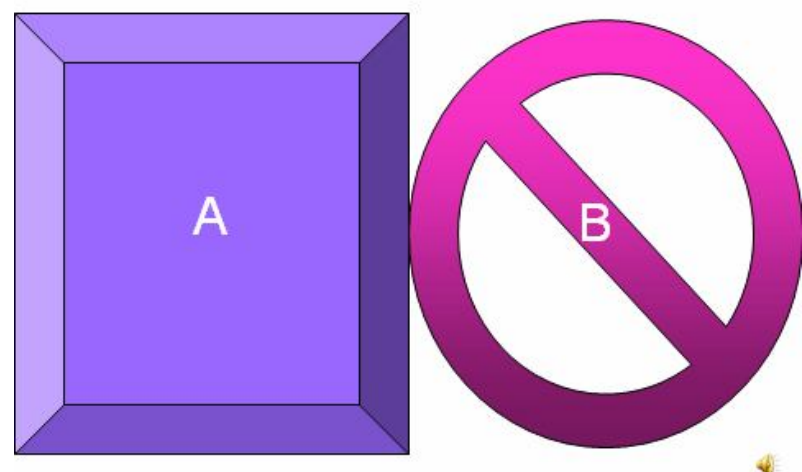

4) Vivaldi. Concierto para violín "La Primavera" $1^{\circ}$ movimiento. Fragmento

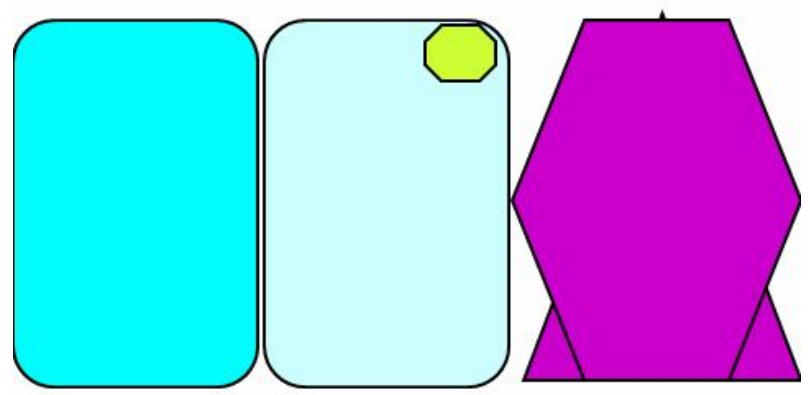

4

5) Grieg. Suite Peer Gynt Danza de Anitra

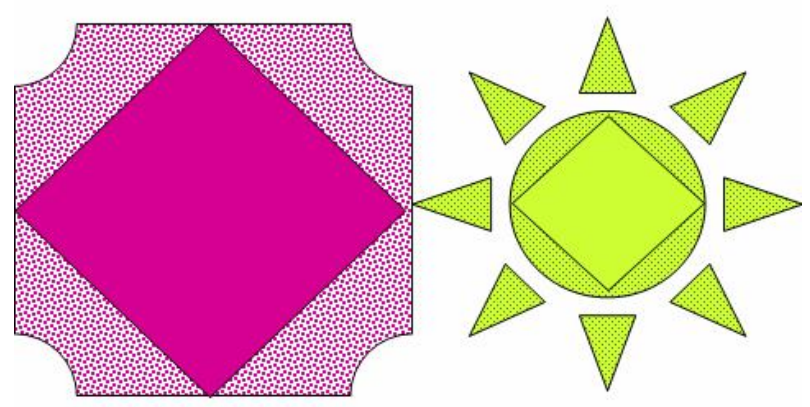


LA COMPRENSIÓN DE LA ESTRUCTURA MUSICAL.

LA REPRESENTACIÓN UTILIZADA EN NIÑOS ENTRE 10 Y 11 AÑOS.

6) Bizet. Ópera Cármen. Suite № Aragonesa

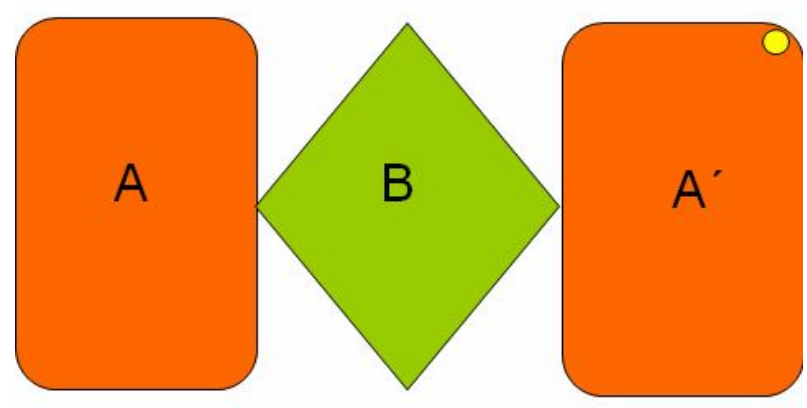

Danza de los moros

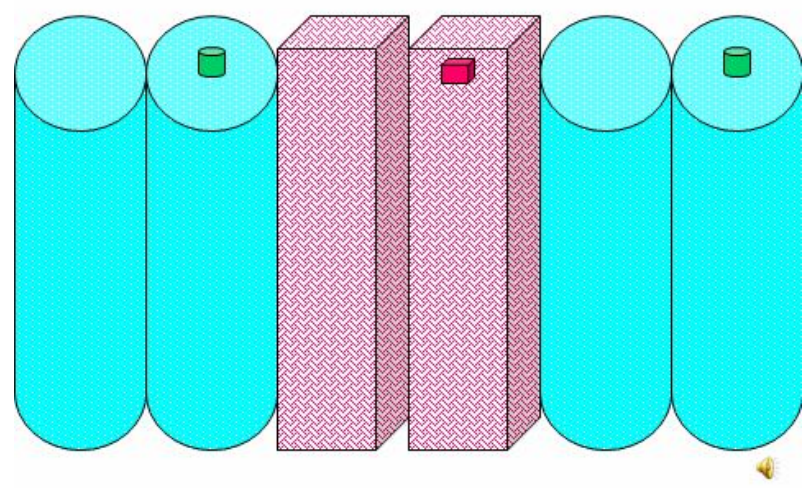

Brahms. Dnaza Húngara N5
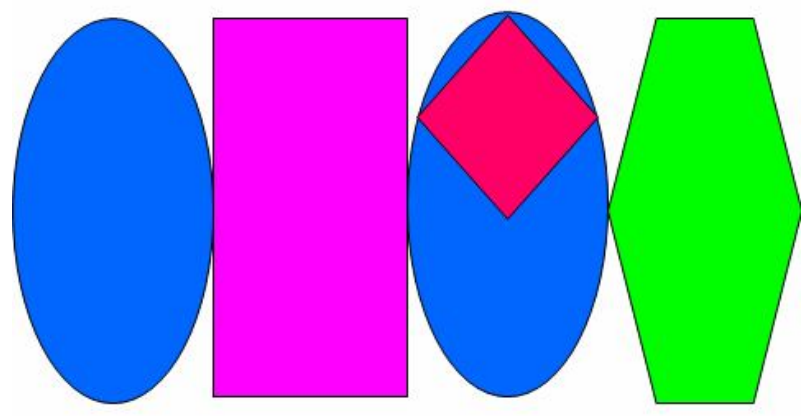


\section{ANEXO 6}

$\underline{\text { Planificaciones de clase para las sesiones con el Grupo Control }}$

Las siguientes planificaciones fueron facilitadas por la Profesora Luci Ferrarini. Dicha profesora se desempeña en otro establecimiento escolar, diferente a donde se realizaron las sesiones experimentales y dado que como parte de sus funciones dicta clases en quinto año, se solicitaron tres de sus planificaciones habituales para este curso en el tema "Forma Musical". El desarrollo de las sesiones estuvo a cargo de la investigadora responsable del proyecto.

\section{Primera Sesión}

Contenidos: forma binaria-ritmo binario-elementos del ritmo: pulso y divisióndesplazamiento corporal.

Objetivos: que el niño sea capaz de reconocer, discriminar y crear en forma grupal la estructura formal de algunas obras musicales.

Ejemplo musical: "Ce fut en mai de moniot de arrás"

Actividades: La maestra dibujará en el pizarrón un triángulo ,un círculo,un cuadrado y un rombo. se les preguntará que son?....se supone que dicen figuras geométricas.

en que se diferencian?......se supone que dicen en la forma.

Luego se dibujará una serie: un cuadrado, un círculo y un cuadrado

un cuadrado, un círculo, un cuadrado, un triángulo y un cuadrado. Que pasó acá?

Ahora se les pide a los niños que sustituyan las figuras por letras en un recuadro de tres para el primero y de cinco para el segundo.

Luego la maestra les explicará que la música necesita también tiene una forma para ser comprendida, y, que un gran número de canciones y danzas se constituyen en forma semejante.

Ahora escucharán una melodía de forma binaria: "Ce fut en mai de moniot de arrás". 
Les pregunto cuántos temas hay? ellos me dicen que tienen dos temas, ahí les explico que tiene forma binaria y que se construyen con dos temas que se repiten o alternan.

Escucharán nuevamente y averiguarán si tiene ritmo binario o ternario.

Marcarán pulso mientras realizan la audición. Contarán los compases del tema a y del b, luego un grupo toca las palmas con el primer instrumento de percusión que interviene y otro grupo golpea en las rodillas acompañando el segundo grupo con la música de fondo hacer dos círculos tomados de la mano, y danzar al paso del ritmo binario, cambiando de sentido cuando aparezca otro tema.

A continuación se les pide que ellos creen otra coreografía.

\section{Segunda Sesión}

Contenidos: forma ternaria .-cambio de tempo- frases conclusivas- creación grupal-

Objetivos: que el niño sea capaz de reconocer, discriminar y crear en forma grupal la estructura formal de algunas obras musicales.

Ejemplo musical: "branle simple de claude gervaise"

\section{Actividades:}

Las actividades pueden ser las mismas que para la forma binaria. Primero audición. "branle simple de claude gervaise ${ }^{\cdots \cdot .}$ danza renacentista, también puede ser el cuando o el minué

Se les pregunta cuántas partes tiene. Las escriben en el pizarrón -aba.

Qué final les parece más conclusivo, el del tema a o el del b.?

El tema a se repite exactamente igual que al principio?

La danza va siempre a la mismo tempo, la misma velocidad?

De que se vale el compositor para distinguir claramente el tema b del a?

Divididos en grupo de no más de 6 niños, espaciados en el aula, o algunos grupos que estén en otro lugar para que puedan trabajar tranquilos, crearán la forma ternaria con instrumentos y con los recursos de la voz. Una vez creada la forma aba la presentan a los demás grupos. Luego explicarán que hicieron en la parte a diferente a la parte b. 


\section{Tercera Sesión}

Contenidos: forma rondó -carácter- creación grupal.

Objetivos: que el niño sea capaz de reconocer, discriminar y crear en forma grupal la estructura formal de algunas obras musicales.

Recursos: Vivladi, Concierto para violín "La primavera” $1^{\circ}$ movimiento.

Actividades:

Recordarán lo que hicieron en la clase anterior. La maestra les dirá que ahora verán otra forma un poco más compleja. Escucharán de Antonio Vivladi, Concierto para violín "La primavera"

Luego de la audición se les preguntará cuántas partes diferentes escucharon?

Se preguntará si algún tema se repetía varias veces?

En una nueva audición indican cual es la parte que se repite.

Se escribe en el pizarrón la forma, y se les explica a los niños que para pasar de un tema a otro a veces el compositor introduce puentes como acordes, arpegios para ensamblar las diferentes partes.

Se les dice que esta es la forma rondó, también basada en la repetición de los temas, siendo el primero el que alterna con la exposición de los demás.

Pueden volver a escuchar y en cada parte o tema se para el cd y los niños si pueden, dicen que carácter tiene.

También pueden cantar la melodía del tema a.

Luego divididos en grupos, crearán un rondó y le pondrán un título. Pueden utilizar percusión corporal, instrumentos de percusión, instrumentos membranófonos, sonidos vocales, pueden integrar nombres, canciones, rimas u onomatopeyas.

Luego realizarán la presentación ante los demás compañeros. 
LA COMPRENSIÓN DE LA ESTRUCTURA MUSICAL.

LA REPRESENTACIÓN UTILIZADA EN NIÑOS ENTRE 10 Y 11 AÑOS. 
LA COMPRENSIÓN DE LA ESTRUCTURA MUSICAL.

LA REPRESENTACIÓN UTILIZADA EN NIÑOS ENTRE 10 Y 11 AÑOS. 